\title{
How Does Mortality Contribute to Lifetime Pension Inequality? Evidence from Five Decades of Swedish Taxation Data
}

\author{
Jiaxin Shi ${ }^{1,2,3}$ and Martin $\mathrm{Kolk}^{3,4,5}$ \\ ${ }^{1}$ Leverhulme Centre for Demographic Science \& Department of Sociology, University of Oxford, \\ Oxford, United Kingdom; ${ }^{2}$ Max Planck Institute for Demographic Research, Rostock, Germany; \\ ${ }^{3}$ Demographic Unit, Department of Sociology, Stockholm University, Stockholm, Sweden; \\ ${ }^{4}$ Institute for Future Studies, Stockholm, Sweden; $5{ }^{5}$ Åbo Akademi University, Vaasa, Finland.
}

\begin{abstract}
As with many social transfer schemes, pension systems around the world are often progressive: individuals with lower incomes receive a higher percentage of their income as a subsequent pension. On the other hand, it is well known that those with lower earnings have higher mortality and thus accumulate fewer years of pension income. These opposite factors, therefore, both influence the progressiveness of pension systems. Thus far, empirical efforts to disentangle the effects of mortality inequality on lifetime pension income have been scarce. Using Swedish taxation data linked with death registers in 1970-2018, we study how education and pre-retirement earnings relate to lifetime pension income from age 60 onwards, as well as how mortality inequalities contribute to overall inequalities in lifetime pension income. The results show that both a progressive replacement structure and mortality differentials contribute to the overall distribution of life-course pension payments. Up to one quarter of the inequality in lifetime pensions is attributable to the fact that socially advantaged groups live longer - this is particularly true for men. Hence, mortality inequalities play an important role in determining the overall degree of between-group income transfers in a pension system, but less so than do inequalities in prior earnings.
\end{abstract}

Keywords Pension progressivity, retirement, mortality inequality, life expectancy, education

Author Note Correspondence concerning this article should be addressed to Jiaxin Shi. Address: Max Planck Institute for Demographic Research, Konrad-Zuse-Str. 1, Rostock 18057, Germany. Email: shi@ demogr.mpg.de. 


\section{Introduction}

A large body of literature has considered the substantial and persistent socioeconomic gradient in mortality risks and longevity. One implication of socioeconomic gradients in mortality is their effects on redistribution through state-regulated programs such as healthcare and pension systems. Demographers are interested in mortality gradients and have examined how population aging differs by SES (Guralnik et al. 1993; Majer et al. 2011), yet how differential mortality affects pension benefits has been examined less. More specifically, do individuals with lower socioeconomic status (SES) benefit less from pension programs due to their higher mortality risks?

Individual accumulated pension over the life course is determined by three factors. First, the mortality gradient means that individuals with higher SES live more years, and accumulate more pension. Second, prior contributions to a pension system (based on pre-retirement earnings). Third, the explicit progressive nature of many pension programs (i.e., the higher the earnings, the lower the proportional benefits). While the first two factors predict greater benefits to those with higher SES, the third does the same for those with lower SES. The relative importance of these three factors is far from self-evident.

Pension progressivity - the extent to which a system redistributes toward lower earnershas often been studied by comparing measures such as the replacement rate across earnings groups (e.g., Whitehouse 2006; Dudel and Schmied 2019). The replacement rate is defined as the proportion of labor earnings that is translated into retirement pension income. Higher replacement rates mean more benefits with respect to prior earnings-based contributions. In contrast, a cohortbased life-course analysis using measures such as the lifetime benefits/tax ratio (e.g., Smith et al. 2003) may modify the association between SES and annual benefits, as it introduces the additional factor of mortality, which counteracts progressivity defined on an annual basis. Recent research has highlighted the detrimental effects of SES mortality differences using various methods, leading to the conclusion: SES mortality differences increase the inequality in lifetime pension benefits and impede the progressivity that is usually conceptualized on an annual basis without considering SES-specific mortality patterns (Sánchez-Romero and Prskawetz 2020).

Understanding lifetime pension inequality is relevant from a policy-making perspective, as the progressivity of pension systems is often a policy goal. Yet this does not afford the same level of progressivity for the entire cohort over the life course if the system only considers replacement among living retirees compared to their previous incomes. An interesting question, therefore, is: Who benefits (more) from pension systems when longevity varies? The answer depends not only on replacement rates but also on mortality inequalities between cohort members across gender, income levels, education, etc.

In this study, we use high-quality Swedish national taxation records on earnings and pension payments from 1970 to 2018 to examine how lifetime pension income is structured across different socioeconomic groups. We disentangle inequalities in lifetime pension income between 
social groups based on gender, education, and pre-retirement earnings into the components that are attributable to differences in annual pension income and differences in mortality, both in the form of age-specific components.

We expand the literature in several ways. Prior research has not used individual-level data over the complete life course. This is to a large extent due to the unusually long span of data required for this kind of lifetime analysis. We measure actual values of lifetime pension payments of real birth cohorts with high-quality register data that - unlike surveys that often suffer from missing values and reporting bias-provide an accurate picture of an entire population. Methodologically, the role of mortality on lifetime pension inequality has mostly been examined by counterfactual analysis, i.e., recalculating lifetime pension based on hypothetical mortality rates (e.g., OECD 2017; Sánchez-Romero et al. 2020), not decomposition techniques that yield additive terms that sum up to the total lifetime pension inequality. Our life-table-based decomposition is a novel approach that not only presents age-specific mortality effects but also additive effects of preretirement earnings and the redistributive role of the pension system. We also explore the potential impacts of policy changes such as raising pensionable ages.

Substantively, our results can inform policymakers who are attempting to balance the goals of social equity and (demographic) actuarial fairness. We also shed new light on the literature on income stratification in later life. As the share of older adults in the population is rising almost everywhere in the world and given that pension income is the main source of income for most older people, reducing old-age poverty is becoming ever more important. The share of state budgets allocated to pensions is rising throughout the aging world; meanwhile, inequalities in pension payments are becoming an increasingly important aspect of economic inequality over the life course.

\section{Background}

\section{What is the Function of Pension Systems?}

Pension systems in contemporary high-income countries serve many goals, including (a) helping individuals redistribute resources over their life courses from working to old age; (b) protecting individuals from poverty in old age; and (c) providing insurance and reducing variance in monthly old-age income, no matter if an individual lives unusually short or long. A final goal, (d), is transferring money from individuals with higher incomes to those with lower incomes as an integrated part of larger tax-funded and mandatory government welfare systems, thus helping meet the requirements of (a), (b), and (c). In traditional typologies of pension systems in OECD countries, some systems are described as "Bismarckian", where the system is oriented towards income replacement (goals a and c), while others as "Beveridgean", with a focus on poverty protection (goal b) with less emphasis on relating pensions to previous earnings (Ebbinghaus 2021). 
While meeting the first goal of life-course transfers does not impact between-individual inequalities, the remaining aspects all involve varying degrees of redistribution between individuals. For instance, goal (c), also known as risk pooling (Ayuso et al. 2017), may counteract the other goals of a pension system if those individuals with unusually long lives are concentrated among high-income individuals.

In theory, everyone could individually buy private pension insurance during working age, which upon retirement would be translated into annuities from their savings through an open market, thereby fulfilling goals (a) and (c). Yet, this has never been practiced at the societal level; countries have instead relied mostly on family care (among countries with lower incomes), which has been gradually replaced by public pension systems as countries become richer. For privately funded pension systems, it is hard to create actuarially fairly funded pension insurances due to several factors: mortality differences between genders and socioeconomic groups; difficulties in forecasting future mortality; the great efforts required to maintain a pension scheme over multiple decades; and the risks involved in providing such insurances. As a consequence, all OECD countries (with the partial exception of Chile) have public pension systems through taxes on working-age individuals that are transferred to pensioners (the so-called Pay-As-You-Go or PAYGO system) and/or mandated (and often tax-favored) pension savings for individuals (Whitehouse 2006) to meet the various goals of a pension system.

Reducing inequality at older ages is intrinsic in most pension systems. Indeed, the initial motivation for all pension systems (particularly those of the "Beveridgean" tradition) was to eliminate poverty among older adults and to ensure a certain level of living standard for them. Pension systems thus protect against socially unacceptable social deprivation among the very old who can no longer work. As individuals live longer beyond retirement ages, however, it has become less realistic for some to be able to save adequate resources during their working years and fund their retirement accordingly. While high earners have other means to ensure financial security in later life, this point is particularly relevant for low earners who are more heavily reliant on public pension schemes (GAO 2019). Due to the equalizing nature of public pension systems, it is found old-age inequality in total income of all sources is smaller in countries where public pension benefits are a larger share of pensioners' total income (Brown and Prus 2004).

\section{Types of Redistributions and Inequalities}

To achieve the aforementioned goals of pension systems, different types of redistributions are involved; accordingly, redistribution and inequality can be assessed for different comparison groups. In systems where working-age individuals fund the current retired population, the contributions and total benefits of one generation tend not to be equal. Thus, intergenerational redistribution is inevitable, which further stimulates discussions on pension fairness across generations. Many studies have focused on this aspect, particularly on whether the overall system is sustainable with an aging population following declining fertility and mortality (Howse 2007; 
Lee and Mason 2011). Other research has focused on pension reforms and differences between funded and non-funded systems (Sinn 2000). We do not elaborate on either of these aspects in this study, but instead focus on the redistribution between individuals of the same cohort, that is, within-generation, interpersonal redistribution and inequality. Such inequality comes from multiple sources, including prior labor income, the extent to which labor income is translated to pension income, and mortality. Mortality is crucial as it determines the length of pension accumulation. Although our focus is on interpersonal redistribution and inequality, understanding intrapersonal redistribution (i.e., redistributing income from working age to old age over the life course) is also integral to our lifetime analysis.

We here summarize the three determinants of within-generation inequality. First, preretirement labor earnings, to which annual pension income is closely linked. Men tend to have higher labor earnings than women, and thus they tend to have higher annual pension incomes. The second determinant is the extent to which the system intends to redistribute incomes from the rich to the poor, often reflected in differential replacement rates. Such redistributive effects of public pension programs, like other government programs, tend to be measured yearly (Nelissen 1998). Significantly, this ignores the fact that individuals face differential mortality risks and thus differ in the total number of years that they can receive a pension. The third determinant of lifetime pension is lifespan; the longer individuals live, the more years they can benefit from the pension system. This reflects the risk-pooling nature of pension systems, which protects individuals against uncertainty around how long they will live. With such an instrument, individuals do not risk using up their money long before they die or having unintentional property left upon their death (Ayuso et al. 2017). Consequently, a pension system redistributes money from the shorter-lived to the longer-lived.

Numerous studies have found that people with higher SES tend to live longer than those with lower SES (e.g., Brønnum-Hansen and Baadsgaard 2012; Mackenbach et al. 2018). The SES gradient in mortality exists even in today's low mortality regimes, although the exact magnitude varies between countries. In the U.S., men in the top 1\% income distribution on average lived 14.6 years longer than those in the bottom 1\% in 2001-2014 (Chetty et al. 2016). In many OECD countries, the SES gap in longevity has been growing (Kravdal 2017; Meara et al. 2008; Östergren 2015; Permanyer et al. 2018).

\section{Existing Research on How Mortality Affects Pension Inequality}

The regressive effects of mortality on the overall redistribution of pension systems have been shown in many contexts, beginning with Aaron (1977). Many studies have focused on the role of mortality inequalities by (lifetime) earnings (e.g., Bishnu et al. 2019; Garrett 1995), probably because public pension income is solely based on prior earnings-related contribution, not race/ethnicity, education, etc. Other researchers have examined differences across social factors 
such as class, education, gender, and race/ethnicity (Brown 2003, 2007; Jijiie et al. 2019; Tan and Koedel 2019; Vidal-Meliá et al. 2019).

The U.S. has been the focus of most prior studies. A study by the National Academies of Science, Engineering, and Medicine (2015) simulated individual life histories for two cohorts (1930 and 1960), finding that the gap in lifetime Social Security benefits between men in the top and bottom income quintiles increased from US $\$ 103,000$ to US $\$ 173,000$ across the two cohorts. This was attributed to the growing inequality in life expectancy: projected life expectancy at age 50 increased for the top quintile (from 31.7 to 38.8 years) but decreased for the bottom quintile (from 26.6 to 26.1 years) across the two cohorts (NASEM 2015). Focusing on cohorts born between 1962-1980, a recent study found that the U.S. retirement system is still modestly progressive, and the progressivity is reduced by mortality inequalities (Tan and Koeddel 2019).

The regressive role of mortality has been confirmed by studies done in other countries with distinct pension systems. Research on Germany and Italy has found that, unlike the case for the U.S., the German and Italian pension systems are regressive, i.e., transferring money from low to high earners (Caselli et al. 2003; Haan et al. 2020; Mazzaferro et al. 2012). The OECD (2017) examined lifetime pensions across its member countries, assuming a three-year difference in life expectancy between low and high earners and an arbitrary ratio of earnings between them $(50 \%$ and $200 \%$ of average earnings, respectively). The study found that the differences in lifetime pension between low and high earners vary between 10.6 and 16.6\% across OECD countries. In reality, the actual magnitude of life expectancy differences between these income groups may be different from that of three years. Nevertheless, fixing the differences at three years is useful to show that the impact of life expectancy gaps is widespread and suggests that the magnitude of lifetime pension inequality depends on the context.

Prior research has also examined the potential impact of pension reforms, motivated by the fact that many countries have moved from defined benefits to (notional) defined-contribution pension systems. Using simulation, Lee and Sánchez-Romero (2019) found that a notional defined-contribution (NDC) system using cohort- and income-specific life tables leads to the lowest level of lifetime pension inequality in the U.S. context; a defined-benefit (DB) system with progressive replacement or an NDC system with cohort- but not income-specific life tables shows slightly higher lifetime pension inequality levels; a DB system with a flat replacement rate shows the highest inequality. Thus, the authors conclude that an NDC system should use income-specific life tables to reduce lifetime pension inequality, and a DB system should move toward a more progressive replacement rate arrangement. Theoretical analyses based on lifecycle hypotheses that incorporate individual behavioral responses (e.g., timing of retirement) have yielded similar conclusions (Sánchez-Romero et al. 2020).

Prior studies have used various methods. Mathematical models have been used to understand the variations of lifetime pension inequality under different pension systems, such as defined-benefit vs. defined-contribution systems (Pestieau and Ponthiere 2016; Sánchez-Romero et al. 2020). Researchers have also analytically calculated SES-specific lifetime pension income 
based on SES-specific life tables and pension formulae (e.g., OECD 2017; Olivera 2019). Inputs are often not from data linked at the individual level, but aggregated from different sources or arbitrary SES-specific inputs. This approach is useful for international comparisons where harmonized microdata are unavailable. Another approach is to use microsimulation to construct hypothetical cohorts, often using data from different sources and mortality forecasts (Goldman and

Orszag 2014; Hurd and Shoven 1985; NASEM 2015; Nelissen 1998). The simulation approach is useful to parse out the effects of different pension systems (Lee and Sánchez-Romero 2019) and changes in individual-level inputs (e.g., earnings trajectory, retirement age, lifespan) on population-level lifetime pension inequality. Another advantage is that simulation can help deal with right censoring, particularly when analyzing future trends of pension inequality. Only a few studies (e.g., Haan et al. 2020) have been able to directly calculate lifetime pension inequality from individual-level microdata with rich information. We impute pensions and mortality at very old ages, but these represent only a trivial share of the total person-years.

\section{Research Gaps and Our Contributions}

Thus far, no study has analyzed lifetime pension inequality based on the actual experience of birth cohorts due to data limitations. The long series of individual-level linked administrative data are not subject to the problems that typically affect surveys, such as missing values and reporting bias, especially for income variables. Hence, one contribution of this study is to provide precise, empirical evidence of the regressive role of the mortality gradient.

Methodologically, our combination of the life table approach with the decomposition technique is a novel addition to research on lifetime pension inequality. This analytical framework can answer research questions that have not been well answered. First, how large are the contributions of mortality and pre-retirement earnings to lifetime pension inequality? In most government pension systems, whether they are based on mandatory savings or a DB or NDC system, pension income is highly correlated with pre-retirement labor income, and therefore a large proportion of lifetime pension inequality results from inequality in pre-retirement labor income. Our decomposition method disentangles total lifetime pension inequality into additive components due to mortality differences, pre-retirement earnings differences, and the intended redistributive effects of the system. We also examine how (hypothetical) changes to the entire pension system, such as overall generosity, pension timing, and life expectancy changes, impact SES differences between groups. Second, how do mortality differences at a given age affect lifetime pension inequality? Prior research has shown that mortality inequality between SES groups becomes smaller with age (Hoffmann 2011; Rehnberg 2020). The narrowing gap in mortality with age suggests that mortality inequality at older ages may contribute less to total lifetime pension inequality than mortality inequality at younger ages. Whether this is true also depends on the age-specific pension variable. Empirically, evidence of the age pattern of the 
contribution of mortality is lacking as prior research has only shown the total mortality contribution due partly to methodological constraints.

While the majority of the existing research refers to the U.S. context, less is known about countries with contrasting pension systems, such as Sweden. Our study is also conceptually different from previous research in that we capture all sources of pensions (income-related government pensions, guaranteed pensions, collective-agreement pensions, disability pensions, and widowhood benefits) and provide a holistic view of the entire Swedish pension system. As such, our study provides a comparison point that shows how an entire national pension system works, rather than evaluating individual components of a (government) pension system (e.g., U.S. Social Security old-age insurance). Compared to prior studies that examine specific pension programs, this is both a drawback and an advantage. The drawback is that this study is not useful for evaluating any individual sub-component of a given pension system; the advantage is that we can assess its overall societal redistribution.

\section{The Swedish Context and Pension System}

For most of the $20^{\text {th }}$ century, life expectancy in Sweden ranked among the world's highest, although this is no longer the case in recent decades (Drefahl et al. 2014). Male mortality remains low from an international perspective, while female mortality is at the average OECD levels (Drefahl et al. 2014). Inequality in life expectancy by income levels at age 35 increased over 19702007 for Swedish men and women (Hederos et al. 2018). In particular, poor and low-educated men were the most vulnerable to premature deaths (Hartman and Sjögren 2018). An increasing gap in life expectancy has also been observed at age 65 over 2006-2015 (Fors et al. 2021).

Sweden is often described as a universalistic welfare state and as an exemplar of the social democratic regime in Esping-Andersen's (1990) typology of welfare states. At the time of our study, Sweden offered a generous public pension system (first pillar), but occupational pension systems (second pillar) linked to collective agreements covering the majority of the population were also important (Palme 2005). Thus, the Swedish pension system could broadly be described as "Bismarckian". An overview of the Swedish pension systems for our cohorts is provided in the Online Appendix 1.

The statutory retirement age was 65 for our cohorts, although it was possible (and common) for individuals to access many of their retirement benefits from age 60 (Hagen 2013). Our pension variable covers a wide selection of first- and second-pillar pensions (Whitehouse 2006), including other pensions targeted at individuals with special needs (e.g., survivor's pension), but it does not cover various sickness and disability pension schemes targeted at ages before the statutory retirement age. For the cohorts analyzed, it was possible to save in private annuities, or "pension insurance", with different tax rates depending on the saver's circumstances. Private pensions (paid out as a normal pension) are included in our pension variable, but are rare. 


\section{Data and Methods}

\section{Data}

Our analyses draw on two datasets: tax and death registers, which are linked with a unique personal ID number. The initial sample includes 209,491 individuals born in 1920 (55.6\%) and 1925 (44.4\%). The use of two cohorts helps test if the results are robust. There was no important institutional change between the two cohorts, so differences in results would reflect cohort differences in mortality schedules and earnings inequality, with the latter partly explained by cohort differences in labor force participation, particularly for women (Tables A1-A2). We exclude 1,628 individuals who had international migration records after age 50, 17,050 individuals who died before age 60, and 5,027 individuals due to missingness in key variables (mainly education). Hence, the analytical sample has 103,712 individuals born in 1920 and 82,074 individuals born in 1925 .

Individuals' yearly labor earnings and pension income are derived from taxation registers. The main outcome variable lifetime pension income includes state pensions, employer-financed pensions, and private pensions (private ones being a very small share, see Online Appendix 1). We focus on pension income at ages 60 and above; lifetime pension is conditional on surviving to $60 .^{1}$

We examine two socioeconomic factors: education and pre-retirement labor earnings. The education variable is obtained from education registers and has three levels: primary, secondary, and tertiary (and above). We group individuals into earnings quintiles based on (pre-tax) labor earnings over ages 50-59, separately by gender. ${ }^{2}$ Ideally, we would have included earnings of younger ages for grouping, but earlier data are not available. Grouping based on lifetime earnings (i.e., earnings over the entire work history) may lead to different results, though at the time of the study, the most important part of the Swedish pension system for our cohorts, the ATP, was based on income during the "best" 15 years (in practice often around ages 50-59) and not lifetime earnings. The average annual earnings over these ten years include years with zero earnings; however, excluding years with zero earnings when calculating average annual earnings leads to very similar results. For women, a large share of them were (mostly) outside the labor force as female labor force participation was far from universal in Sweden at the time. Therefore, the lowest quintile mostly includes women outside the labor market. Women in the second quintile had some labor force attachment. For the third and higher quintiles, the variable reflects different income levels among working women (see Table A2 in the Online Appendix). Earnings and pension income are shown in the unit of 1,000 Swedish krona (SEK). The exchange rate of SEK to the USD varied over the period, with an average of around 8 SEK to 1 USD.

\footnotetext{
${ }^{1}$ Conditioning upon surviving to age 50,5.8\% $(11,418)$ did not reach age 60 . Men, the less educated, and those with less income were more likely to die before age 60 than women, the more educated, and those with more income (see details in Table A3 in the Online Appendix).

${ }^{2}$ In the Online Appendix, we show the proportion of individuals with years of zero earnings over ages 50-59 in Tables A1-A2, and mean and standard deviation of the earnings variable in Table A4.
} 
Death records are available until 2019. In total, 1,658 (1.6\%) individuals from the 1920 cohort survived to 2020 (age 99), and 8,387 (10.2\%) individuals from the 1925 cohort survived to 2020 (age 94). For individuals who survived to 2020, we assume their pension income to be constant with the last three years' average over subsequent years, and their mortality to follow the forecasts by Statistics Sweden (2020). ${ }^{3}$

\section{Lifetime Pension Income}

Our analyses are based on cohort life tables. For each subgroup, we construct a life table from age 60 to age $105+$. Then, we add a column of age-specific pension income, $p e n_{x}$, to the life table. Lifetime pension conditional upon surviving to $60, L P_{60}$, is a function of inputs: total number of individuals survived to age $60, l_{60}$, person-years lived in the age interval $[x, x+1), L_{x}$, and $p e n_{x}$. The equation is as follows:

$$
L P_{60}=f\left(l_{60}, L_{x}, \text { pen }_{x}\right)=\frac{1}{l_{60}} \sum_{60}^{\omega} L_{x} \times p e n_{x}
$$

where $\omega$ is the terminal age 105 , and the radix $l_{60}$ is 1 . This equation is analogous to Sullivan's (1971) method of healthy life expectancy, a widely-used technique in population health research. The difference is that we replace the proportion of individuals without morbidity by $p e n_{x}$. Applying life table equations suggested by Chiang $(1960,1972)$, the $L_{x}$ can be written in the form of age-specific mortality rates, $m_{x}$, and average person-years lived in the age interval $[x, x+1)$ for persons dying in this interval, $a_{x}$,

$$
L_{x}=L_{x-1} \times \frac{1-m_{x-1} a_{x-1}}{1+m_{x}-m_{x} a_{x}}
$$

We assume $a_{x}$ to be 0.5 . This assumption works well and is widely used for calculating life tables. Hence, $L P_{60}$ is a function of $m_{x}$ and $p e n_{x}$ :

$$
L P_{60}=f\left(m_{x}, \text { pen }_{x}\right)
$$

For earnings and pension income, we adjust for inflation with 2018 as the base year.

\footnotetext{
${ }^{3}$ This assumption is reasonable since inflation-adjusted pension income is relatively invariable over time (see Figures A1-A2 in the Online Appendix). We use mortality forecasts by Statistics Sweden (2020) for ages that were not observable (100 and above for the 1920 cohort, 95 and above for the 1925 cohort). Within gender, we calculate mortality rates for SES groups by assuming relative mortality differences (i.e., mortality ratios) between SES groups in future years to be the same as those observed in 2015-2019, while matching total gender-specific mortality rates with those forecasted by Statistics Sweden. The potential bias in our assumption should be minor for our estimates of lifetime pension at age 60, given that only a small proportion of individuals survived to 2020 from the two cohorts.
} 
Some prior studies have used a discount rate when calculating lifetime pensions as they focus on the actuarial sustainability of pension systems (e.g., NASEM 2015; Whitehouse 2006; Whitehouse and Zaidi 2008), which results in adding less weight to pensions at older ages. We do not include a discount rate in our main analyses, as our primary interest is in the received money flows in the pension system. Also, accumulating non-discounted values is standard for research in social stratification. To provide comparability with previous studies focusing on pension sustainability, we present results with a discount rate of $2 \%$ in the Online Appendix. We choose $2 \%$ because it approximates the GDP/capita growth and wage growth over the period, and overall income growth determines the long-term financial sustainability of a PAYGO system (Samuelson 1958).

Using the life table approach, we aggregate individuals by their lifespan and then calculate the average lifetime pension. This approach essentially gives the same result as directly taking the average of individual accumulated pension over the lifetime (i.e., without aggregating by lifespan first), whereas the variation across individuals of the entire population calculated from a life table approach (e.g., Olivera 2019) may be different from direct individual calculations. This is because aggregating individuals to the mid-point of one-year age groups reduces the variation to some extent.

\section{Decomposition}

Decomposition techniques are widely applied to explain the difference in an aggregate measure between two (sub)populations by differences in its input covariates. As described earlier, lifetime pension is a function of covariates $m_{x}$ and $p e n_{x}$, and our aim is to explain the difference in lifetime pension between SES groups by differences in $m_{x}$ and $p e n_{x}$. We apply the decomposition method proposed by Horiuchi et al. (2008). Specifically, $L P_{60}$ can be seen as a differentiable function of the covariates $m_{x}$ and pen $_{x}$. We assume continuous changes between the two groups of interest (e.g., low and high SES). Lifetime pension of the two groups are denoted as $L P_{60}^{1}$ and $L P_{60}^{2}$, and the difference between them can be written as:

$$
L P_{60}^{2}-L P_{60}^{1}=\sum_{x=60}^{\omega}\left(\int_{m_{x}^{1}}^{m_{x}^{2}} \frac{\partial f\left(m_{x}, p e n_{x}\right)}{\partial m_{x}} d m_{x}+\int_{p e n_{x}^{1}}^{p e n n_{x}^{2}} \frac{\partial f\left(m_{x}, p e n_{x}\right)}{\partial p e n_{x}} d p e n_{x}\right)
$$

This way, the total difference between $L P_{60}^{1}$ and $L P_{60}^{2}$ is split into components attributable to differences in $m_{x}$ and pen $_{x}$. Numeric integration is used for the estimation (Horiuchi et al. 2008). This decomposition method has been widely used to decompose health expectancies (van Raalte and Nepomuceno, 2020).

We apply a second decomposition by further splitting the pen $_{x}$ into two components: earn and $\operatorname{diff}_{x}$, and pen $_{x}=e$ earn $+\operatorname{diff} f_{x}$, where earn is the average yearly labor earnings between age 50 and 59 and $\operatorname{diff}_{x}$ is the difference between pension income at each age and the average 
earnings at ages 50-59. ${ }^{4}$ The covariates are $m_{x}$, diff $f_{x}$ and earn. This reformulation is motivated by the fact that a large proportion of inequalities in yearly pension income is due to inequalities in pre-retirement labor earnings. Generally, dif $f_{x}$ takes negative values, as individuals' pension income tends to be lower than their previous labor earnings. A dif $f_{x}$ closer to zero means pension income matches labor earnings better. Comparing $\operatorname{diff}_{x}$ across SES therefore indicates the redistribution effect (perceived on a yearly basis). If $\operatorname{dif} f_{x}$ is smaller in absolute value among low SES groups than high SES groups, the system is progressive. The total contributions of earn and dif $f_{x}$ sum to the total contributions of $p e n_{x}$ in the first decomposition. The decomposition method is implemented using the $R$ package DemoDecomp (Riffe 2018).

We also analyze the impacts of several scenarios of policy and mortality changes. Changes in retirement ages are examined by shifting $p e n_{x}$ along age $x .{ }^{5}$ Changes in the generosity of the pension system are assessed by recalculating $p e n_{x}$. Mortality scenarios are evaluated by modifying the $m_{x}{ }^{6}$

\footnotetext{
${ }^{4}$ Alternatively, one can specify the relationship between prior earnings and yearly pension income as the ratio instead of the absolute difference term we use here. Our pension variable is the sum of pension incomes from various programs, and many of them are not earnings-related. Thus, theoretically, the relationship between yearly pension income and prior earnings is neither additive nor relative. Empirically, the relationship between earnings and yearly pension income depends on the location of the earnings distribution. Particularly, at the lower end of the earnings distribution, yearly pension income is unlikely to be related to earnings on a "ratio" basis. For instance, for women with zero earnings (which constitutes over $40 \%$ of the lowest income quintile for the 1920 cohort), the ratio would be positive infinity. A small increase in earnings does not lead to a big increase in pension income because of the guarantee pension. The ratio between average yearly pension and average earnings for the lowest female quintile in 1920 is 15.14 - a very large number, whereas the usual replacement rate of occupational pension is smaller than 1. Thus, the specification of using ratios is empirically less meaningful than the specification of using absolute differences.

${ }^{5}$ When examining the impact of raising retirement age by one year, we replace $p e n_{x}$ by $p e n_{x-1}$ for ages $61-105$, and set $p e n_{60}$ as zero. When examining the impact of lowering retirement age by one year, we replace $p e n_{x}$ by $p e n_{x+1}$ for ages $60-104$, and keep $p e n_{105}$ unchanged. This approach might not reflect the reality perfectly as individuals' retirement patterns may change due to changes in statutory retirement age, but it is a good starting point for the analysis of such policies.

${ }^{6}$ We examine simple scenarios where mortality rates across all age experience the same proportional reduction.
} 


\section{Results}

Table 1 shows that life expectancy at age 60 increases by education and earnings quintile for both men and women. ${ }^{7}$ For the 1920 cohort, 60 -year old men in the highest earnings quintile were expected to live 4.5 years more than their peers in the lowest quintile (22.0 vs. 17.5 years). Similarly, for the 1920 cohort, men with primary education had 2.6 years less life expectancy than did men with tertiary education; the gap became 3.4 years for men born in 1925. Similar patterns were also found for women, but to a lesser extent. Interestingly, unlike men, women in the lowest earnings quintile did not have the lowest life expectancy. Overall, mortality differences by earnings were smaller for women than for men. Table 1 also shows that people who were more educated and who earned higher incomes also had higher pension incomes at age 70, reflecting an incomebased pension system. Overall, pensions increased rapidly up to age 66, and remained stable for all groups thereafter. ${ }^{8}$

We find substantial gaps in lifetime pension income between education and earnings groups. ${ }^{9}$ The lifetime pension income of men with tertiary education was more than twice that of men with primary education. The absolute difference was almost 3 million SEK (approximately 375,000 USD). We find similar levels of differences between women with primary and tertiary education. Additionally, lifetime pension increased by earnings quintile. The largest difference is observed between the fourth and highest quintiles for both genders and both cohorts.

We also find large differences by gender: men had a shorter life expectancy but a higher lifetime pension than women. Women of a given quintile had lifetime pensions approximately similar to men of the preceding quintile. Additional analysis (Figure A9) shows that women's lower mortality contributed to higher lifetime pension compared to men, but a disadvantage in yearly pension income more than offset the mortality component and led to an overall male advantage in lifetime pension.

In addition, we find larger education and earnings differences in life expectancy among men than among women. Gendered differences in the association between SES and mortality have long been documented in the literature (Pappas et al. 1993). On the other hand, differences in yearly pension income were smaller (in absolute terms) between female SES groups than between male SES groups due to more homogeneous income distribution among working-age women than working-age men. Mortality and yearly pension levels both resulted in larger gaps in lifetime pension income between male SES groups.

\footnotetext{
${ }^{7}$ See the corresponding survival curves in Figures A1 and A2 in the Online Appendix.

${ }^{8}$ See age-specific pension income in Figures A3 and A4 in the Online Appendix.

${ }^{9}$ See Figures A5 and A6 in the Online Appendix for boxplots of observed (i.e., truncated) accumulated pension income until the end of 2018. While our lifetime pension income is defined as the expected value of accumulated pension from age 60 to death, one could also calculate the expected lifetime pension within a specific age interval starting from 60, analogous to temporary life expectancy (i.e., expected years of life within the specified age interval). These results are presented in Figures A7-A8.
} 
Table 1. Descriptive statistics for remaining life expectancy at age 60, average pension at age 70, and lifetime pension.

\begin{tabular}{|c|c|c|c|c|c|c|c|c|}
\hline \multirow[b]{2}{*}{ Cohort } & \multicolumn{2}{|c|}{ Number (\%) } & \multicolumn{2}{|c|}{$\mathrm{LE}_{60}($ year$)$} & \multicolumn{2}{|c|}{$\begin{array}{c}\text { Mean pension at } 70 \\
(1000 \mathrm{SEK})^{1}\end{array}$} & \multicolumn{2}{|c|}{$\begin{array}{l}\text { Lifetime pension } \\
(1000 \mathrm{SEK})^{1}\end{array}$} \\
\hline & 1920 & 1925 & 1920 & 1925 & 1920 & 1925 & 1920 & 1925 \\
\hline Men total & $\begin{array}{l}51088 \\
(100 \%)\end{array}$ & $\begin{array}{l}40368 \\
(100 \%)\end{array}$ & 20.0 & 21.0 & 192.2 & 197.6 & 3173.5 & 3589.2 \\
\hline \multicolumn{9}{|c|}{ Men by education } \\
\hline Primary & $\begin{array}{l}34757 \\
(68 \%)\end{array}$ & $\begin{array}{l}25486 \\
(63 \%)\end{array}$ & 19.5 & 20.2 & 168.5 & 169.3 & 2705.7 & 2992.8 \\
\hline Secondary & $\begin{array}{l}13086 \\
(26 \%)\end{array}$ & $\begin{array}{l}11328 \\
(28 \%)\end{array}$ & 20.8 & 21.7 & 222.3 & 221.0 & 3795.6 & 4128.6 \\
\hline Tertiary & $3245(6 \%)$ & $3554(9 \%)$ & 22.1 & 23.6 & 311.4 & 311.9 & 5650.4 & 6138.8 \\
\hline \multicolumn{9}{|c|}{ Men by earnings } \\
\hline Lowest & $\begin{array}{l}10218 \\
(20 \%)\end{array}$ & $8074(20 \%)$ & 17.5 & 18.6 & 105.8 & 113.6 & 1606.6 & 1913.6 \\
\hline Second & $\begin{array}{l}10217 \\
(20 \%)\end{array}$ & $8073(20 \%)$ & 19.3 & 20.2 & 158.4 & 161.4 & 2465.2 & 2802.0 \\
\hline Third & $\begin{array}{l}10218 \\
(20 \%)\end{array}$ & $8074(20 \%)$ & 20.2 & 21.0 & 178.0 & 178.6 & 2932.9 & 3273.3 \\
\hline Fourth & $\begin{array}{l}10217 \\
(20 \%)\end{array}$ & $8073(20 \%)$ & 20.9 & 21.8 & 204.6 & 209.8 & 3507.8 & 3930.9 \\
\hline Highest & $\begin{array}{l}10218 \\
(20 \%)\end{array}$ & $8074(20 \%)$ & 22.0 & 23.2 & 298.3 & 309.6 & 5334.9 & 6014.1 \\
\hline Women total & $\begin{array}{c}52624 \\
(100 \%)\end{array}$ & $\begin{array}{l}41706 \\
(100 \%)\end{array}$ & 24.5 & 25.1 & 109.4 & 118.8 & 2405.8 & 2725.6 \\
\hline \multicolumn{9}{|c|}{ Women by education } \\
\hline Primary & $\begin{array}{l}41128 \\
(78 \%)\end{array}$ & $\begin{array}{l}31049 \\
(74 \%)\end{array}$ & 24.2 & 24.7 & 99.8 & 107.3 & 2178.0 & 2443.5 \\
\hline Secondary & $\begin{array}{l}9363 \\
(18 \%)\end{array}$ & $8300(20 \%)$ & 25.3 & 26.0 & 131.6 & 136.6 & 2925.3 & 3169.1 \\
\hline Tertiary & $2133(4 \%)$ & $2357(6 \%)$ & 27.1 & 27.3 & 192.8 & 203.3 & 4503.0 & 4888.5 \\
\hline \multicolumn{9}{|c|}{ Women by earnings } \\
\hline Lowest & $\begin{array}{l}10525 \\
(20 \%)\end{array}$ & $8341(20 \%)$ & 24.6 & 24.9 & 65.6 & 63.5 & 1481.0 & 1621.4 \\
\hline Second & $\begin{array}{l}10525 \\
(20 \%)\end{array}$ & $8341(20 \%)$ & 23.2 & 23.8 & 72.2 & 79.6 & 1618.6 & 1871.8 \\
\hline Third & $\begin{array}{l}10524 \\
(20 \%)\end{array}$ & $8341(20 \%)$ & 24.7 & 25.6 & 93.2 & 109.0 & 2117.8 & 2526.0 \\
\hline Fourth & $\begin{array}{l}10525 \\
(20 \%)\end{array}$ & $8341(20 \%)$ & 24.7 & 25.2 & 127.9 & 141.0 & 2761.8 & 3134.1 \\
\hline Highest & $\begin{array}{l}10525 \\
(20 \%)\end{array}$ & $8342(20 \%)$ & 25.4 & 26.1 & 185.9 & 198.0 & 4044.4 & 4475.2 \\
\hline
\end{tabular}

Source: Authors' calculation based on linked administrative data from Statistics Sweden.

Notes: See summary statistics for the earnings variable in Table A2. 1 Inflation was adjusted to the 2018 level when computing average pension at age 70 and lifetime pension (third to sixth columns). Units are in $1000 \mathrm{SEK}, \approx 125$ USD. 
Figure 1 presents the decomposition results for the comparison between primary and tertiary education groups by gender and cohort. In each panel, the sum of all bars equals to the total difference in lifetime pension. The results show that mortality differences accounted for an important part of the total differences in lifetime pension. For men born in 1920, differences in mortality rates of all ages above 60 resulted in a difference of 636,000 SEK in lifetime pension income, constituting $22 \%$ of the total difference $(2,945,000 \mathrm{SEK})$; these figures increased to 852,000 SEK and $27 \%$ for the 1925 cohort, while lifetime pension differences due to yearly pension income showed almost no change across the cohorts.

Differences between primary and tertiary education, men

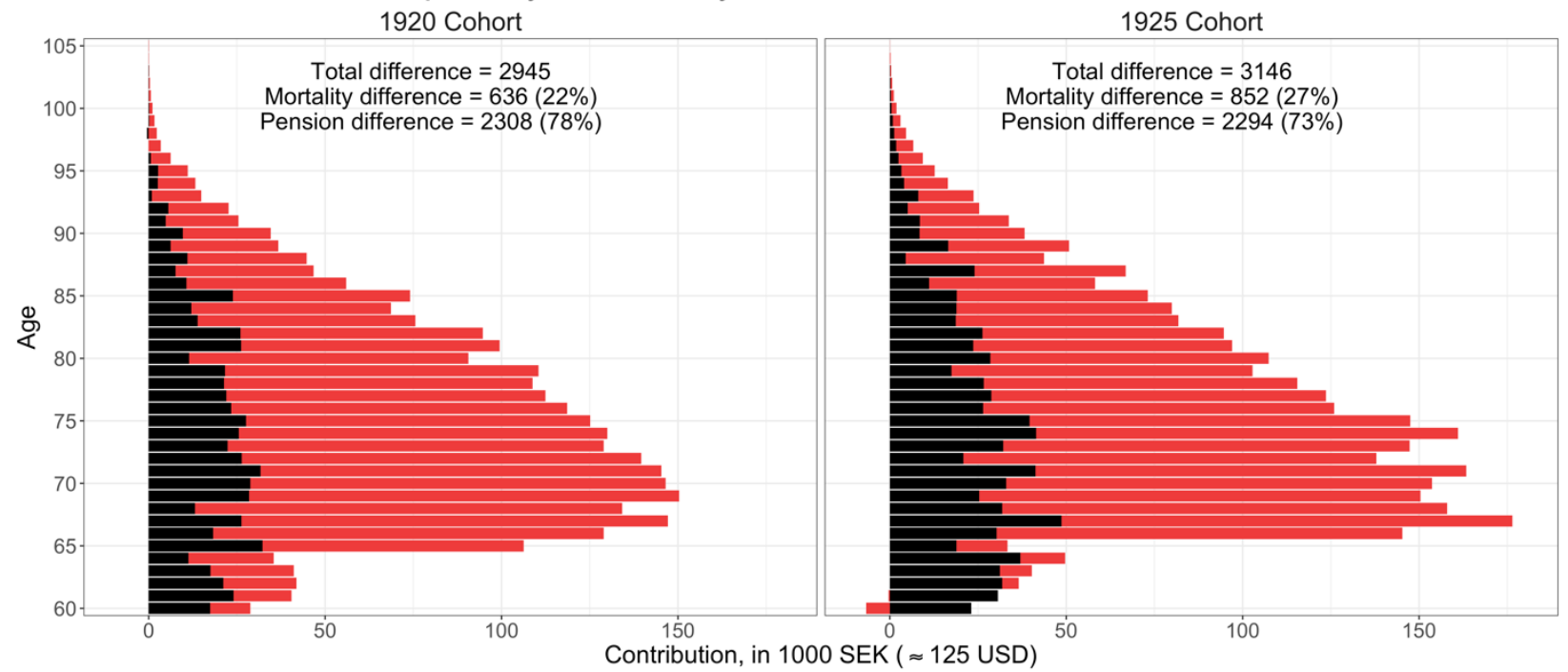

Differences between primary and tertiary education, women

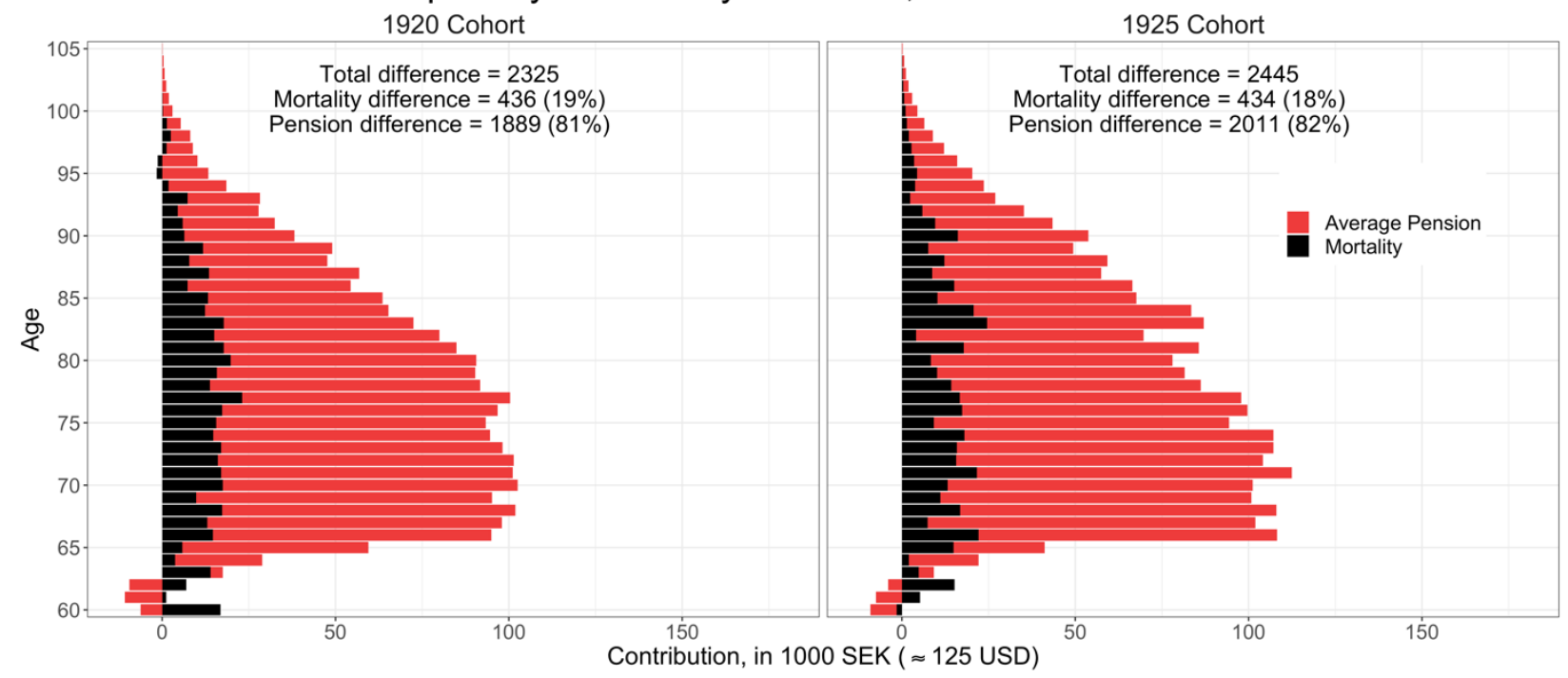

Figure 1. Decomposition of total lifetime pension differences between primary and tertiary education groups into differences explained by mortality and yearly pension. Source: As for Table 1. 
As shown in Table 1, women had lower annual and lifetime pensions than men, and overall, we find a similar SES gradient in annual pension levels for men and women. In absolute terms, but not in relative terms, we find a larger difference in total pension across SES groups of men than of women. Women had a less marked SES gradient for mortality, in particular for earnings.

Among men, we find a small increase in the importance of mortality differences between the two cohorts, in line with the increasing gap in remaining life expectancy (from 2.6 to 3.4 years). Compared to men, contributions of mortality were smaller for female educational groups (both in absolute and relative terms), as mortality differences between female education groups were also smaller. The magnitude of contributions of mortality differences decreased only at advanced ages (around 85); before this point, age-specific mortality contributions were relatively stable. This could be explained by the fact that SES differences in mortality declined with age and the slope was steeper above age 85 (Figure A10). Indeed, the age patterns of mortality in Figure 1 resemble the age patterns of mortality when decomposing life expectancy differences (Figure A11). The contributions of age-specific pension and mortality were much lower at older ages because much fewer people survived to these ages.

Meanwhile, age-specific differences in pension income only began to contribute significantly from the ages at which individuals usually retire (i.e., 65). Before 65, contributions to yearly pension income were minor and even reversed among women, as lower educated women retired earlier much more frequently and had higher average pension income at these ages. From age 66, the contributions of yearly pension differences were consistently high and started to decrease rapidly at approximately age 80 .

Figure 2 shows the decomposition results when comparing the lowest and highest earnings quintiles. For men, we largely find the same patterns as for education. The differences in lifetime pension were larger in the 1925 born cohort. The results for women are different, as the contributions of mortality differences were much smaller, only accounting for $4 \%$ and $6 \%$ for the 1920 and 1925 cohorts, respectively. As we have presented above, for women, life expectancy at 60 was not the lowest among the lowest earnings quintile, and mortality was only slightly higher among women in the lowest quintile compared to women in the highest quintile.

Figures 1 and 2 both show that the majority of lifetime pension inequalities was explained by differences in yearly pension income, which, to a large extent, was determined by preretirement labor earnings. On the other hand, as discussed earlier, most pension systems are progressive and aim to provide higher replacements for low SES groups. Thus, the differences in total pension between SES groups explained by average yearly pensions (red bars) observed in Figures 1 and 2 are a function of both labor earnings and the pension system's redistribution effect. We further explored this aspect by splitting age-specific pension income into two components: pre-retirement labor earnings and the difference between pension income and labor earnings. Hence, we estimated the extent to which pre-retirement labor earnings and the pension system's redistribution function (perceived on a yearly basis) played contributory roles. Before showing these results, we first show how pension income is attached to labor earnings by education and 
earnings group in Table 2. Specifically, we calculated the difference and ratio between individuals' average yearly pension income between ages 66-75 and average yearly earnings between ages 5059. Note that this does not reflect any formula for how earnings were translated into pensions in the pension system; this was not possible as our pension variable included divergent pension programs.

Differences between the lowest and the highest quintiles, men

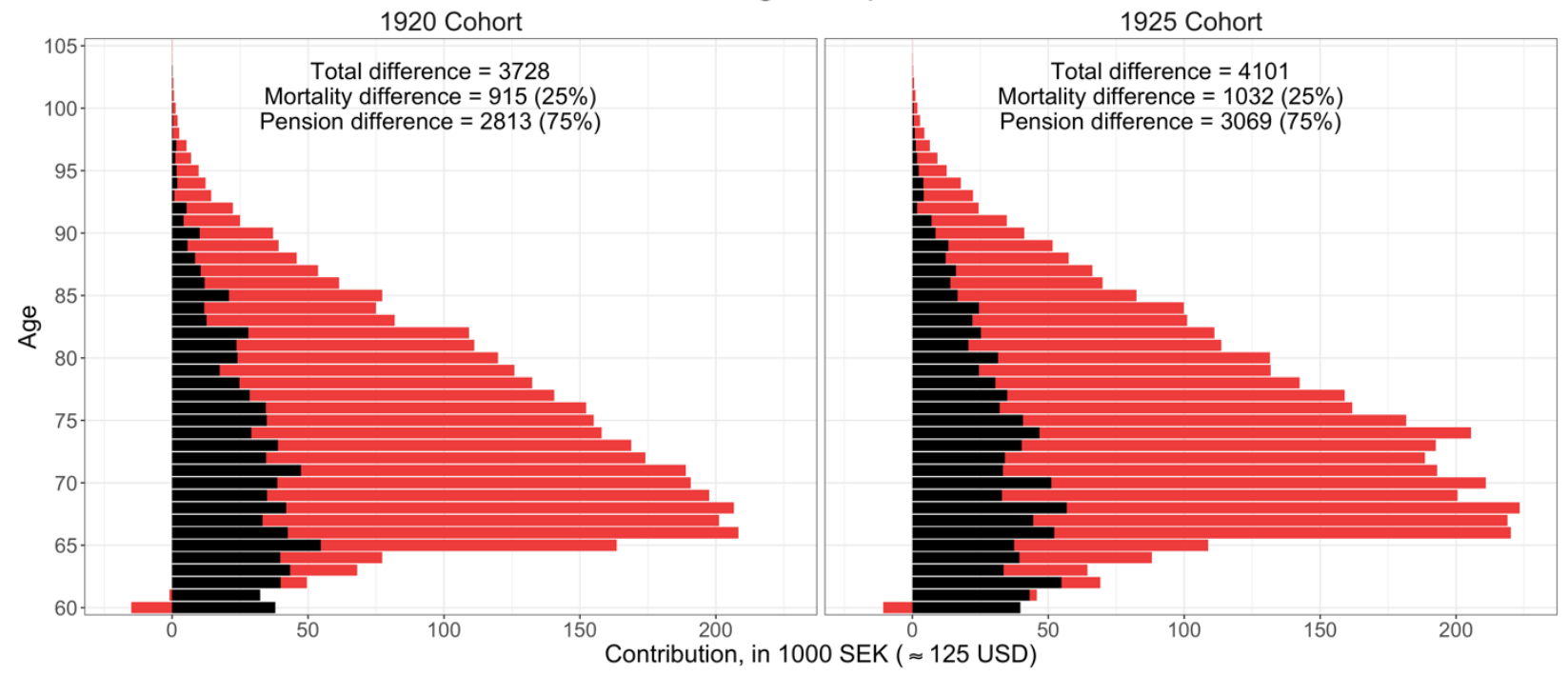

Differences between the lowest and the highest quintiles, women

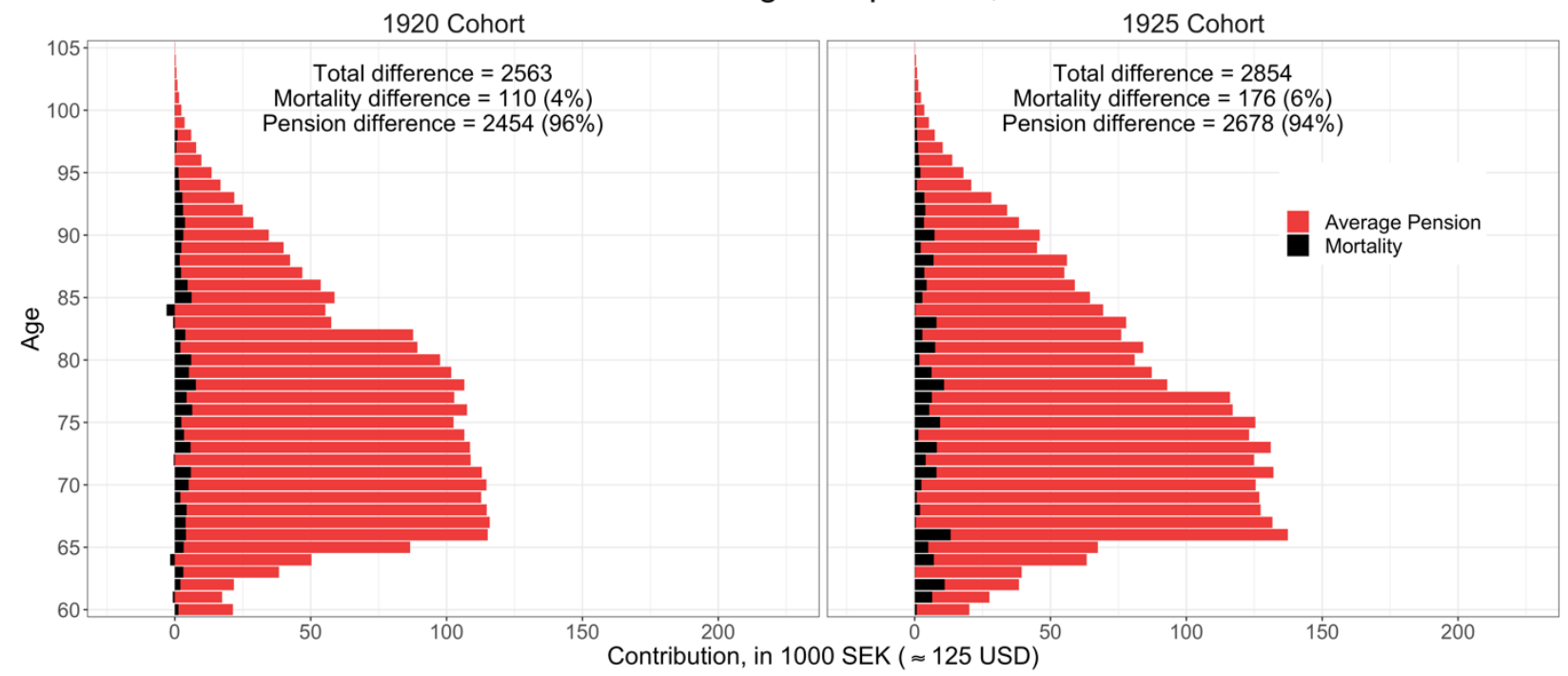

Figure 2. Decomposition of total lifetime pension differences between the bottom and the top earnings quintile groups into differences explained by mortality and yearly pension. Source: As for Table 1. 
Table 2 shows that both the difference and the ratio declined with education and earnings quintile, indicating progressivity in the pension system. In particular, while women in the highest earnings quintile born in 1920 received 0.74 of their labor earnings, their peers in the lowest received pensions over 15 times their labor earnings. This reflects a guaranteed pension, which benefits individuals with very low earnings such as homemakers. However, from the second to the fourth quintiles, the ratio (also the difference) decreased little for men and moderately for women. In the 1925 cohort, it decreased from 0.78 to 0.74 for men, and from 0.94 to 0.77 for women. Thus, the pension system translated earnings into pensions at a relatively constant rate for those with medium earnings, with only modest progressivity. The relatively weak link between earnings and pension of women partly reflects that women received a relatively large share of their income as widow pension (which was independent of their own earnings), as those women often married older husbands (Kolk 2015) and outlived their husbands.

Table 2. Absolute and relative differences between average yearly pension income (66-75) and average yearly labor earnings (50-59) across different educational groups in earnings quintiles.

\begin{tabular}{|c|c|c|c|c|c|c|c|c|}
\hline & \multicolumn{4}{|c|}{ Men } & \multicolumn{4}{|c|}{ Women } \\
\hline & \multicolumn{2}{|c|}{1920 cohort } & \multicolumn{2}{|c|}{1925 cohort } & \multicolumn{2}{|c|}{1920 cohort } & \multicolumn{2}{|c|}{1925 cohort } \\
\hline & $\begin{array}{c}\text { Diff } \\
\left(1000 \text { SEK}^{1}\right)\end{array}$ & Ratio & $\begin{array}{c}\text { Diff } \\
\left(1000 \text { SEK}^{1}\right)\end{array}$ & Ratio & $\begin{array}{c}\text { Diff } \\
\left(1000 \text { SEK}^{1}\right)\end{array}$ & Ratio & $\begin{array}{c}\text { Diff } \\
\left(1000 \text { SEK}^{1}\right)\end{array}$ & Ratio \\
\hline Total & -74.08 & 0.72 & -66.89 & 0.75 & -0.40 & 1.00 & -17.21 & 0.88 \\
\hline \multicolumn{9}{|l|}{ By education } \\
\hline Primary & -55.54 & 0.75 & -51.56 & 0.77 & 5.30 & 1.06 & -12.78 & 0.90 \\
\hline Secondary & -95.57 & 0.70 & -80.92 & 0.74 & -13.66 & 0.91 & -25.38 & 0.85 \\
\hline Tertiary & -200.63 & 0.60 & -148.09 & 0.68 & -58.44 & 0.77 & -52.00 & 0.80 \\
\hline \multicolumn{9}{|l|}{ By earnings } \\
\hline Lowest & -12.10 & 0.90 & -12.17 & 0.90 & 60.05 & 15.14 & 45.62 & 3.32 \\
\hline Second & -46.28 & 0.77 & -46.45 & 0.78 & 28.29 & 1.65 & -4.76 & 0.94 \\
\hline Third & -63.31 & 0.74 & -62.06 & 0.75 & -3.24 & 0.97 & -21.89 & 0.84 \\
\hline Fourth & -82.04 & 0.71 & -76.46 & 0.74 & -25.98 & 0.83 & -42.11 & 0.77 \\
\hline Highest & -183.41 & 0.62 & -154.00 & 0.67 & -63.75 & 0.74 & -65.98 & 0.75 \\
\hline
\end{tabular}

Source: As for Table 1.

Notes: ${ }^{1}$ Units are in 1000 SEK, $\approx 125$ USD.

Table 3 shows the results from an extended three-way decomposition. For simplicity, we refer to the three components attributable to mortality, differences between pension income and pre-retirement labor earnings, and labor earnings as mortality effect, redistribution effect, and earnings effect, respectively. The results show that the majority of the total lifetime pension difference was due to the earnings effect. Meanwhile, differences in lifetime pensions would have been considerably larger without a progressive pension system. If there had been no redistribution between groups, SES differences would have been approximately twice as large. It is noteworthy 
that the decompositions were based on comparisons between the lowest and highest SES groups. We expect to see much smaller redistribution when comparing groups in the middle of the SES distribution, as suggested by Table 2 . The overall patterns in Table 3 are similar across different comparisons, except for the comparison between the lowest vs. highest earnings quintiles among women. Compared to women in the lowest quintile, women in the highest quintile only had a slight longevity advantage (even disadvantages at certain ages), whereas their earnings were much higher; meanwhile, as shown in Table 2, women in the highest quintile only received $72 \%$ of their labor earnings as their pension (at age 70), whereas women in the lowest quintile received over 1,500\%. Such substantial differences resulted in huge redistribution and earnings effects, but in opposite directions. The differences explained by mortality are clearly of lower magnitude than SES differences in earnings and the progressive redistribution of the pension system.

Table 3. Three-way decompositions of differences in total lifetime pension between education and earnings groups.

\begin{tabular}{|c|c|c|c|c|c|c|c|c|}
\hline & \multicolumn{4}{|c|}{ Men } & \multicolumn{4}{|c|}{ Women } \\
\hline & \multicolumn{2}{|c|}{1920 cohort } & \multicolumn{2}{|c|}{1925 cohort } & \multicolumn{2}{|c|}{1920 cohort } & \multicolumn{2}{|c|}{1925 cohort } \\
\hline & 1000 SEK & $\%$ & 1000 SEK & $\%$ & $1000 \mathrm{SEK}$ & $\%$ & $1000 \mathrm{SEK}$ & $\%$ \\
\hline \multicolumn{9}{|c|}{ Primary vs. tertiary education } \\
\hline Mortality effect & 636.2 & $21.6 \%$ & 852.1 & $27.1 \%$ & 436.1 & $18.8 \%$ & 433.5 & $17.7 \%$ \\
\hline Redistribution effect & -3597.8 & $-122.2 \%$ & -2963.6 & $-94.2 \%$ & -2086.4 & $-89.7 \%$ & -1569.4 & $-64.2 \%$ \\
\hline Earnings effect & 5906.2 & $200.6 \%$ & 5257.5 & $167.1 \%$ & 3975.2 & $171.0 \%$ & 3580.9 & $146.5 \%$ \\
\hline Total & 2944.7 & $100.0 \%$ & 3146.0 & $100.0 \%$ & 2325.0 & $100.0 \%$ & 2444.9 & $100.0 \%$ \\
\hline \multicolumn{9}{|c|}{ Lowest vs. highest earnings quintiles } \\
\hline Mortality effect & 915.0 & $24.5 \%$ & 1032.0 & $25.2 \%$ & 109.6 & $4.3 \%$ & 175.8 & $6.2 \%$ \\
\hline Redistribution effect & -4269.7 & $-114.5 \%$ & -4026.9 & $-98.2 \%$ & -3632.8 & $-141.7 \%$ & -3655.3 & $-128.1 \%$ \\
\hline Earnings effect & 7083.0 & $190.0 \%$ & 7095.5 & $173.0 \%$ & 6086.5 & $237.4 \%$ & 6333.4 & $221.9 \%$ \\
\hline Total & 3728.3 & $100.0 \%$ & 4100.6 & $100.0 \%$ & 2563.3 & $100.0 \%$ & 2853.8 & $100.0 \%$ \\
\hline
\end{tabular}

Source: As for Table 1.

Notes: Mortality effect, redistribution effect, and earnings effect refer to the parts of total lifetime pension difference that are attributable to differences in mortality, differences in the differences between pension income and labor earnings, and differences in labor earnings, respectively. Units are in $1000 \mathrm{SEK}, \approx 125 \mathrm{USD}$.

When comparing SES groups that are less divergent (e.g., primary vs. secondary education, lowest vs. third earnings quintiles), the absolute differences in lifetime pension are unsurprisingly smaller, yet the share explained by mortality differences is more or less constant across comparisons (see Tables A5-A6 and Figures A12-A16 in the Online Appendix). All our main findings are robust in these comparisons. Among them, the largest differences in lifetime pension are found to be between secondary vs. tertiary education groups and third vs. highest earnings quintiles, suggesting that the differences between SES groups were particularly large between the most advantageous groups and others. To make our results comparable to previous studies that 
focused on actuarial aspects and financing of pension systems, we also replicated our calculations where we introduced a discount rate of $2 \%$, giving more weight to present rather than future pension incomes (see Table A7 and Figures A17-A18 in the Online Appendix). A consequence of this is that money received at younger ages is valued more. Hence, in calculations with a discount rate, we observe that mortality was less explanatory of differences in lifetime pension between SES groups, as low SES groups obtained a relatively higher share of their pensions earlier. In other words, the longevity advantage of high SES groups at older ages becomes less important when a discount rate is used.

In Table 4, we show ratios of yearly earnings, yearly pension, lifetime pension income, and life expectancy between low and high SES groups. Yearly pension income is the most equal among the three monetary outcomes, while yearly earnings are the most unequal. The inequality level of lifetime pension income falls between the two. One exception is for women in the lowest vs. highest earnings quintiles, yearly pension is more unequal than lifetime pension income. This is likely due to the ages used to compare yearly pension income (ages 66-75), as we find yearly pension income between the highest and lowest female earnings quintiles is more equal at older ages (Figure A2 in the Online Appendix). We also find that differences in life expectancy between SES groups (and between men and women) are much smaller than differences in lifetime pension.

Table 4. Ratios of yearly earnings, yearly pension, lifetime pension, and life expectancy at 60 between education and earnings groups.

\begin{tabular}{|c|c|c|c|c|}
\hline \multirow{2}{*}{ Ratio } & \multicolumn{2}{|c|}{ Men } & \multicolumn{2}{|c|}{ Women } \\
\hline & 1920 cohort & 1925 cohort & 1920 cohort & 1925 cohort \\
\hline \multicolumn{5}{|l|}{ Primary vs. tertiary education } \\
\hline Yearly earnings (average over 50-59) & 2.28 & 2.08 & 2.66 & 2.13 \\
\hline Yearly pension (average over 66-75) & 1.84 & 1.84 & 1.93 & 1.90 \\
\hline Lifetime pension income $(60+)$ & 2.09 & 2.05 & 2.07 & 2.00 \\
\hline Life expectancy at 60 & 1.13 & 1.17 & 1.12 & 1.11 \\
\hline \multicolumn{5}{|l|}{ Lowest vs. highest earnings quintiles } \\
\hline Yearly earnings (average over 50-59) & 4.10 & 3.69 & 58.33 & 13.63 \\
\hline Yearly pension (average over 66-75) & 2.82 & 2.74 & 2.86 & 3.10 \\
\hline Lifetime pension income $(60+)$ & 3.32 & 3.14 & 2.73 & 2.76 \\
\hline Life expectancy at 60 & 1.25 & 1.25 & 1.03 & 1.05 \\
\hline
\end{tabular}

Source: As for Table 1. 
Lastly, in addition to decompositions based on experiences of the 1920 and 1925 cohorts, we examined how counterfactual scenarios of policy changes and mortality reduction can affect lifetime pension differences. Through this approach, we gain an understanding of which factors are important for lifetime pension, and how they will affect SES differences in lifetime pension. Table 5 shows the results for the comparisons between primary and tertiary education for the 1920 cohort. Results for other comparison groups are highly consistent (Tables A8-A10 in the Online Appendix). We examined both how uniform changes in the timing of retirement and generosity of the pension system will affect SES gradients, as well as when changes only take place in low or high SES groups. A uniform increase in retirement age would have led to a smaller gap in lifetime pension in absolute terms. This is because people who were more educated had higher yearly pension income and thus would have lost more pension benefits in absolute terms. Yet, uniform increases in retirement age would have enlarged lifetime pension inequality in relative terms, as lower earners would have lost a higher proportion of lifetime pension. These changes are small in magnitude, particularly for relative inequalities. If the change in retirement timing had differed by education and the less-educated were to retire earlier or the more-educated were to retire later, lifetime pension inequality would have been reduced in both absolute and relative terms. In the extreme case where only people with tertiary education were to postpone their retirement age by three years, the absolute differences in lifetime pension would have decreased by $30.2 \%$ and $25 \%$ for men and women, respectively. However, the absolute differences in lifetime pension would have remained high (over 2 million SEK for men and 1.7 million for women).

Increasing yearly pension by the same fixed amount for all individuals would have increased lifetime pension inequality in absolute terms, as the more-educated would have benefited more because of their longer life expectancy. On the other hand, it would have predictably reduced relative inequality. Not surprisingly, increasing minimum pension, which would mainly have affected those with the least pension, would have reduced both absolute and relative inequality. Finally, we consider changing mortality rates. If mortality had decreased by $10 \%$ across all ages for all groups, absolute inequality in lifetime pension would have been larger, but relative inequality would have been smaller. If mortality rates had been reduced by $10 \%$ for the less educated but remained stable for the more educated, lifetime pension inequality would have decreased in both absolute and relative terms. Stagnation of mortality among the less educated and a $10 \%$ reduction in mortality among the more-educated would have exacerbated lifetime pension inequality. The effects of these scenarios are even more limited in magnitude as compared to the retirement age scenarios. Overall, even though these scenarios reflect quite large changes in the pension system/behavior, the impact on overall SES differences in lifetime pension are quite small compared to empirically observed differences (Table 1). This underscores the importance of prior earnings inequality in generating old-age inequalities. 
Table 5. Lifetime pension inequality between primary and tertiary education under policy and mortality scenarios, 1920 cohort.

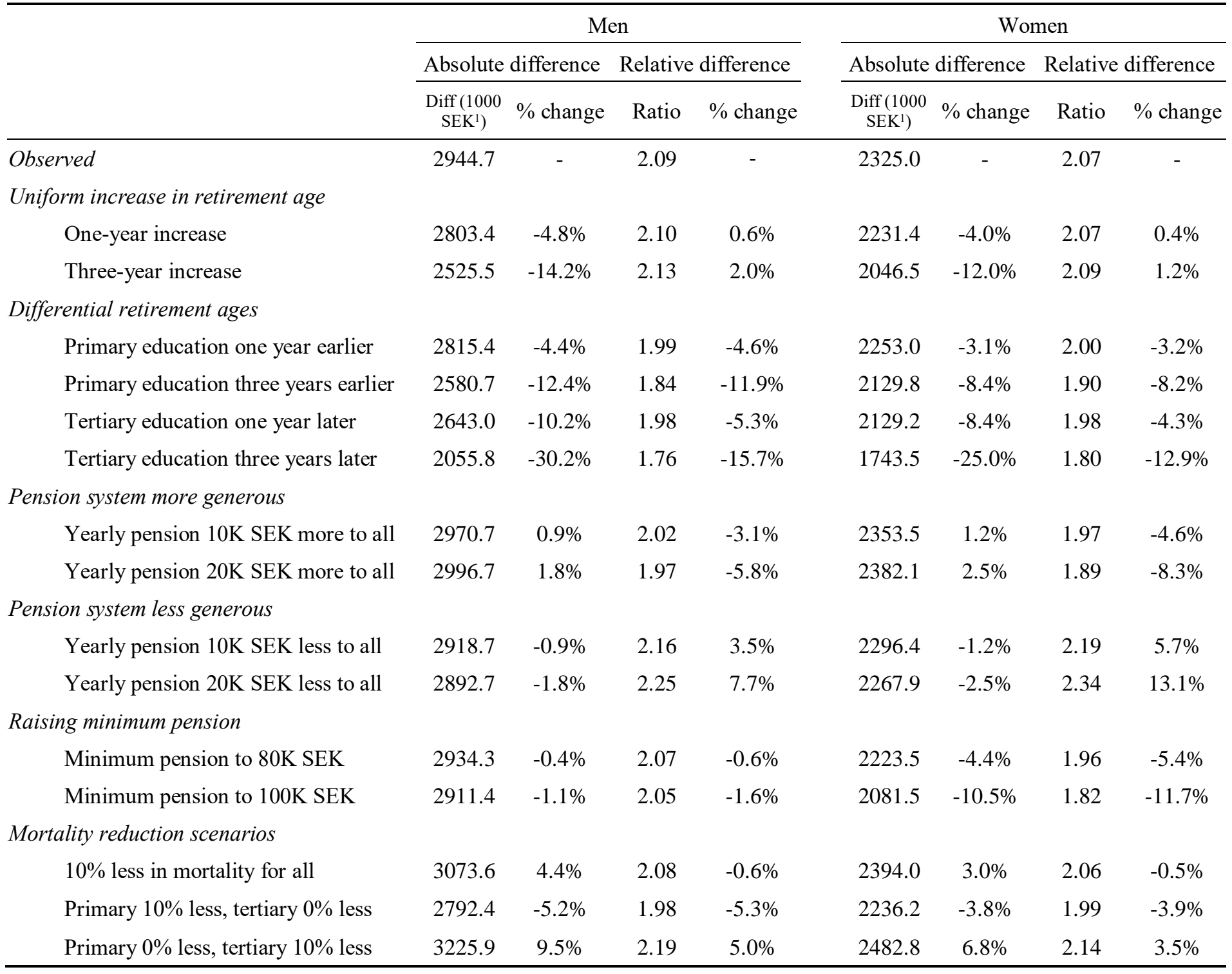

Source: As for Table 1.

Notes: For the 1920 cohort, the observed lifetime pension is $2705.7 \mathrm{~K}$ SEK for men with primary education, $5650.4 \mathrm{~K}$ SEK for men with tertiary education, 2178.0K SEK for women with primary education, and 4503.0K SEK for women with tertiary education. For the scenarios of changing retirement age, we shift the observed yearly pension income to younger or older ages by certain years. In the case of earlier retirement by one year, the last year (i.e., age 105) of pension income is assumed to be the same as the pension income in the last observed year (i.e., age 104). In the case of later retirement by one year, the first year (i.e., age 60) of pension income is set to be zero. For the mortality reduction scenarios, we reduce mortality rates across all ages by $10 \% .{ }^{1}$ Units for absolute differences are in 1000 SEK, $\approx 125$ USD. 


\section{Discussion}

This study finds large differences in lifetime pensions across groups defined by both educational attainment and pre-retirement labor earnings. Total lifetime pension inequality is determined by three factors. First, higher annual earnings before retirement translate into a higher annual pension income. Second, higher life expectancy in high SES groups results in more lifetime pensions. These two factors contribute to higher inequalities in lifetime pensions. Third, a higher replacement rate among low SES groups decreases lifetime pension inequalities through a redistributive pension system. We show that a longevity advantage explains up to one quarter of the higher lifetime pension among high SES groups, particularly among men. Thus, on a lifetime basis, mortality differentials between SES groups dampen the progressivity of pension systems. On the other hand, the results also indicate that mortality is less important than the underlying earnings inequality that carries over from the working years into retirement.

Our findings are generally in line with previous research on the topic, which has used different methodological approaches. Many prior studies have examined the extent of redistribution (the relationship between prior contributions into a pension system and total benefits) and how that is affected by mortality differences. It is found that mortality cancels out over $25 \%$ of the redistribution in the French pension system, almost fully offsets the redistribution in the U.S. old-age Social Security system, and makes the German and Italian systems regressive (Bloom et al. 2005; Haan et al. 2020; Mazzaferro et al. 2012; Sánchez-Romero et al. 2020). Taken together, these studies highlight that the role of mortality in a pension system varies across countries. Pension designs, individual work histories, and SES mortality patterns may all explain crosscountry differences. Comparative studies may elucidate the relative importance of them in future work. Such analyses of redistribution involve lifetime contributions. Due to data limitations, we focus only on inequalities in lifetime benefits and do not directly examine redistribution.

Socioeconomic inequalities in health and mortality inequalities in Sweden have been among the lowest in Europe since the 1980s (Mackenbach et al. 2018). In 2011, the gap in life expectancy at age 65 between Swedish men with low and high education was 2.8 years, lower than the average of 18 OECD countries 3.6 years; for women, the gap was 2.9 years, higher than the OECD average of 2.6 years (Murtin et al. 2021). Higher SES mortality gradients in other countries or future cohorts mean that mortality plays a more important role in lifetime pension than it does in the two Swedish cohorts analyzed here.

Research suggests an increasing SES gap in longevity globally (Brønnum-Hansen and Baadsgaard 2012; Kravdal 2017; Meara et al. 2008; Östergren, 2015; Permanyer et al. 2018). An open topic is whether the Covid-19 pandemic will affect the socioeconomic mortality gradient in Sweden and elsewhere (Drefahl et al. 2020; Clouston et al. 2021), and how that will affect lifetime pension inequality. Accordingly, we may in the future see that mortality inequality will contribute more to lifetime pension inequality. In this study, we found only small cohort differences, but the direction of change suggested a trend toward larger differences. 
The design of the pension system may help interpret our results. The contribution of mortality to SES differences in lifetime pension is arguably much larger without the collective agreement occupational pensions, which provides more generous replacement rates above the state income pension (particularly the guarantee pension). This is consistent with the finding that the ratio between yearly pension income and prior labor earnings decreases only slightly from the second to the highest quintiles (Table 2). In an extreme case where pension income is unrelated to prior earnings, SES differences in lifetime pension would be solely determined by mortality. Because of generous replacement rates in occupational pensions for higher earners, the overall net replacement rate in the mandatory pension schemes (excluding private pensions) appears to be $\mathrm{U}$ shaped across earnings, which is unique among OECD countries (OECD 2021). Since Sweden has one of the least progressive first and second pillar pension systems among OECD countries (OECD 2011), we expect the role of prior earnings to be less important in other countries, and accordingly, mortality should be more important. Across cohorts, the share of public pensions has decreased, whereas the share of occupational and private pensions ${ }^{10}$ has increased in Sweden (Hagen 2017). Prior earnings will be more important in generating SES inequalities in retirement income in future cohorts. $^{11}$

Lifetime pensions are more unequally distributed across male SES groups than female SES groups. There are three potential explanations. First, the SES mortality gradient is usually stronger for men than for women (Mackenbach et al. 2018), which we also find in our study. Among women, the association between low income and high mortality is even reversed in the lowest two quintiles. This may be explained by the fact that, for our cohorts, women in the lowest quintile are often outside the labor market and rely on their husbands with higher incomes, whereas women in the second and third quintiles are more often in the labor market and live alone or in households with low income. ${ }^{12}$ Second, the redistributive effect is stronger for women. Women in the lowest earnings quintile are protected by the minimum pension and to some extent widow-pensions (shown by the much higher ratio between pension income and earnings for women in the lowest quintile than women in higher quintiles). Third, women have smaller inequality in pre-retirement earnings than men. As the majority of lifetime pension inequality is explained by pre-retirement earnings, gender differences in the magnitude of lifetime pension inequality by SES could also be explained by the more homogeneous earnings distribution across female SES groups.

\footnotetext{
${ }^{10}$ Presumably, private pensions are more utilized by higher earners.

${ }^{11}$ Additionally, the reliance of first- vs. second-pillar pensions differ considerably across sub-groups of the labor market, which may help understand the role of mortality. For instance, the second and fourth quintiles together arguably relied more on the first pillar than the third and highest quintiles combined. Accordingly, we find that mortality explained a notably larger share of the gap in lifetime pension between the second and fourth quintiles than between the third and highest quintiles for both genders (Figures A15 and A16).

${ }^{12}$ See Table A2 in the Online Appendix. Prior research has also shown that the type of income measure (individual vs. household) has large impacts on the results of mortality inequalities between income groups. Women's longevity monotonically increases with household income, which is not always found for female individual income (Shi et al. 2021). Table A11 in the Online Appendix shows that the share of married women was the largest in the lowest female quintile with the opposite pattern for men.
} 
The difference between yearly pension income and pre-retirement labor earnings is similar from the second to the fourth earnings quintiles, suggesting that the redistributive role of the Swedish pension system is limited for the majority of the population who sit in the middle range of the earnings distribution. In contrast, the pension system plays a relatively more significant role in redistributing money from the very rich to the very poor, as illustrated by the comparisons between the highest earnings group (who had a large share of earnings that was not translated into lifetime pension) and the lowest earnings group (who received a guaranteed pension, even in the absence of contributions during the time studied), particularly for women.

Recent policy discussions on pension reforms often do not consider SES differences in longevity. Because of increasing overall longevity, many low-mortality countries (e.g., Denmark, Finland, Greece, Italy, the Netherlands, Portugal) link the statutory retirement age to life expectancy and Sweden has also planned to do so (OECD 2021). Implications of such policies on redistribution will be particularly relevant for Bismarckian pension systems, which explicitly aim to redistribute earnings into pensions in an actuarially fair way. Hence, making use of SES-specific life tables would increase pension fairness in DC and NDC pension systems. Individuals with higher SES and earnings live longer. This would then be reflected in assumptions on lifespan. Thus, individuals with higher SES and earnings should have lower payout rates. This requires overcoming several practical challenges-e.g., how to measure SES, what ages of SES should be considered, how to deal with income mobility over the life course. Another concern of policies on pensionable retirement ages is about inequalities in lifespan after retirement (Alvarez et al. 2021; Shi et al. 2022). A widening gap in SES in longevity will make the low SES group more vulnerable to such policies. Sweden has a rather stable trend in SES inequalities in longevity, yet evidence from other countries is mixed (OECD 2021).

Our definition of "lifetime" is from the age of 60 , so premature mortality before age 60 is not included. SES differences in lifetime pension measured at age 50 would have been larger than our estimates, as the SES-mortality gradient tends to be higher in ages 40 to 60 (Rehnberg et al. 2019). Future research may wish to examine lifetime pension benefits from a younger age to capture such effects.

The first contribution of our study is the use of an exceptionally long series of high-quality data on observed earnings, mortality, and all sources of pensions. Prior mathematical models have illustrated the importance of differential mortality to lifetime pension progressivity (Auerbach et al. 2017; Sánchez-Romero et al. 2020). Previous empirical studies have often modeled mortality rates for cohorts whose complete mortality schedules were still unknown (Haan et al. 2020; Olivera 2018). As compared to previous studies, we use observed income, mortality, and pension data for cohorts whose life course has been almost entirely observed. Thus, our approach is more datadriven, and has the advantage of introducing much fewer assumptions.

Second, our decomposition approach is novel. It helps show the age patterns of mortality contributions, as well as the amount of money that lower SES individuals lose due to their mortality disadvantages at each age. An additional methodological contribution is that we disentangle three 
effects: mortality, earnings, and the pension system's redistributive effects. Furthermore, our hypothetical analysis is a useful way to show the impacts of potential policy changes.

A limitation of our hypothetical scenarios is that they assume that these scenarios would not affect individual behaviors such as retirement timing (for scenarios of pension generosity and mortality), and they also do not reflect that later retirement would imply higher contributions. This is clearly a limitation. Yet the counterfactuals are primarily useful to contrast the effects of different dimensions of a pension system, such as retirement age, mortality, and pension levels.

Another limitation is that our earnings grouping is based on earnings over ages 50-59 and ignores earlier earnings trajectories. Our comparison of average yearly earnings over these ten years and average yearly pension payments (over ages 66-75) are only illustrative; this differs from strict actuarial calculations of the rate of return on actual pension payments. Our entirely empirical approach is both an advantage and a disadvantage compared to previous research. Thus, our study is conceptually different from previous research, as our pension variable is the sum of pensions of all pillars. The distribution of pension types differs substantially across SES. Therefore, we provide a broad picture of how a national pension system works in practice and their consequences for social stratification, rather than providing calculations for the extent of redistribution of specific pension programs. This is a contribution lacking in the current literature, but it also makes our results in some ways hard to be compared with many previous studies. Further research may wish to disentangle how different pension programs (e.g., guarantee pensions, survivor's pensions, collective agreement pensions, private pensions) explain overall lifetime pension differences between SES groups. ${ }^{13}$

A further implication of our approach is that our cohorts for whom we observe nearly their entire lives were born in the early $20^{\text {th }}$ century. This means we study the pension system in the 1990s and 2000s. It would be interesting to examine whether pension reforms in Sweden in 1999 have changed the broad patterns observed in this study. The reform introduced an NDC system to the public pension with balances for intergenerational redistribution and flexible retirement ages that are actuarially fair. It later became a model for many other OECD countries (Palme 2005). The first cohorts that experienced this new system were born in the mid-1950s.

13 Our data do not allow disentangling different types of pension incomes. 


\section{Acknowledgement}

We thank Qi Cui, Jennifer Dowd, Christian Dudel, John Ermisch, Christiaan Monden, Julian Schmied, Alyson van Raalte, and participants at the Sociology Monday meeting at Oxford, the lab talk at the Max Planck Institute for Demographic Research, and at the SUDA Demographic Colloquium at Stockholm University for helpful comments on earlier drafts. Jiaxin Shi was supported by a Starting Grant from the European Research Council (grant no. 716323, PI: Alyson van Raalte) and a Leverhulme Trust Grant for the Leverhulme Centre for Demographic Science. Martin Kolk was supported by Riksbankens Jubileumsfond (grant no. P17-0330:1) and the Swedish Research Council for Health, Working life and Welfare (FORTE, grant number 201607115). 


\section{References}

Alvarez, J. A., Kallestrup-Lamb, M., \& Kjærgaard, S. (2021). Linking retirement age to life expectancy does not lessen the demographic implications of unequal lifespans. Insurance: Mathematics and Economics, 99, 363-375.

Auerbach, A. J., Charles, K. K., Coile, C. C., Gale, W., Goldman, D., Lee, R., ... \& Wong, R. (2017). How the growing gap in life expectancy may affect retirement benefits and reforms. The Geneva Papers on Risk and Insurance-Issues and Practice, 42(3), 475-499.

Ayuso, M., Bravo, J. M., \& Holzmann, R. (2017). Addressing Longevity Heterogeneity in Pension Scheme Design. Journal of Finance and Economics, 6(1), 1-21.

Bishnu, M., Guo, N. L., \& Kumru, C. S. (2019). Social security with differential mortality. Journal of Macroeconomics, 62, 103077.

Bommier, A., Magnac, T., Rapoport, B., \& Roger, M. (2005). Droits à la retraite et mortalité différentielle. Économie et Prévision, (2), 1-16.

Brønnum-Hansen, H., \& Baadsgaard, M. (2012). Widening social inequality in life expectancy in Denmark. A register-based study on social composition and mortality trends for the Danish population. BMC Public Health, 12(1), 994. https://doi.org/10.1186/1471-2458-12-994

Brown, J. R. (2003). Redistribution and insurance: Mandatory annuitization with mortality heterogeneity. Journal of Risk and insurance, 70(1), 17-41.

Brown, J. R. (2007). Differential mortality and the value of individual account retirement annuities. In M. Feldstein \& J. B. Liebman (Eds.), The Distributional Aspects of Social Security and Social Security Reform (pp. 401-446). University of Chicago Press.

Brown, R. L., \& Prus, S. G. (2004). Social transfers and income inequality in old age: A multinational perspective. North American Actuarial Journal, 8(4), 30-36.

Caselli, G., Peracchi, F., Barbi, E., \& Lipsi, R. M. (2003). Differential mortality and the design of the Italian system of public pensions. Labour, 17, 45-78.

Chetty, R., M. Stepner, S. Abraham, S. Lin, B. Scuderi, N. Turner, A. Bergeron, and D. Cutler. (2016). The association between income and life expectancy in the United States, 2001-2014. Journal of the American Medical Association, 315(16):1750-1766.

Chiang, C. L. (1960). A stochastic study of the life table and its applications: II. Sample variance of the observed expectation of life and other biometric functions. Human Biology, 32(3), 221-238.

Chiang, C. L. (1972). On constructing current life tables. Journal of the American Statistical Association, 67(339), 538-541.

Clouston, S. A., Natale, G., \& Link, B. G. (2021). Socioeconomic inequalities in the spread of coronavirus-19 in the United States: A examination of the emergence of social inequalities. Social Science \& Medicine, 268, 113554.

Coronado, J. L., Fullerton, D., \& Glass, T. (2002). Long-run effects of social security reform proposals on lifetime progressivity. In The Distributional Aspects of Social Security and Social Security Reform (pp. 149-206). University of Chicago Press.

Drefahl, S., Wallace, M., Mussino, E., Aradhya, S., Kolk, M., Brandén, M., ... \& Andersson, G. (2020). A population-based cohort study of socio-demographic risk factors for COVID-19 deaths in Sweden. Nature Communications, 11(1), 1-7.

Dudel, C., \& Schmied, J. (2019). Pension adequacy standards: an empirical estimation strategy and results for the United States and Germany. Rostock: Max Planck Institute for Demographic Research (MPIDR Working Paper WP-2019-003).

Ebbinghaus, B. (2021). Inequalities and poverty risks in old age across Europe: The double-edged income effect of pension systems. Social Policy \& Administration, 55, 440-455. https://doi.org/10.1111/spol.12683

Edebalk, P. G. (2000). Emergence of a welfare state-social insurance in Sweden in the 1910s. Journal of Social Policy, 29(4), 537-551. 
Esping-Andersen, G. (1990). The Three Worlds of Welfare Capitalism. Cambridge, UK: Polity Press.

Fors, S., Wastesson, J. W., \& Morin, L. (2021). Growing Income-Based Inequalities in Old-Age Life Expectancy in Sweden, 2006-2015. Demography, 58(6), 2117-2138.

GAO. (2019). Income and Wealth Disparities Continue Through Old Age. Washington, DC: Government Printing Office.

Garrett, D. M. (1995). The effects of differential mortality rates on the progressivity of social security. Economic Inquiry, 33(3), 457-475.

Goldman, D. P., \& Orszag, P. R. (2014). The growing gap in life expectancy: using the Future Elderly Model to estimate implications for Social Security and Medicare. American Economic Review, 104(5), 230-33.

Haan, P., Kemptner, D., \& Lüthen, H. (2020). The rising longevity gap by lifetime earningsDistributional implications for the pension system. The Journal of the Economics of Ageing, 17, 100199.

Hagen, J. (2013). A History of the Swedish Pension System. Department of Economics, Uppsala University.

Hagen, J. (2017). Pension principles in the Swedish pension system. Scandinavian Economic History Review, 65(1), 28-51.

Hartman, L., \& Sjögren, A. (2018). Hur ojämlik är hälsan i Sverige. Sociala och regionala skillnader bland 30-60-åringar 1994-2014, IFAU Rapport, 2018-10 (available at https://www.ifau.se/globalassets/pdf/se/2018/r-2018-10-hur-ojamlikt-ar-sverige.pdf)

Hederos, K., Jäntti, M., Lindahl, L., \& Torssander, J. (2018). Trends in life expectancy by income and the role of specific causes of death. Economica, 85(339), 606-625.

Hoffmann, R. (2011). Illness, not age, is the leveler of social mortality differences in old age. Journals of Gerontology Series B: Psychological Sciences and Social Sciences, 66(3), 374-379.

Horiuchi, S., Wilmoth, J. R., \& Pletcher, S. D. (2008). A decomposition method based on a model of continuous change. Demography, 45(4), 785-801.

Howse, K. (2007). Updating the Debate on Intergenerational Fairness in Pension Reform. Social Policy \& Administration 41(1):50-64.

Hurd, M. D., \& Shoven, J. B. (1985). The distributional impact of social security. In Pensions, Labor, and Individual Choice (pp. 193-222). University of Chicago Press.

Jijiie, A. S., Alonso-García, J., \& Arnold, S. (2019). Mortality by socio-economic class and its impact on the retirement schemes: How to render the systems fairer?. Sydney: ARC Centre of Excellence in Population Ageing Research (CEPAR).

Kitagawa, E. M., \& Hauser, P. M. (1973). Differential mortality in the United States: A study in socioeconomic epidemiology. Harvard University Press. Cambridge, Massachusetts.

Kolk, M. (2015). Age differences in unions: Continuity and divergence among Swedish couples between 1932 and 2007. European Journal of Population, 31(4), 365-382.

Kravdal, Ø. (2017). Large and growing social inequality in mortality in Norway: The combined importance of marital status and own and spouse's education. Population and Development Review, 645-665.

Laslett, P. (1988). Family, Kinship and Collectivity as Systems of Support in Pre-Industrial Europe: A Consideration of the 'Nuclear-Hardship' Hypothesis. Continuity and Change 3(2):153-75. doi:10.1017/S026841600000093X.

Laun, T., Markussen, S., Vigtel, T. C., \& Wallenius, J. (2019). Health, longevity and retirement reform. Journal of Economic Dynamics and Control, 103, 123-157.

Lee, R. \& Andrew M. (2011). Population Aging and the Generational Economy: A Global Perspective. Cheltenham: Edward Elgar.

Lee, R., \& Sánchez-Romero, M. (2019). Overview of Heterogeneity in Longevity and Pension Schemes. Progress and Challenges of Nonfinancial Defined Contribution Pension Schemes : Volume 1. Addressing marginalization, polarization, and the labor market. The World Bank. 
Lindquist, G. S. \& Wadensjö, E. (2009). Retirement, Pensions and Work in Sweden. The Geneva Papers on Risk and Insurance-Issues and Practice 34(4):578-90.

Mackenbach, J. P., Valverde, J. R., Artnik, B., Bopp, M., Brønnum-Hansen, H., Deboosere, P., ... \& Nusselder, W. J. (2018). Trends in health inequalities in 27 European countries. Proceedings of the National Academy of Sciences, 115(25), 6440-6445.

Martikainen, P., Mäkelä, P., Peltonen, R., \& Myrskylä, M. (2014). Income differences in life expectancy: the changing contribution of harmful consumption of alcohol and smoking. Epidemiology, 182190.

Mazzaferro, C., Morciano, M., \& Savegnago, M. (2012). Differential mortality and redistribution in the Italian notional defined contribution system. Journal of Pension Economics \& Finance, 11(4), 500-530.

Murtin, F., Mackenbach, J. P., Jasilionis, D., \& d'Ercole, M. M. (2021). Educational inequalities in longevity in 18 OECD countries. Journal of Demographic Economics, 1-29.

National Academy of Sciences, Engineering and Medicine (NASEM). (2015). The Growing Gap in Life Expectancy by Income: Implications for Federal Programs and Policy Responses. Committee on the Long-Run Macroeconomic Effects of the Aging U.S. Population Phase II. Washington, DC: National Academies Press.

Nelissen, J. H. (1998). Annual versus lifetime income redistribution by social security. Journal of Public Economics, 68(2), 223-249.

OECD. (2011). Pensions at a Glance 2011: Retirement-income Systems in OECD and G20 Countries. OECD Publishing. http://dx.doi.org/10.1787/pension_glance-2011-en

OECD. (2017). Preventing Ageing Unequally. OECD Publishing, Paris. http://dx.doi.org/10.1787/9789264279087-en

OECD. (2021). Pensions at a Glance 2021: OECD and G20 Indicators, OECD Publishing, Paris, https://doi.org/10.1787/ca401ebd-en.

Olivera, J. (2019). The distribution of pension wealth in Europe. The Journal of the Economics of Ageing, $13,30-42$.

Östergren, O. (2015). Growing gaps: the importance of income and family for educational inequalities in mortality among Swedish men and women 1990-2009. Scandinavian Journal of Public Health, 43(6), 563-570.

Palme, J. (2005). Features of the Swedish Pension Reform. The Japanese Journal of Social Security Policy $4(1): 42-53$.

Palmer, E. (2008). The market for retirement products in Sweden. World Bank Policy Research Working Paper, (4748).

Pamuk, E. R. (1985). Social class inequality in mortality from 1921 to 1972 in England and Wales.

Population Studies, 39(1), 17-31.

Pappas, G., Queen, S., Hadden, W., \& Fisher, G. (1993). The increasing disparity in mortality between socioeconomic groups in the United States, 1960 and 1986. New England Journal of

Medicine, 329(2), 103-109.

Pensionsmyndigheten. (2020). "Table from the Swedish Pension Agency on Source of Pension by Cohort for the Year 2018". https://www.pensionsmyndigheten.se/statistik/pensionsstatistik/?domain=tab6\&report=report-6-1 accessed 2021-02-10.

Pestieau, P., \& Ponthiere, G. (2016). Longevity variations and the Welfare State. Journal of Demographic Economics, 82(2), 207-239.

Rehnberg, J. (2020). What Levels the Association Between Income and Mortality in Later Life: Age or Health Decline?. The Journals of Gerontology: Series B, 75(2), 426-435.

Rehnberg, J., Fors, S., \& Fritzell, J. (2019). Divergence and convergence: How do income inequalities in mortality change over the life course?. Gerontology, 65(3), 313-322.

Riffe, T. (2018). DemoDecomp: Decompose Demographic Functions. R package version 1.0.1.https://CRAN.R-project.org/package=DemoDecomp 
Samuelson, P. A. (1958). An Exact Consumption-Loan Model of Interest with or without the Social Contrivance of Money. Journal of Political Economy 66(6):467-82.

Sánchez-Romero, M., Lee, R. D., \& Prskawetz, A. (2020). Redistributive effects of different pension systems when longevity varies by socioeconomic status. The Journal of the Economics of Ageing, 17, 100259.

Sánchez-Romero, M., \& Prskawetz, A. (2020). The impact of reducing the pension generosity on inequality and schooling. De Economist, 1-26.

Smith, K., Toder, E., \& Iams, H. (2003). Lifetime distributional effects of Social Security retirement benefits. Social Security Bulletin, 65, 33-61.

Statistics Sweden. (2020). The Future Population of Sweden 2020-2070. Statistiska Meddelanden BE 18 SM 2001.

Shi, J., Dudel, C., Monden, C., \& van Raalte, A. (2022). Inequalities in retirement lifespan in the United States (Working Paper No. WP-2022-015). Rostock, Germany: Max Planck Institute for Demographic Research.

Shi, J., Tarkiainen, L., Martikainen, P., \& van Raalte, A. (2021). The impact of income definitions on mortality inequalities. SSM-Population Health, 15, 100915.

Sinn, H. W. (2000). Why a Funded Pension System Is Useful and Why It Is Not Useful. Vol.: National Bureau of Economic Research.

Sullivan, D. F. (1971). A single index of mortality and morbidity. Health Service Mental Health Administration Health Reports, 86(4), 347-354.

Tan, L., \& Koedel, C. (2019). The effects of differential income replacement and mortality on US social security redistribution. Southern Economic Journal, 86(2), 613-637.

Torssander, J. \& Robert E. (2010). Stratification and Mortality-a Comparison of Education, Class, Status, and Income. European Sociological Review 26(4):465-74.

van Raalte, A. A., \& Nepomuceno, M. R. (2020). Decomposing gaps in healthy life expectancy. In International Handbook of Health Expectancies (pp. 107-122). Springer, Cham.

Vidal-Meliá, C., Ventura-Marco, M., \& Pla-Porcel, J. (2019). Unisex life care annuities embedded in a payas-you-go pension system: Analysing the issue of gender redistribution. Journal of Population Ageing, 12(4), 405-426.

Whitehouse, E. (2006). New Indicators of 30 OECD Countries' Pension Systems. Journal of Pension Economics \& Finance 5(3):275.

Whitehouse, E. \& A. Zaidi (2008), Socio-Economic Differences in Mortality: Implications for Pensions Policy, OECD Social, Employment and Migration Working Papers, No. 71, OECD Publishing, Paris, https://doi.org/10.1787/231747416062. 


\title{
Online Appendix
}

\section{How does mortality contribute to lifetime pension inequality? \\ Evidence from five decades of Swedish taxation data}

\author{
Jiaxin Shi and Martin Kolk
}




\section{Appendix 1: Overview of pension systems of the cohorts studied}

For the cohorts in our study (those born 1920 and 1925), the first pillar of the Swedish pension systems consisted of a universal guarantee pension (folkpension) and an earnings-related part (Allmän Tillägspension or ATP). The ATP was more important than the guarantee pension, and it was targeted to contribute $60 \%$ of the average of the best 15 years out of a 30 -year working period (30 years is the requirement for full pension). In practice, the pension payments were based entirely on 15 years of prior labor income. Later, a supplemental part was added to the ATP pension for those with very low ATP pensions. For a more detailed description, see Hagen (2013). The ATPsystem was introduced in 1960 (Hagen 2013). The cohorts in this study were entirely covered retroactively. In practice, therefore, full retirement required fewer than 30 years, making the system more generous. Both systems were defined-benefit (DB) systems, funded as PAYGO systems. In the 1980s, political actors saw this pension system as unsustainable, leading to the introduction of a Notional-Defined Contribution (NDC) system which was an early example of pension reforms (Hagen 2013; Palme 2005). The NDC system differs in substantial ways from the pension system we describe above but is not of relevance for the cohorts in our study.

Importantly, together with the public pension, over $90 \%$ of all workers in Sweden are also covered by the second-pillar, sector-wide collective agreement pensions negotiated between labor unions and employers (Lindquist and Wadensjö 2009). The characteristics of the collective agreement pensions vary a lot (for our cohorts they were mostly DB plans). The collective agreement pensions could contribute substantially to the pensions of, in particular, high earners and government workers (rising up to $50 \%$ of all pension earnings for the highest-earnings decile), as the ATP system had an income ceiling (Hagen 2013). The different collective agreement pensions (second pillar) were introduced gradually over the 1970s and 1980s covering a large share of the labor force (mostly being funded DB schemes that have been gradually replaced with funded defined contribution schemes). They were generally more generous for private sector white-collar workers with higher earnings than blue-collar workers (Olofsson, 1993). A typical target was often that workers would receive $80 \%$ of their pre-retirement salary (if they had worked for 30 years) through the combination of all pensions described above, though it could be either higher or lower (Hagen 2013). These pensions are also included in our variables.

Private savings (e.g. capital investments, savings in bank accounts, or housing) for old age in Sweden are usually different from any formal pension-like savings or annuity. In other words, they are not related to monthly payments as from an annuity or a pension, where the total payment is linked to length of life. We do not consider such private savings in this study, as it is not possible to distinguish them from overall wealth. Unlike pension, wealth will often be bequeathed to children. However, we included private pension incomes, which are often not lifetime annuities but paid out as temporary annuities in a fixed period of 5 or 10 years (Palmer 2008). It is 
noteworthy that such private pension incomes account only a limited share of the total pension payments at the population level (Hagen 2013). In 2018, private pensions constituted less than $2 \%$ of all pension payments for cohorts born before 1928 (Pensionsmyndigheten 2020). Private pensions are arguably more important at younger ages, as they are mostly paid out in a short period of 5 or 10 years (Palmer 2008). Hence, the small amount and the short payout length together suggest that private pensions only have a minor impact on our overall pension variable.

\section{References}

Hagen, J. (2013). A History of the Swedish Pension System. Department of Economics, Uppsala University.

Lindquist, G. S. \& Wadensjö, E. (2009). Retirement, Pensions and Work in Sweden. The Geneva Papers on Risk and Insurance-Issues and Practice 34(4):578-90.

Olofsson, G. (1993). Det svenska pensionssystemet 1913-1993: historia, struktur och konflikter. Arkiv för studier $i$ arbetarrörelsens historia (58-59): 29-84

Palme, J. (2005). Features of the Swedish Pension Reform. The Japanese Journal of Social Security Policy $4(1): 42-53$.

Palmer, E. (2008). The market for retirement products in Sweden. World Bank Policy Research Working Paper, (4748).

Pensionsmyndigheten. (2020). Table from the Swedish Pension Agency on Source of Pension by Cohort for the Year 2018. https://www.pensionsmyndigheten.se/statistik/pensionsstatistik/?domain=tab6\&report=report-6-1 Accessed 2021-02-10. 


\section{Appendix 2: Tables}

Table A1. Proportion of men with years of zero earnings over ages 50-59.

\begin{tabular}{|c|c|c|c|c|c|c|c|c|c|c|c|c|}
\hline & \multicolumn{11}{|c|}{ Number of years of zero earnings } & \multirow{2}{*}{$N$} \\
\hline & 0 & 1 & 2 & 3 & 4 & 5 & 6 & 7 & 8 & 9 & 10 & \\
\hline \multicolumn{13}{|l|}{1920 cohort } \\
\hline Total & $86.6 \%$ & $9.3 \%$ & $1.7 \%$ & $0.8 \%$ & $0.4 \%$ & $0.4 \%$ & $0.3 \%$ & $0.4 \%$ & $0.1 \%$ & $0.0 \%$ & $0.1 \%$ & 51088 \\
\hline \multicolumn{13}{|l|}{ By education } \\
\hline Primary & $85.7 \%$ & $9.4 \%$ & $1.9 \%$ & $0.9 \%$ & $0.5 \%$ & $0.5 \%$ & $0.4 \%$ & $0.5 \%$ & $0.1 \%$ & $0.0 \%$ & $0.1 \%$ & 34757 \\
\hline Secondary & $87.9 \%$ & $9.5 \%$ & $1.3 \%$ & $0.7 \%$ & $0.2 \%$ & $0.1 \%$ & $0.1 \%$ & $0.1 \%$ & $0.1 \%$ & $0.0 \%$ & $0.0 \%$ & 13086 \\
\hline Tertiary & $91.1 \%$ & $7.2 \%$ & $0.8 \%$ & $0.2 \%$ & $0.3 \%$ & $0.1 \%$ & $0.0 \%$ & $0.1 \%$ & $0.0 \%$ & $0.0 \%$ & $0.0 \%$ & 3245 \\
\hline \multicolumn{13}{|l|}{ By earnings } \\
\hline Lowest & $61.6 \%$ & $19.1 \%$ & $7.4 \%$ & $3.9 \%$ & $2.1 \%$ & $1.8 \%$ & $1.4 \%$ & $1.8 \%$ & $0.5 \%$ & $0.1 \%$ & $0.3 \%$ & 10218 \\
\hline Second & $90.1 \%$ & $9.4 \%$ & $0.4 \%$ & $0.1 \%$ & $0.0 \%$ & $0.0 \%$ & $0.0 \%$ & $0.0 \%$ & $0.0 \%$ & $0.0 \%$ & $0.0 \%$ & 10217 \\
\hline Third & $93.2 \%$ & $6.6 \%$ & $0.1 \%$ & $0.1 \%$ & $0.0 \%$ & $0.0 \%$ & $0.0 \%$ & $0.0 \%$ & $0.0 \%$ & $0.0 \%$ & $0.0 \%$ & 10218 \\
\hline Fourth & $94.2 \%$ & $5.6 \%$ & $0.1 \%$ & $0.0 \%$ & $0.0 \%$ & $0.0 \%$ & $0.0 \%$ & $0.0 \%$ & $0.0 \%$ & $0.0 \%$ & $0.0 \%$ & 10217 \\
\hline Highest & $93.7 \%$ & $5.9 \%$ & $0.3 \%$ & $0.0 \%$ & $0.0 \%$ & $0.0 \%$ & $0.0 \%$ & $0.0 \%$ & $0.0 \%$ & $0.0 \%$ & $0.0 \%$ & 10218 \\
\hline \multicolumn{13}{|l|}{1925 cohort } \\
\hline Total & $97.1 \%$ & $1.5 \%$ & $0.8 \%$ & $0.2 \%$ & $0.1 \%$ & $0.1 \%$ & $0.0 \%$ & $0.0 \%$ & $0.0 \%$ & $0.0 \%$ & $0.0 \%$ & 40368 \\
\hline \multicolumn{13}{|l|}{ By education } \\
\hline Primary & $96.6 \%$ & $1.6 \%$ & $1.1 \%$ & $0.3 \%$ & $0.1 \%$ & $0.1 \%$ & $0.0 \%$ & $0.1 \%$ & $0.0 \%$ & $0.0 \%$ & $0.1 \%$ & 25486 \\
\hline Secondary & $97.9 \%$ & $1.2 \%$ & $0.4 \%$ & $0.2 \%$ & $0.2 \%$ & $0.1 \%$ & $0.0 \%$ & $0.0 \%$ & $0.0 \%$ & $0.0 \%$ & $0.0 \%$ & 11328 \\
\hline Tertiary & $98.3 \%$ & $1.2 \%$ & $0.2 \%$ & $0.2 \%$ & $0.1 \%$ & $0.1 \%$ & $0.0 \%$ & $0.0 \%$ & $0.0 \%$ & $0.0 \%$ & $0.0 \%$ & 3554 \\
\hline \multicolumn{13}{|l|}{ By earnings } \\
\hline Lowest & $87.9 \%$ & $5.4 \%$ & $3.9 \%$ & $1.1 \%$ & $0.5 \%$ & $0.4 \%$ & $0.1 \%$ & $0.2 \%$ & $0.1 \%$ & $0.1 \%$ & $0.2 \%$ & 8074 \\
\hline Second & $99.2 \%$ & $0.7 \%$ & $0.1 \%$ & $0.0 \%$ & $0.0 \%$ & $0.0 \%$ & $0.0 \%$ & $0.0 \%$ & $0.0 \%$ & $0.0 \%$ & $0.0 \%$ & 8073 \\
\hline Third & $99.7 \%$ & $0.2 \%$ & $0.0 \%$ & $0.0 \%$ & $0.0 \%$ & $0.0 \%$ & $0.0 \%$ & $0.0 \%$ & $0.0 \%$ & $0.0 \%$ & $0.0 \%$ & 8074 \\
\hline Fourth & $99.6 \%$ & $0.3 \%$ & $0.1 \%$ & $0.0 \%$ & $0.0 \%$ & $0.0 \%$ & $0.0 \%$ & $0.0 \%$ & $0.0 \%$ & $0.0 \%$ & $0.0 \%$ & 8073 \\
\hline Highest & $99.2 \%$ & $0.6 \%$ & $0.0 \%$ & $0.1 \%$ & $0.0 \%$ & $0.0 \%$ & $0.0 \%$ & $0.0 \%$ & $0.0 \%$ & $0.0 \%$ & $0.0 \%$ & 8074 \\
\hline
\end{tabular}

Source: Authors' calculation based on linked administrative data from Statistics Sweden. 
Table A2. Proportion of women with years of zero earnings over ages 50-59.

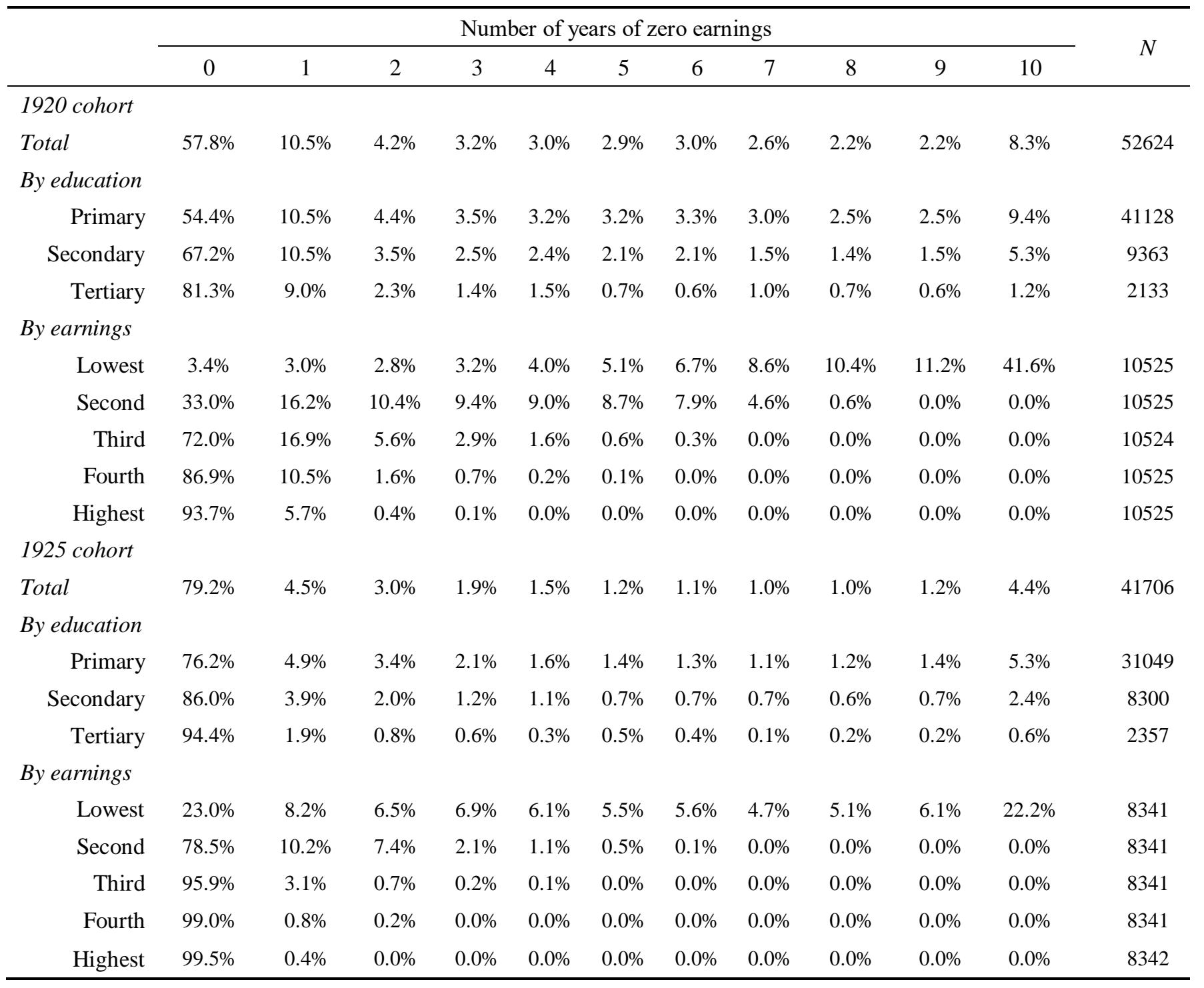

Source: As for Table A1. 
Table A3. Probability of dying before age 60 conditional upon surviving to age 50 .

\begin{tabular}{rccccc}
\hline & \multicolumn{2}{c}{ Men } & & \multicolumn{2}{c}{ Women } \\
\cline { 2 - 3 } \cline { 5 - 6 } \cline { 5 - 6 } Total & 1920 cohort & 1925 cohort & & 1920 cohort & 1925 cohort \\
By education & $7.4 \%$ & $7.6 \%$ & & $4.1 \%$ & $4.0 \%$ \\
Primary & $7.9 \%$ & $8.2 \%$ & & $4.2 \%$ & $4.2 \%$ \\
Secondary & $6.8 \%$ & $7.1 \%$ & & $3.7 \%$ & $3.5 \%$ \\
Tertiary & $4.8 \%$ & $4.9 \%$ & & $3.3 \%$ & $3.2 \%$ \\
By earnings & & & & $5.7 \%$ & $5.2 \%$ \\
Lowest & $13.8 \%$ & $11.8 \%$ & & $5.3 \%$ & $4.9 \%$ \\
Second & $7.2 \%$ & $7.5 \%$ & & $5.3 \%$ \\
Third & $5.3 \%$ & $6.5 \%$ & & $3.6 \%$ & $3.7 \%$ \\
Fourth & $5.2 \%$ & $5.9 \%$ & & $3.2 \%$ & $2.9 \%$ \\
Highest & $4.9 \%$ & $6.2 \%$ & & $2.5 \%$ & $3.3 \%$ \\
\hline
\end{tabular}

Source: As for Table A1.

Notes: In the main analysis, individuals were selected conational upon surviving to age 60. Earnings quintiles were classified based on average year income between ages 50 and 59. Here, we use the same earnings cut-points as those used in the main analysis. For individuals who died between 51 and 59, we used average yearly earnings between age 50 and the age in the year prior to death. 
Table A4. Mean and standard deviation of average yearly earnings between ages 50 and 59 .

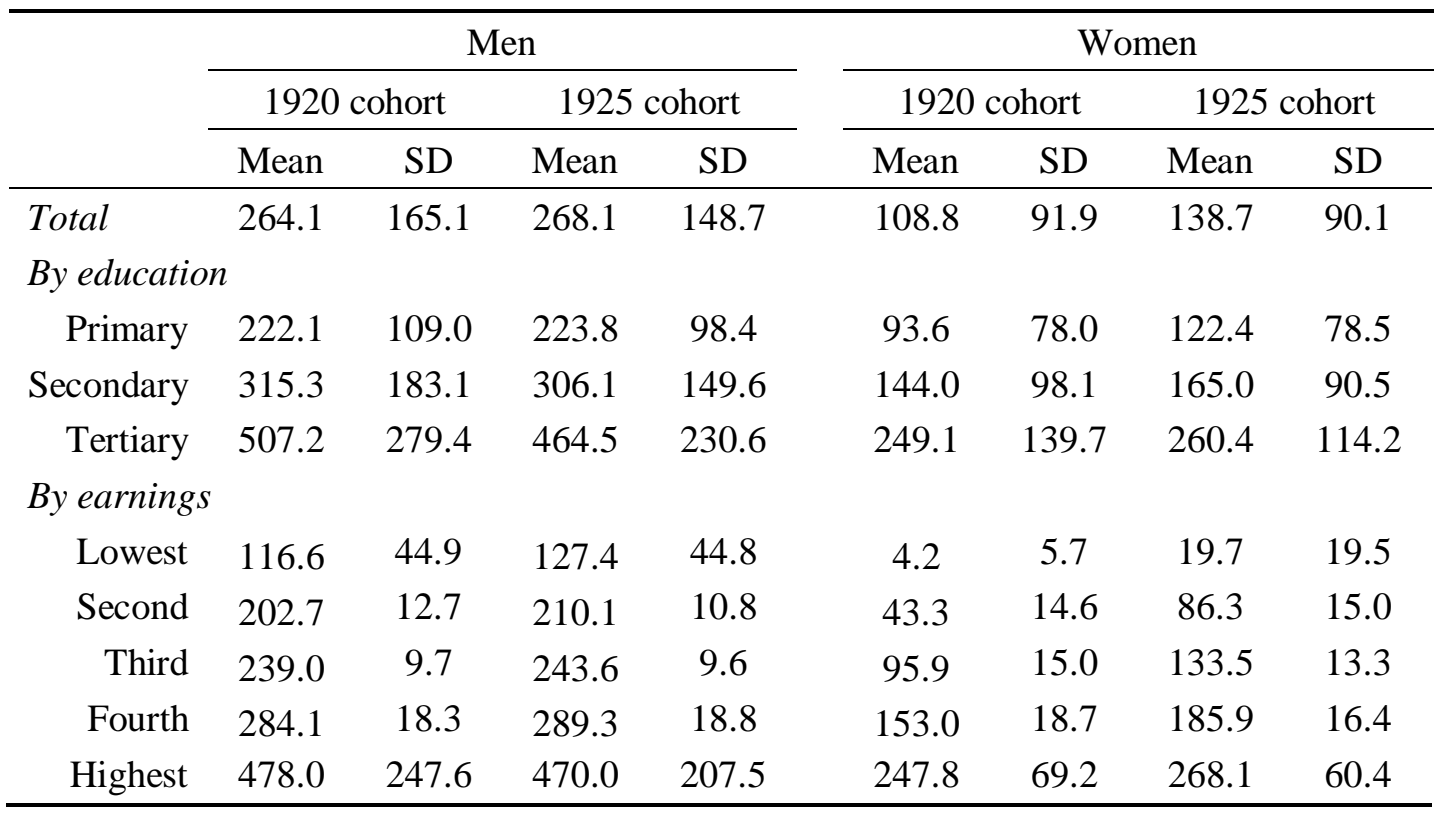

Source: As for Table A1.

Notes: Means and standard deviations are shown in $1000 \mathrm{SEK}, \approx 125$ USD. Inflation was adjusted to the 2018 level.

Number of individuals in each group is shown in Table 1. 
Table A5. Three-way decompositions of differences in total lifetime pensions between primary and secondary education and between secondary and tertiary education.

\begin{tabular}{|c|c|c|c|c|c|c|c|c|}
\hline & \multicolumn{4}{|c|}{ Men } & \multicolumn{4}{|c|}{ Women } \\
\hline & \multicolumn{2}{|c|}{1920 cohort } & \multicolumn{2}{|c|}{1925 cohort } & \multicolumn{2}{|c|}{1920 cohort } & \multicolumn{2}{|c|}{1925 cohort } \\
\hline & 1000 SEK & $\%$ & 1000 SEK & $\%$ & 1000 SEK & $\%$ & 1000 SEK & $\%$ \\
\hline \multicolumn{9}{|c|}{ Primary vs. secondary education } \\
\hline Mortality effect & 261.1 & $24.0 \%$ & 305.5 & $26.9 \%$ & 136.8 & $18.3 \%$ & 159.7 & $22.0 \%$ \\
\hline Redistribution effect & -1047.0 & $-96.1 \%$ & -895.4 & $-78.8 \%$ & -636.6 & $-85.2 \%$ & -513.5 & $-70.8 \%$ \\
\hline Earnings effect & 1875.9 & $172.1 \%$ & 1725.7 & $151.9 \%$ & 1247.1 & $166.9 \%$ & 1079.4 & $148.8 \%$ \\
\hline Total & 1090.0 & $100.0 \%$ & 1135.8 & $100.0 \%$ & 747.2 & $100.0 \%$ & 725.6 & $100.0 \%$ \\
\hline \multicolumn{9}{|c|}{ Secondary vs. tertiary education } \\
\hline Mortality effect & 341.6 & $18.4 \%$ & 519.6 & $25.8 \%$ & 284.0 & $18.0 \%$ & 243.4 & $14.2 \%$ \\
\hline Redistribution effect & -2598.8 & $-140.1 \%$ & -2099.3 & $-104.4 \%$ & -1457.9 & $-92.4 \%$ & -1062.3 & $-61.8 \%$ \\
\hline Earnings effect & 4112.0 & $221.7 \%$ & 3589.9 & $178.6 \%$ & 2751.6 & $174.4 \%$ & 2538.3 & $147.6 \%$ \\
\hline Total & 1854.7 & $100.0 \%$ & 2010.3 & $100.0 \%$ & 1577.8 & $100.0 \%$ & 1719.4 & $100.0 \%$ \\
\hline
\end{tabular}

Source: As for Table A1.

Notes: Mortality effect, redistribution effect, and earnings effect refer to the parts of total lifetime pension difference that are attributable to differences in mortality, differences in the differences between pension income and labor earnings, and differences in labor earnings, respectively. Units are in $1000 \mathrm{SEK}, \approx 125 \mathrm{USD}$. 
Table A6. Three-way decompositions of differences in total lifetime pensions between earnings income quintiles.

\begin{tabular}{|c|c|c|c|c|c|c|c|c|}
\hline & \multicolumn{4}{|c|}{ Men } & \multicolumn{4}{|c|}{ Women } \\
\hline & \multicolumn{2}{|c|}{1920 cohort } & \multicolumn{2}{|c|}{1925 cohort } & \multicolumn{2}{|c|}{1920 cohort } & \multicolumn{2}{|c|}{1925 cohort } \\
\hline & 1000 SEK & $\%$ & 1000 SEK & $\%$ & 1000 SEK & $\%$ & 1000 SEK & $\%$ \\
\hline \multicolumn{9}{|c|}{ Lowest vs. third earnings quintiles } \\
\hline Mortality effect & 368.8 & $27.8 \%$ & 374.9 & $27.6 \%$ & 8.7 & $1.4 \%$ & 66.9 & $7.4 \%$ \\
\hline Redistribution effect & -1346.5 & $-101.5 \%$ & -1311.0 & $-96.4 \%$ & -1629.4 & $-255.9 \%$ & -2033.6 & $-224.8 \%$ \\
\hline Earnings effect & 2304.1 & $173.7 \%$ & 2295.8 & $168.8 \%$ & 2257.4 & $354.5 \%$ & 2871.2 & $317.4 \%$ \\
\hline Total & 1326.4 & $100.0 \%$ & 1359.7 & $100.0 \%$ & 636.8 & $100.0 \%$ & 904.5 & $100.0 \%$ \\
\hline \multicolumn{9}{|c|}{ Second vs. fourth earnings quintiles } \\
\hline Mortality effect & 288.1 & $27.6 \%$ & 317.7 & $28.1 \%$ & 162.4 & $14.2 \%$ & 160.9 & $12.7 \%$ \\
\hline Redistribution effect & -881.5 & $-84.5 \%$ & -851.0 & $-75.4 \%$ & -1644.1 & $-143.8 \%$ & -1337.0 & $-105.9 \%$ \\
\hline Earnings effect & 1636.0 & $156.9 \%$ & 1662.2 & $147.2 \%$ & 2625.0 & $229.6 \%$ & 2438.5 & $193.2 \%$ \\
\hline Total & 1042.6 & $100.0 \%$ & 1128.9 & $100.0 \%$ & 1143.3 & $100.0 \%$ & 1262.3 & $100.0 \%$ \\
\hline \multicolumn{9}{|c|}{ Third vs. highest earnings quintiles } \\
\hline Mortality effect & 425.9 & $17.7 \%$ & 543.4 & $19.8 \%$ & 105.7 & $5.5 \%$ & 88.6 & $4.5 \%$ \\
\hline Redistribution effect & -3053.5 & $-127.1 \%$ & -2798.9 & $-102.1 \%$ & -1982.5 & $-102.9 \%$ & -1618.1 & $-83.0 \%$ \\
\hline Earnings effect & 5029.6 & $209.4 \%$ & 4996.4 & $182.3 \%$ & 3803.4 & $197.4 \%$ & 3478.8 & $178.5 \%$ \\
\hline Total & 2402.0 & $100.0 \%$ & 2740.9 & $100.0 \%$ & 1926.5 & $100.0 \%$ & 1949.3 & $100.0 \%$ \\
\hline
\end{tabular}

Source: As for Table A1.

Notes: Mortality effect, redistribution effect, and earnings effect refer to the parts of total lifetime pension difference that are attributable to differences in mortality, differences in the differences between pension income and labor earnings, and differences in labor earnings, respectively. Units are in $1000 \mathrm{SEK}, \approx 125$ USD. 
Table A7. Three-way decompositions of differences in total lifetime pensions between primary and tertiary education and between the lowest and highest earnings quintiles, with $2 \%$ discount rate.

\begin{tabular}{|c|c|c|c|c|c|c|c|c|}
\hline & \multicolumn{4}{|c|}{ Men } & \multicolumn{4}{|c|}{ Women } \\
\hline & \multicolumn{2}{|c|}{1920 cohort } & \multicolumn{2}{|c|}{1925 cohort } & \multicolumn{2}{|c|}{1920 cohort } & \multicolumn{2}{|c|}{1925 cohort } \\
\hline & 1000 SEK & $\%$ & 1000 SEK & $\%$ & 1000 SEK & $\%$ & 1000 SEK & $\%$ \\
\hline \multicolumn{9}{|c|}{ Primary vs. tertiary education } \\
\hline Mortality effect & 417.1 & $19.4 \%$ & 556.8 & $24.8 \%$ & 271.7 & $16.7 \%$ & 265.1 & $15.6 \%$ \\
\hline Redistribution effect & -2980.8 & $-138.8 \%$ & -2471.1 & $-110.1 \%$ & -1704.0 & $-104.5 \%$ & -1312.5 & $-77.1 \%$ \\
\hline Earnings effect & 4711.3 & $219.4 \%$ & 4159.0 & $185.3 \%$ & 3062.9 & $187.8 \%$ & 2748.7 & $161.6 \%$ \\
\hline Total & 2147.6 & $100.0 \%$ & 2244.7 & $100.0 \%$ & 1630.6 & $100.0 \%$ & 1701.3 & $100.0 \%$ \\
\hline \multicolumn{9}{|c|}{ Lowest vs. highest earnings quintiles } \\
\hline Mortality effect & 618.5 & $22.6 \%$ & 688.8 & $23.1 \%$ & 67.2 & $3.5 \%$ & 108.7 & $5.2 \%$ \\
\hline Redistribution effect & -3573.7 & $-130.6 \%$ & -3357.9 & $-112.5 \%$ & -2886.9 & $-152.5 \%$ & -2894.3 & $-138.0 \%$ \\
\hline Earnings effect & 5691.8 & $208.0 \%$ & 5653.6 & $189.4 \%$ & 4712.3 & $249.0 \%$ & 4883.0 & $232.8 \%$ \\
\hline Total & 2736.6 & $100.0 \%$ & 2984.5 & $100.0 \%$ & 1892.5 & $100.0 \%$ & 2097.4 & $100.0 \%$ \\
\hline
\end{tabular}

Source: As for Table A1.

Notes: Mortality effect, redistribution effect, and earnings effect refer to the parts of total lifetime pension difference that are attributable to differences in mortality, differences in the differences between pension income and labor earnings, and differences in labor earnings, respectively. Units are in $1000 \mathrm{SEK}, \approx 125 \mathrm{USD}$. 
Table A8. Lifetime pension inequality between primary and tertiary education under policy and mortality scenarios, 1925 cohort.

\begin{tabular}{|c|c|c|c|c|c|c|c|c|}
\hline & \multicolumn{4}{|c|}{ Men } & \multicolumn{4}{|c|}{ Women } \\
\hline & \multicolumn{2}{|c|}{$\begin{array}{c}\text { Absolute } \\
\text { difference }\end{array}$} & \multicolumn{2}{|c|}{$\begin{array}{l}\text { Relative } \\
\text { difference }\end{array}$} & \multicolumn{2}{|c|}{$\begin{array}{l}\text { Absolute } \\
\text { difference }\end{array}$} & \multicolumn{2}{|c|}{$\begin{array}{l}\text { Relative } \\
\text { difference }\end{array}$} \\
\hline & $\begin{array}{l}\operatorname{Diff}(1000 \\
\left.\text { SEK }^{1}\right) \\
\end{array}$ & $\begin{array}{c}\% \\
\text { change }\end{array}$ & Ratio & $\begin{array}{c}\% \\
\text { change }\end{array}$ & $\begin{array}{l}\operatorname{Diff}(1000 \\
\left.\text { SEK }^{1}\right) \\
\end{array}$ & $\begin{array}{c}\% \\
\text { change }\end{array}$ & Ratio & $\begin{array}{c}\% \\
\text { change }\end{array}$ \\
\hline Observed & 3146.0 & - & 2.05 & - & 2444.9 & - & 2.00 & - \\
\hline \multicolumn{9}{|l|}{ Uniform increase in retirement age } \\
\hline One year later & 3006.8 & $-4.4 \%$ & 2.07 & $0.7 \%$ & 2345.3 & $-4.1 \%$ & 2.01 & $0.3 \%$ \\
\hline Three years later & 2730.6 & $-13.2 \%$ & 2.10 & $2.2 \%$ & 2148.5 & $-12.1 \%$ & 2.02 & $0.8 \%$ \\
\hline \multicolumn{9}{|l|}{ Differential retirement ages } \\
\hline Primary education one year earlier & 3009.9 & $-4.3 \%$ & 1.96 & $-4.4 \%$ & 2366.0 & $-3.2 \%$ & 1.94 & $-3.1 \%$ \\
\hline Primary education three years earlier & 2777.0 & $-11.7 \%$ & 1.83 & $-11.0 \%$ & 2232.4 & $-8.7 \%$ & 1.84 & $-8.0 \%$ \\
\hline Tertiary education one year later & 2836.5 & $-9.8 \%$ & 1.95 & $-5.0 \%$ & 2233.9 & $-8.6 \%$ & 1.91 & $-4.3 \%$ \\
\hline Tertiary education three years later & 2230.8 & $-29.1 \%$ & 1.75 & $-14.9 \%$ & 1817.7 & $-25.7 \%$ & 1.74 & $-12.8 \%$ \\
\hline \multicolumn{9}{|l|}{ Pension system more generous } \\
\hline Yearly pension $10 \mathrm{~K}$ SEK more to all & 3180.0 & $1.1 \%$ & 2.00 & $-2.7 \%$ & 2471.0 & $1.1 \%$ & 1.92 & $-4.1 \%$ \\
\hline Yearly pension $20 \mathrm{~K}$ SEK more to all & 3213.9 & $2.2 \%$ & 1.95 & $-5.1 \%$ & 2497.0 & $2.1 \%$ & 1.85 & $-7.5 \%$ \\
\hline \multicolumn{9}{|l|}{ Pension system less generous } \\
\hline Yearly pension 10K SEK less to all & 3112.0 & $-1.1 \%$ & 2.12 & $3.1 \%$ & 2418.9 & $-1.1 \%$ & 2.10 & $5.0 \%$ \\
\hline Yearly pension 20K SEK less to all & 3078.1 & $-2.2 \%$ & 2.19 & $6.7 \%$ & 2392.9 & $-2.1 \%$ & 2.23 & $11.4 \%$ \\
\hline \multicolumn{9}{|l|}{ Raising minimum pension } \\
\hline Minimum pension to $80 \mathrm{~K}$ SEK & 3143.9 & $-0.1 \%$ & 2.04 & $-0.3 \%$ & 2371.0 & $-3.0 \%$ & 1.93 & $-3.5 \%$ \\
\hline Minimum pension to $100 \mathrm{~K}$ SEK & 3130.2 & $-0.5 \%$ & 2.03 & $-0.9 \%$ & 2253.1 & $-7.8 \%$ & 1.83 & $-8.4 \%$ \\
\hline \multicolumn{9}{|l|}{ Mortality reduction scenarios } \\
\hline $10 \%$ less in mortality for all & 3263.5 & $3.7 \%$ & 2.04 & $-0.8 \%$ & 2523.8 & $3.2 \%$ & 1.99 & $-0.3 \%$ \\
\hline Primary $10 \%$ less, tertiary $0 \%$ less & 2986.2 & $-5.1 \%$ & 1.95 & $-5.1 \%$ & 2349.2 & $-3.9 \%$ & 1.93 & $-3.8 \%$ \\
\hline Primary $0 \%$ less, tertiary $10 \%$ less & 3423.3 & $8.8 \%$ & 2.14 & $4.5 \%$ & 2619.6 & $7.1 \%$ & 2.07 & $3.6 \%$ \\
\hline
\end{tabular}

Source: As for Table A1.

Notes: For the 1925 cohort, the observed lifetime pension is $2992.8 \mathrm{~K}$ SEK for men with primary education, $6138.8 \mathrm{~K}$ SEK for men with tertiary education, 2443.5K SEK for women with primary education, and 4888.5K SEK for women with tertiary education. For the scenarios of changing retirement age, we shift the observed yearly pension income to younger or older ages by certain years. In the case of earlier retirement by one year, the last year (i.e., age 105) of pension income is assumed to be the same as the pension income in the last observed year (i.e., age 104). In the case of later retirement by one year, the first year (i.e., age 60) of pension income is set to be zero. For the mortality reduction scenarios, we reduce mortality rates across all ages by $10 \% .{ }^{1}$ Units for absolute differences are in 1000 SEK, $\approx 125$ USD. 
Table A9. Lifetime pension inequality between the lowest and the highest earnings quintiles under policy and mortality scenarios, 1920 cohort.

\begin{tabular}{|c|c|c|c|c|c|c|c|c|}
\hline & \multicolumn{4}{|c|}{ Men } & \multicolumn{4}{|c|}{ Women } \\
\hline & \multicolumn{2}{|c|}{$\begin{array}{l}\text { Absolute } \\
\text { difference }\end{array}$} & \multicolumn{2}{|c|}{$\begin{array}{c}\text { Relative } \\
\text { difference }\end{array}$} & \multicolumn{2}{|c|}{$\begin{array}{l}\text { Absolute } \\
\text { difference }\end{array}$} & \multicolumn{2}{|c|}{$\begin{array}{c}\text { Relative } \\
\text { difference }\end{array}$} \\
\hline & $\begin{array}{l}\operatorname{Diff}(1000 \\
\left.\text { SEK }^{1}\right)\end{array}$ & $\begin{array}{c}\% \\
\text { change }\end{array}$ & Ratio & $\begin{array}{c}\% \\
\text { change }\end{array}$ & $\begin{array}{l}\text { Diff }(1000 \\
\left.\text { SEK }^{1}\right)\end{array}$ & $\begin{array}{c}\% \\
\text { change }\end{array}$ & Ratio & $\begin{array}{c}\% \\
\text { change }\end{array}$ \\
\hline Observed & 3728.3 & - & 3.32 & - & 2563.3 & - & 2.73 & - \\
\hline \multicolumn{9}{|l|}{ Uniform increase in retirement age } \\
\hline One year later & 3545.4 & $-4.9 \%$ & 3.36 & $1.0 \%$ & 2456.6 & $-4.2 \%$ & 2.74 & $0.5 \%$ \\
\hline Three years later & 3184.7 & $-14.6 \%$ & 3.43 & $3.2 \%$ & 2244.1 & $-12.5 \%$ & 2.77 & $1.5 \%$ \\
\hline \multicolumn{9}{|l|}{ Differential retirement ages } \\
\hline Lowest quintile one year earlier & 3671.0 & $-1.5 \%$ & 3.21 & $-3.4 \%$ & 2505.5 & $-2.3 \%$ & 2.63 & $-3.8 \%$ \\
\hline Lowest quintile three years earlier & 3564.3 & $-4.4 \%$ & 3.01 & $-9.3 \%$ & 2415.1 & $-5.8 \%$ & 2.48 & $-9.1 \%$ \\
\hline Highest quintile one year later & 3444.3 & $-7.6 \%$ & 3.14 & $-5.3 \%$ & 2383.8 & $-7.0 \%$ & 2.61 & $-4.4 \%$ \\
\hline Highest quintile three years later & 2890.3 & $-22.5 \%$ & 2.80 & $-15.7 \%$ & 2029.0 & $-20.8 \%$ & 2.37 & $-13.2 \%$ \\
\hline \multicolumn{9}{|l|}{ Pension system more generous } \\
\hline Yearly pension $10 \mathrm{~K}$ SEK more to all & 3772.6 & $1.2 \%$ & 3.12 & $-6.1 \%$ & 2571.7 & $0.3 \%$ & 2.49 & $-8.8 \%$ \\
\hline Yearly pension $20 \mathrm{~K}$ SEK more to all & 3817.0 & $2.4 \%$ & 2.95 & $-11.2 \%$ & 2580.2 & $0.7 \%$ & 2.31 & $-15.5 \%$ \\
\hline \multicolumn{9}{|l|}{ Pension system less generous } \\
\hline Yearly pension $10 \mathrm{~K}$ SEK less to all & 3684.0 & $-1.2 \%$ & 3.57 & $7.6 \%$ & 2554.9 & $-0.3 \%$ & 3.07 & $12.4 \%$ \\
\hline Yearly pension $20 \mathrm{~K}$ SEK less to all & 3639.6 & $-2.4 \%$ & 3.90 & $17.4 \%$ & 2546.5 & $-0.7 \%$ & 3.57 & $30.9 \%$ \\
\hline \multicolumn{9}{|l|}{ Raising minimum pension } \\
\hline Minimum pension to $80 \mathrm{~K}$ SEK & 3673.5 & $-1.5 \%$ & 3.20 & $-3.7 \%$ & 2233.1 & $-12.9 \%$ & 2.23 & $-18.5 \%$ \\
\hline Minimum pension to $100 \mathrm{~K}$ SEK & 3582.3 & $-3.9 \%$ & 3.03 & $-8.9 \%$ & 1890.7 & $-26.2 \%$ & 1.87 & $-31.5 \%$ \\
\hline \multicolumn{9}{|l|}{ Mortality reduction scenarios } \\
\hline $10 \%$ less in mortality for all & 3892.2 & $4.4 \%$ & 3.28 & $-1.2 \%$ & 2652.6 & $3.5 \%$ & 2.72 & $-0.4 \%$ \\
\hline $\begin{array}{l}\text { Lowest quintile } 10 \% \text { less, highest } \\
\text { quintile } 0 \% \text { less }\end{array}$ & 3629.6 & $-2.6 \%$ & 3.13 & $-5.8 \%$ & 2501.0 & $-2.4 \%$ & 2.62 & $-4.0 \%$ \\
\hline $\begin{array}{l}\text { Lowest quintile } 0 \% \text { less, highest } \\
\text { quintile } 10 \% \text { less }\end{array}$ & 3990.9 & $7.0 \%$ & 3.48 & $4.9 \%$ & 2714.9 & $5.9 \%$ & 2.83 & $3.7 \%$ \\
\hline
\end{tabular}

Source: As for Table A1.

Notes: For the 1920 cohort, the observed lifetime pension is 1606.6K SEK for men in the lowest quintile, 5334.9K SEK for men in the highest quintile, 1481.0K SEK for women in the lowest quintile, and 4044.4K SEK for women in the highest quintile. For the scenarios of changing retirement age, we shift the observed yearly pension income to younger or older ages by certain years. In the case of earlier retirement by one year, the last year (i.e., age 105) of pension income is assumed to be the same as the pension income in the last observed year (i.e., age 104). In the case of later retirement by one year, the first year (i.e., age 60) of pension income is set to be zero. For the mortality reduction scenarios, we reduce mortality rates across all ages by $10 \% .{ }^{1}$ Units for absolute differences are in 1000 SEK, $\approx 125$ USD. 
Table A10. Lifetime pension inequality between the lowest and the highest earnings quintiles under policy and mortality scenarios, 1925 cohort.

\begin{tabular}{|c|c|c|c|c|c|c|c|c|}
\hline & \multicolumn{4}{|c|}{ Men } & \multicolumn{4}{|c|}{ Women } \\
\hline & \multicolumn{2}{|c|}{$\begin{array}{l}\text { Absolute } \\
\text { difference }\end{array}$} & \multicolumn{2}{|c|}{$\begin{array}{l}\text { Relative } \\
\text { difference }\end{array}$} & \multicolumn{2}{|c|}{$\begin{array}{l}\text { Absolute } \\
\text { difference }\end{array}$} & \multicolumn{2}{|c|}{$\begin{array}{c}\text { Relative } \\
\text { difference }\end{array}$} \\
\hline & $\begin{array}{l}\operatorname{Diff}(1000 \\
\left.\text { SEK }^{1}\right)\end{array}$ & $\begin{array}{c}\% \\
\text { change }\end{array}$ & Ratio & $\begin{array}{c}\% \\
\text { change }\end{array}$ & $\begin{array}{l}\operatorname{Diff}(1000 \\
\left.\text { SEK }^{1}\right)\end{array}$ & $\begin{array}{c}\% \\
\text { change }\end{array}$ & Ratio & $\begin{array}{c}\% \\
\text { change }\end{array}$ \\
\hline Observed & 4100.6 & - & 3.14 & - & 2853.8 & - & 2.76 & - \\
\hline \multicolumn{9}{|l|}{ Uniform increase in retirement age } \\
\hline One year later & 3912.7 & $-4.6 \%$ & 3.18 & $1.1 \%$ & 2737.6 & $-4.1 \%$ & 2.77 & $0.5 \%$ \\
\hline Three years later & 3540.3 & $-13.7 \%$ & 3.25 & $3.4 \%$ & 2507.3 & $-12.1 \%$ & 2.80 & $1.5 \%$ \\
\hline \multicolumn{9}{|l|}{ Differential retirement ages } \\
\hline Lowest quintile one year earlier & 4025.6 & $-1.8 \%$ & 3.02 & $-3.8 \%$ & 2796.3 & $-2.0 \%$ & 2.67 & $-3.4 \%$ \\
\hline Lowest quintile three years earlier & 3894.0 & $-5.0 \%$ & 2.84 & $-9.7 \%$ & 2704.9 & $-5.2 \%$ & 2.53 & $-8.4 \%$ \\
\hline Highest quintile one year later & 3796.6 & $-7.4 \%$ & 2.98 & $-5.1 \%$ & 2659.9 & $-6.8 \%$ & 2.64 & $-4.3 \%$ \\
\hline Highest quintile three years later & 3201.3 & $-21.9 \%$ & 2.67 & $-15.0 \%$ & 2277.1 & $-20.2 \%$ & 2.40 & $-12.9 \%$ \\
\hline \multicolumn{9}{|l|}{ Pension system more generous } \\
\hline Yearly pension $10 \mathrm{~K}$ SEK more to all & 4146.9 & $1.1 \%$ & 2.98 & $-5.3 \%$ & 2866.5 & $0.4 \%$ & 2.53 & $-8.2 \%$ \\
\hline Yearly pension $20 \mathrm{~K}$ SEK more to all & 4193.2 & $2.3 \%$ & 2.84 & $-9.8 \%$ & 2879.1 & $0.9 \%$ & 2.36 & $-14.5 \%$ \\
\hline \multicolumn{9}{|l|}{ Pension system less generous } \\
\hline Yearly pension $10 \mathrm{~K}$ SEK less to all & 4054.3 & $-1.1 \%$ & 3.35 & $6.5 \%$ & 2841.2 & $-0.4 \%$ & 3.07 & $11.2 \%$ \\
\hline Yearly pension $20 \mathrm{~K}$ SEK less to all & 4008.0 & $-2.3 \%$ & 3.60 & $14.5 \%$ & 2828.5 & $-0.9 \%$ & 3.52 & $27.4 \%$ \\
\hline \multicolumn{9}{|l|}{ Raising minimum pension } \\
\hline Minimum pension to $80 \mathrm{~K}$ SEK & 4066.8 & $-0.8 \%$ & 3.08 & $-2.1 \%$ & 2586.5 & $-9.4 \%$ & 2.36 & $-14.4 \%$ \\
\hline Minimum pension to $100 \mathrm{~K}$ SEK & 4001.7 & $-2.4 \%$ & 2.97 & $-5.4 \%$ & 2261.9 & $-20.7 \%$ & 2.01 & $-27.1 \%$ \\
\hline \multicolumn{9}{|l|}{ Mortality reduction scenarios } \\
\hline $10 \%$ less in mortality for all & 4260.6 & $3.9 \%$ & 3.10 & $-1.3 \%$ & 2949.5 & $3.4 \%$ & 2.75 & $-0.4 \%$ \\
\hline $\begin{array}{l}\text { Lowest quintile } 10 \% \text { less, highest } \\
\text { quintile } 0 \% \text { less }\end{array}$ & 3987.4 & $-2.8 \%$ & 2.97 & $-5.6 \%$ & 2787.7 & $-2.3 \%$ & 2.65 & $-3.9 \%$ \\
\hline $\begin{array}{l}\text { Lowest quintile } 0 \% \text { less, highest } \\
\text { quintile } 10 \% \text { less }\end{array}$ & 4373.8 & $6.7 \%$ & 3.29 & $4.5 \%$ & 3015.6 & $5.7 \%$ & 2.86 & $3.6 \%$ \\
\hline
\end{tabular}

Source: As for Table A1.

Notes: For the 1925 cohort, the observed lifetime pension is 1913.6K SEK for men in the lowest quintile, 6014.1K SEK for men in the highest quintile, 1621.4K SEK for women in the lowest quintile, and 4475.2K SEK for women in the highest quintile. For the scenarios of changing retirement age, we shift the observed yearly pension income to younger or older ages by certain years. In the case of earlier retirement by one year, the last year (i.e., age 105) of pension income is assumed to be the same as the pension income in the last observed year (i.e., age 104). In the case of later retirement by one year, the first year (i.e., age 60) of pension income is set to be zero. For the mortality reduction scenarios, we reduce mortality rates across all ages by $10 \%$. ${ }^{1}$ Units for absolute differences are in 1000 SEK, $\approx 125$ USD. 
Table A11. Distribution of marital status within income quintiles.

\begin{tabular}{|c|c|c|c|c|c|c|c|c|}
\hline & \multicolumn{4}{|c|}{ Men } & \multicolumn{4}{|c|}{ Women } \\
\hline & Married & Divorced & Widowed & $\begin{array}{l}\text { Never } \\
\text { married }\end{array}$ & Married & Divorced & Widowed & $\begin{array}{l}\text { Never } \\
\text { married }\end{array}$ \\
\hline \multicolumn{9}{|l|}{1920 cohort } \\
\hline Lowest & $60.5 \%$ & $8.2 \%$ & $1.3 \%$ & $30.0 \%$ & $97.0 \%$ & $0.6 \%$ & $0.3 \%$ & $2.1 \%$ \\
\hline Second & $79.2 \%$ & $4.8 \%$ & $1.4 \%$ & $14.7 \%$ & $86.0 \%$ & $4.0 \%$ & $2.6 \%$ & $7.4 \%$ \\
\hline Third & $85.8 \%$ & $4.2 \%$ & $1.2 \%$ & $8.8 \%$ & $85.6 \%$ & $4.6 \%$ & $5.9 \%$ & $3.9 \%$ \\
\hline Fourth & $91.2 \%$ & $3.1 \%$ & $1.2 \%$ & $4.5 \%$ & $78.9 \%$ & $9.0 \%$ & $5.0 \%$ & $7.1 \%$ \\
\hline Highest & $94.6 \%$ & $2.2 \%$ & $0.9 \%$ & $2.3 \%$ & $61.3 \%$ & $12.8 \%$ & $9.7 \%$ & $16.1 \%$ \\
\hline \multicolumn{9}{|l|}{1925 cohort } \\
\hline Lowest & $57.8 \%$ & $11.8 \%$ & $1.9 \%$ & $28.5 \%$ & $93.7 \%$ & $1.6 \%$ & $1.9 \%$ & $2.8 \%$ \\
\hline Second & $71.9 \%$ & $9.7 \%$ & $2.3 \%$ & $16.1 \%$ & $78.8 \%$ & $7.4 \%$ & $7.4 \%$ & $6.4 \%$ \\
\hline Third & $81.3 \%$ & $8.2 \%$ & $1.8 \%$ & $8.6 \%$ & $83.0 \%$ & $8.2 \%$ & $5.1 \%$ & $3.6 \%$ \\
\hline Fourth & $86.8 \%$ & $6.8 \%$ & $1.8 \%$ & $4.6 \%$ & $68.0 \%$ & $15.7 \%$ & $8.9 \%$ & $7.4 \%$ \\
\hline Highest & $90.3 \%$ & $6.1 \%$ & $1.6 \%$ & $2.1 \%$ & $54.4 \%$ & $16.2 \%$ & $15.3 \%$ & $14.0 \%$ \\
\hline
\end{tabular}

Source: As for Table A1.

Notes: Marital status is obtained from census data. The 1970 and 1980 census data are used for the 1920 and 1925 cohorts, respectively. Thus, marital status at age 50 is used for the 1920 cohort, and at age 55 is used for the 1925 cohort. 


\section{Appendix 3. Figures}

Figure A1. Age-specific average pension income by education.

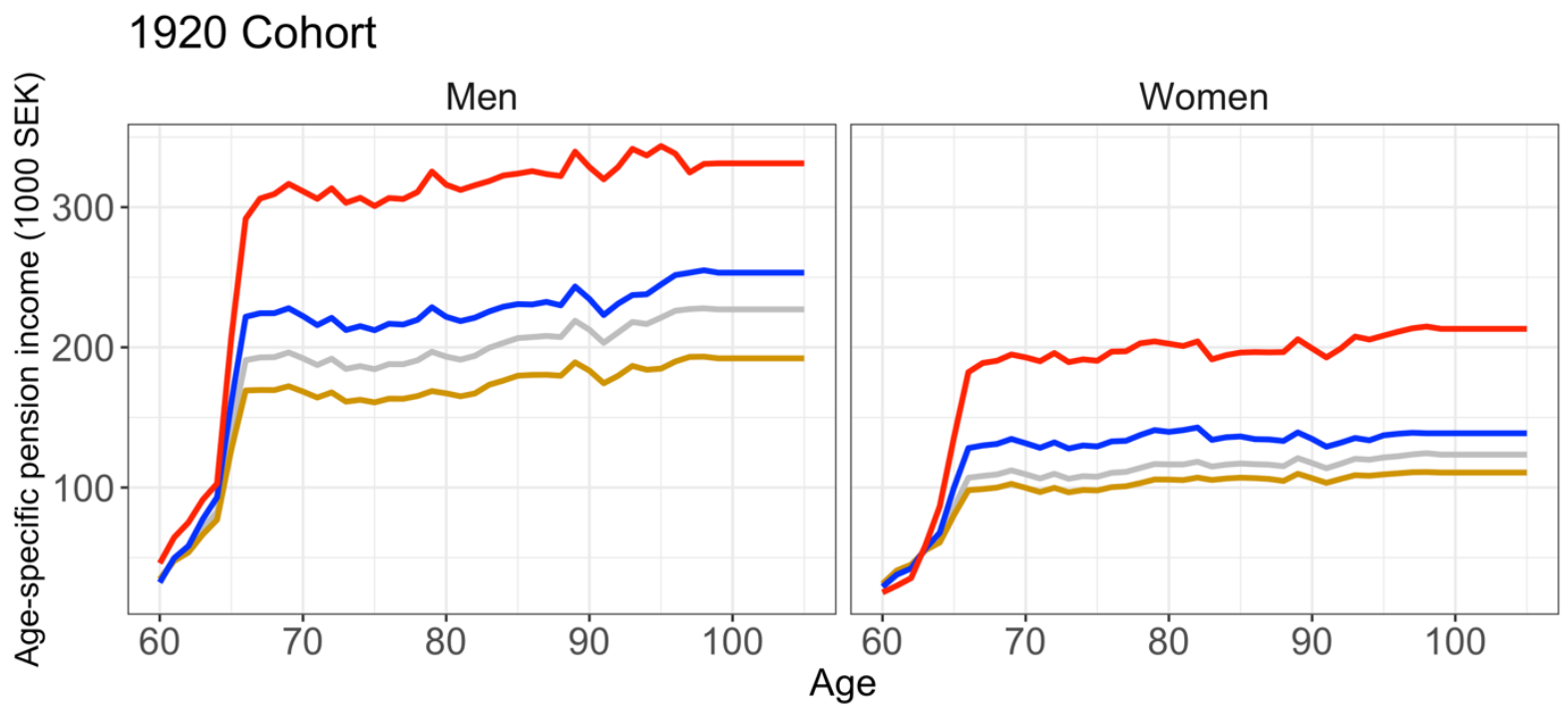

1925 Cohort

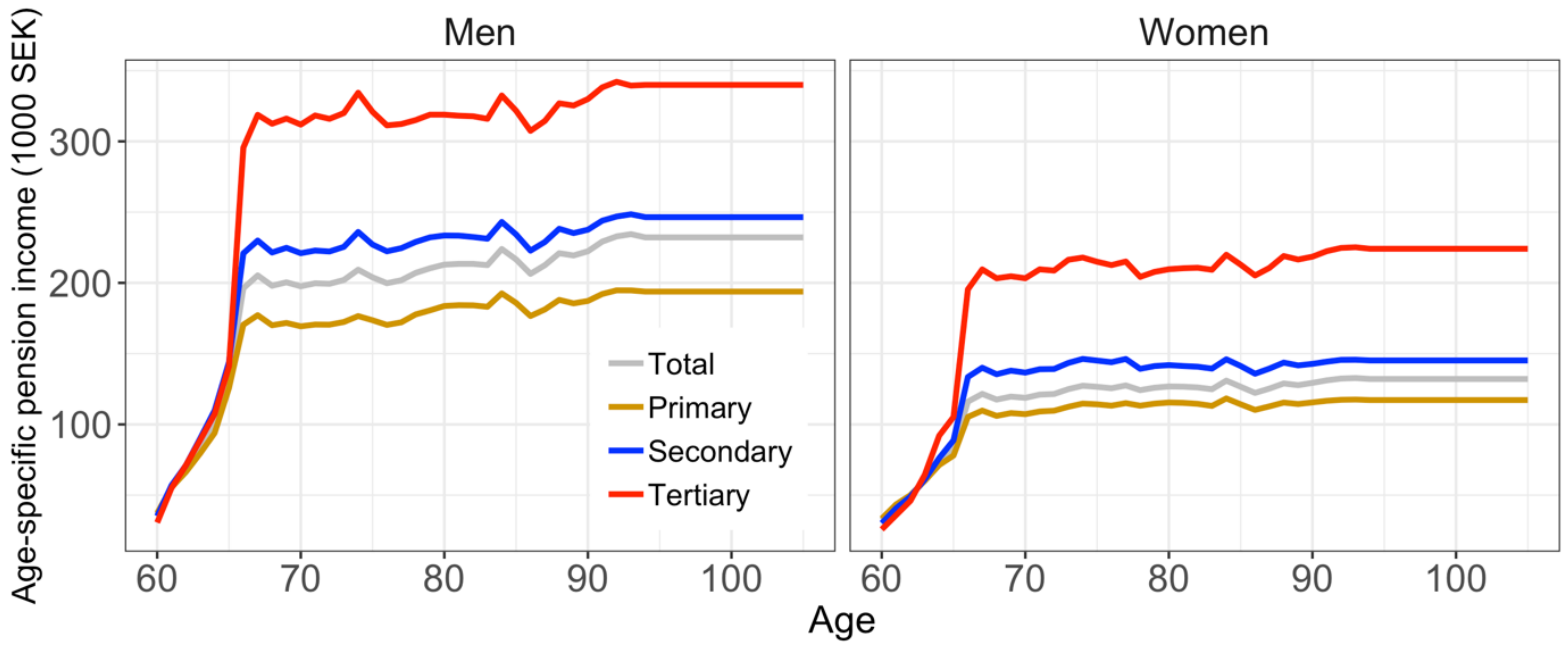

Source: As for Table A1. 
Figure A2. Age-specific average pension income by earnings quintile.
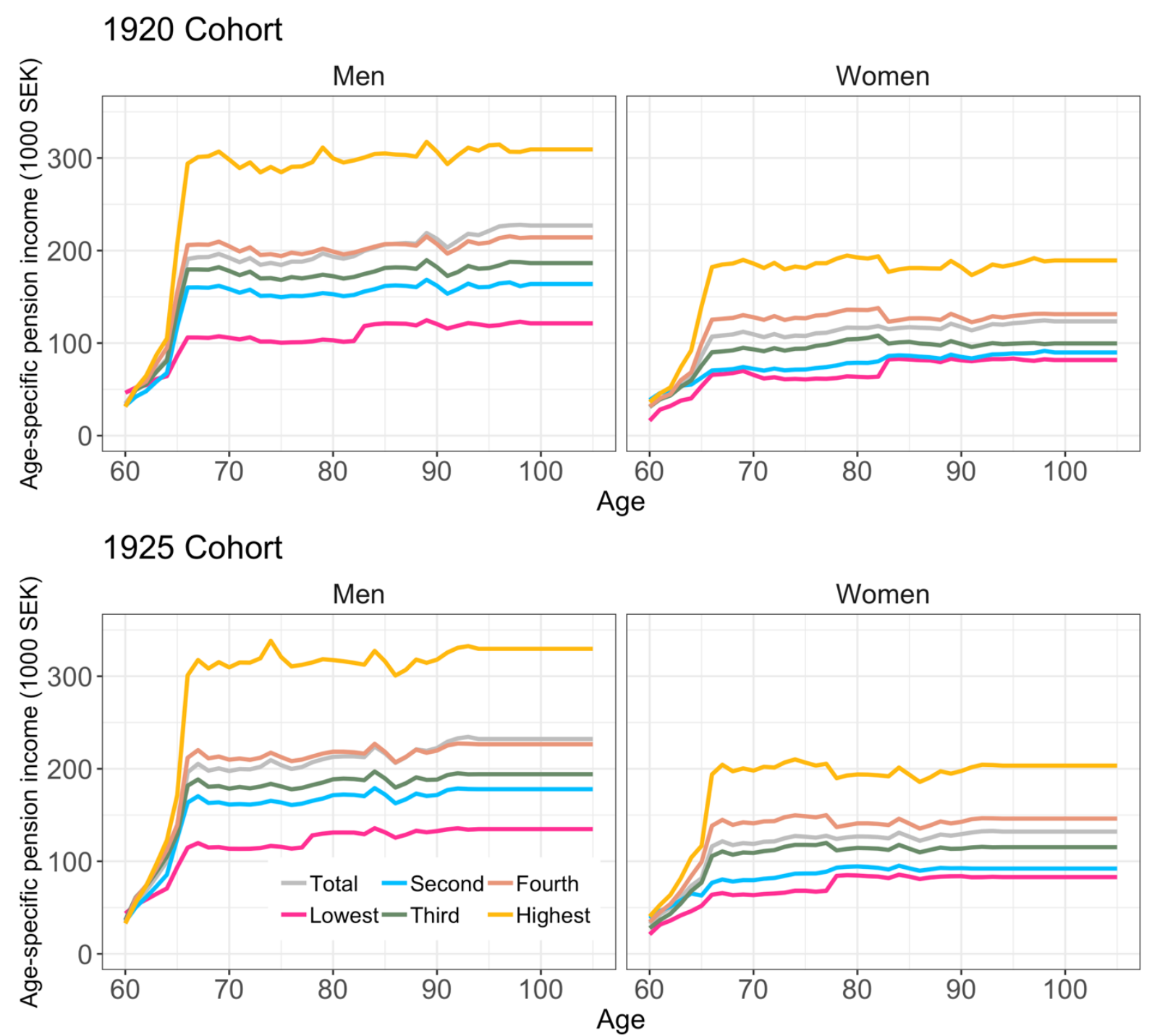

Source: As for Table A1. 
Figure A3. Survival curves by education.

\section{Cohort}

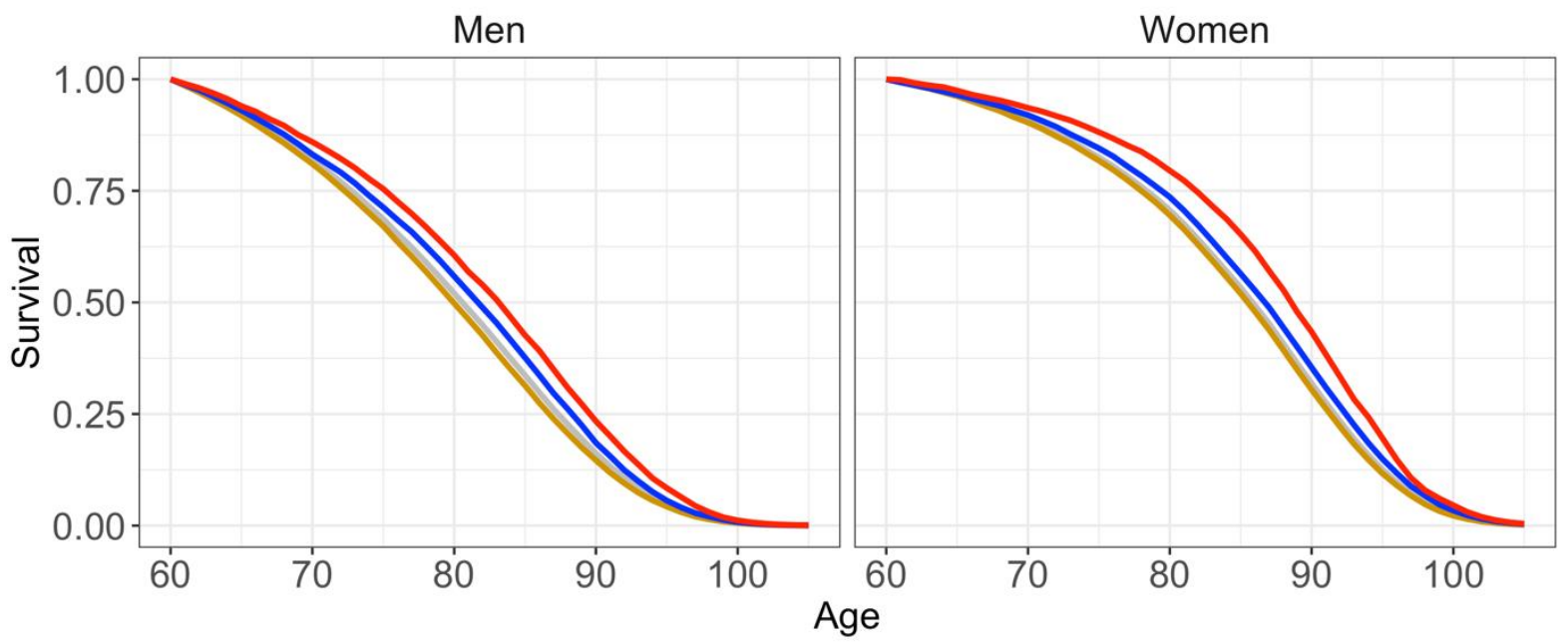

1925 Cohort

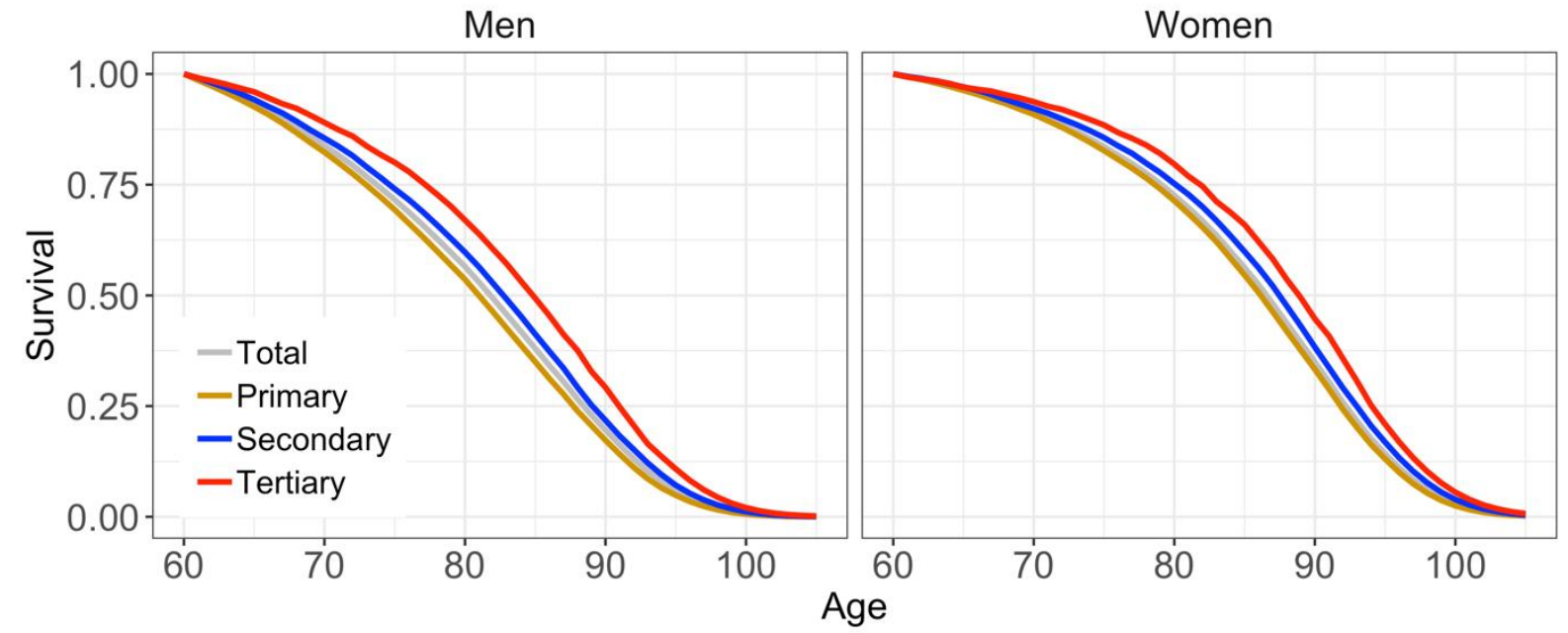

Source: As for Table A1. 
Figure A4. Survival curves by income quintile.

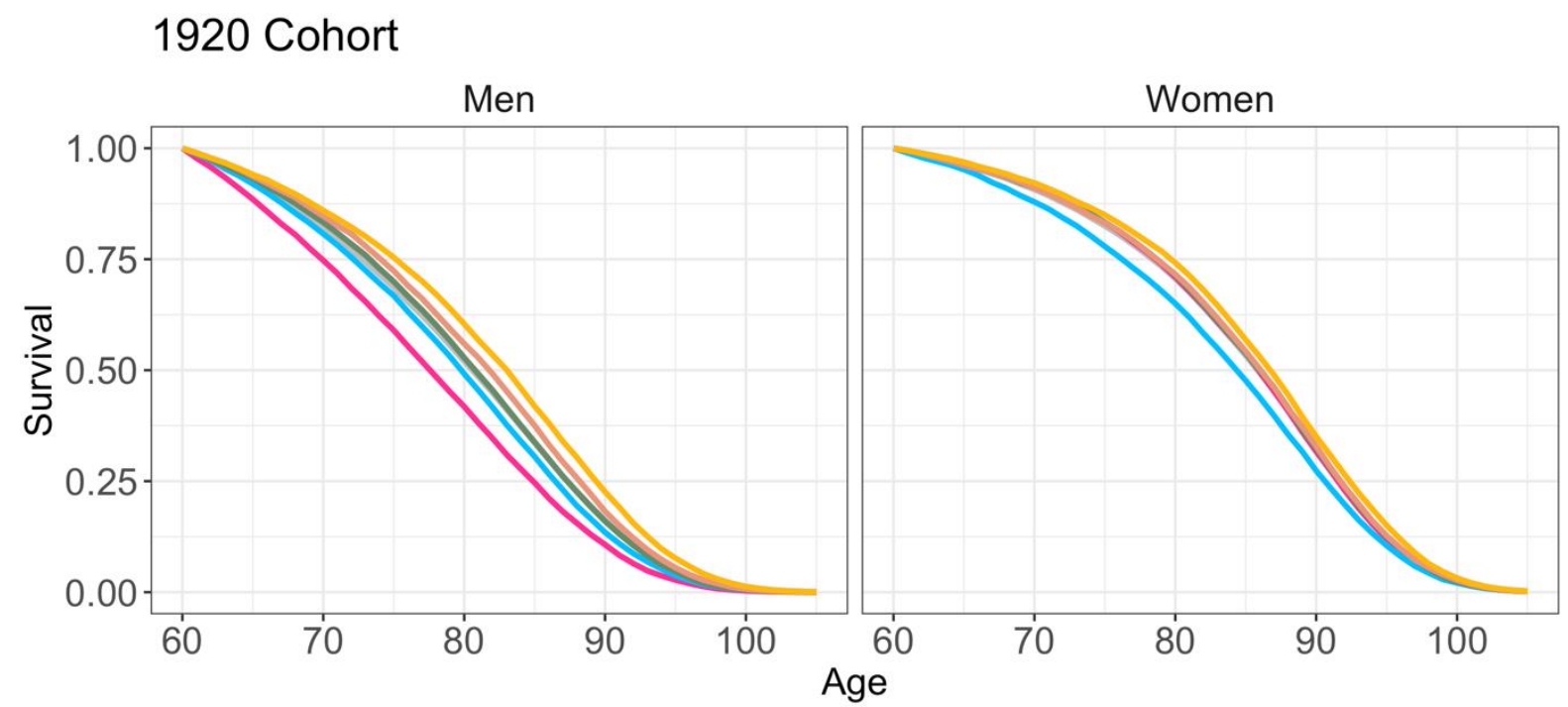

1925 Cohort

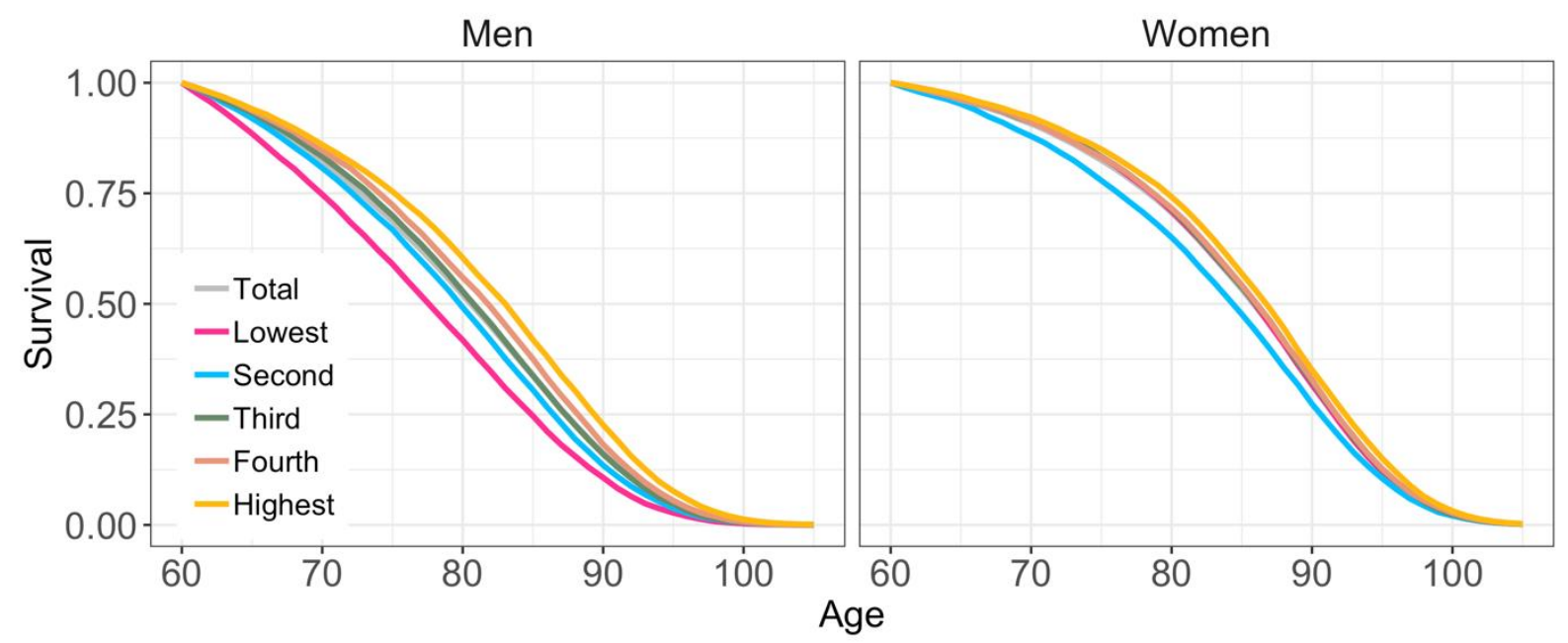

Source: As for Table A1. 
Figure A5. Boxplots of accumulated pension income until 2018, by education.

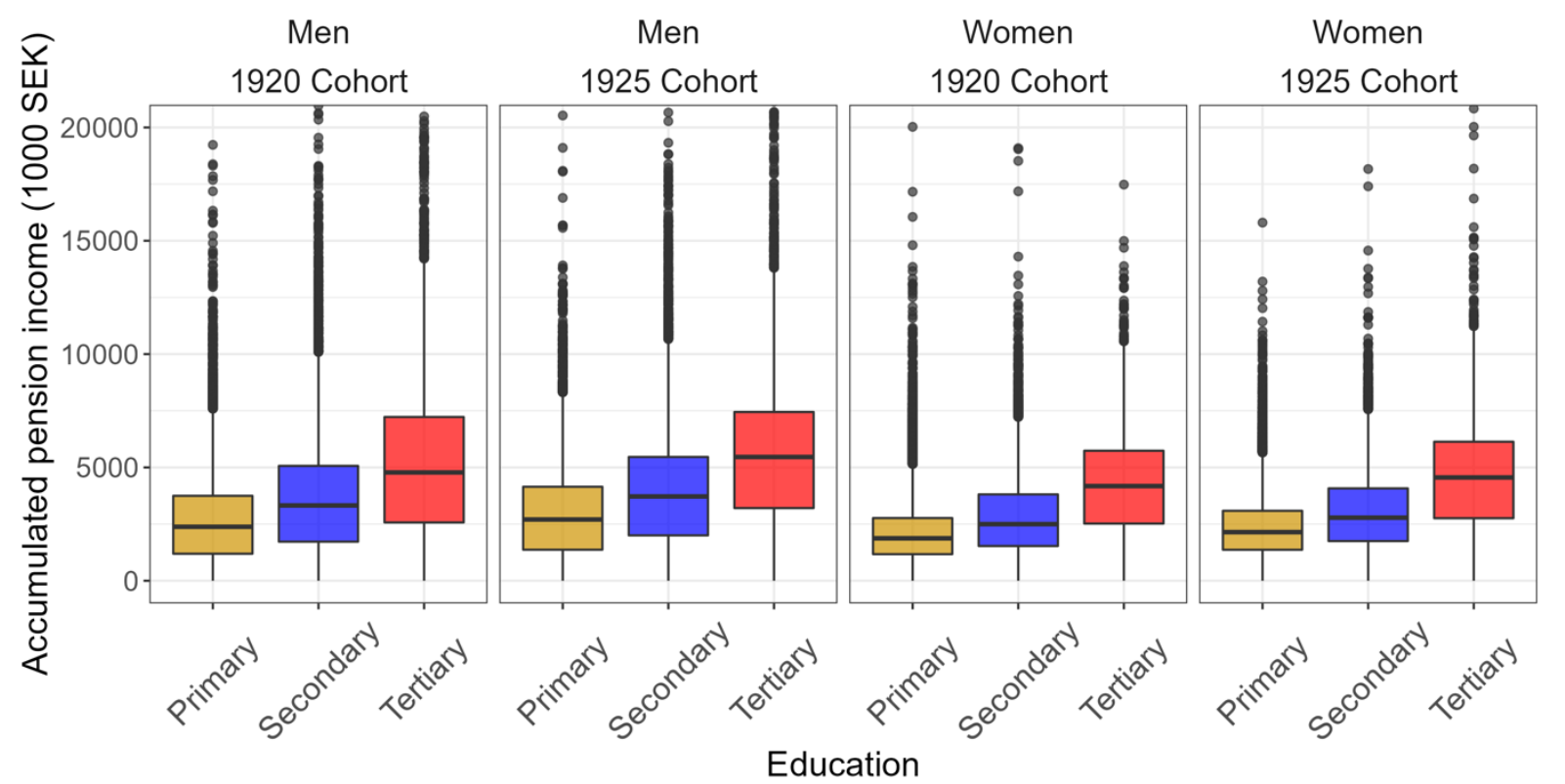

Source: As for Table A1.

Notes: Accumulated pension income is the sum of pension income from age 60 to 98 for the 1920 cohort, and from age 60 to 93 for the 1925 cohort. Outliers (dots) that are defined as above the Q3 + 1.5IQR are displayed. The y axis is truncated. Extreme outliers and the maximum are not shown. 
Figure A6. Boxplots of accumulated pension income until 2018, by earnings.

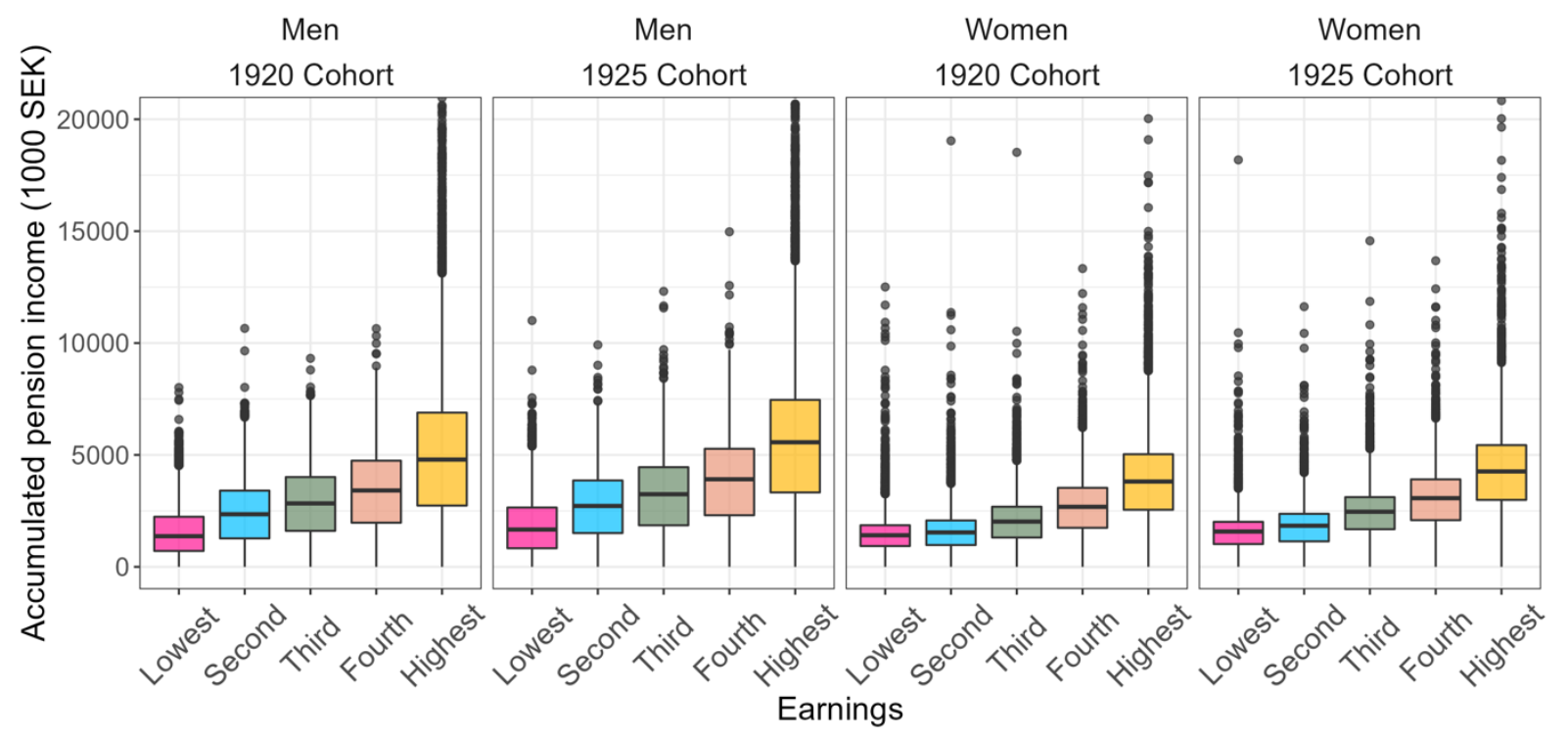

Source: As for Table A1.

Notes: Accumulated pension income is the sum of pension income from age 60 to 98 for the 1920 cohort, and from age 60 to 93 for the 1925 cohort. Outliers (dots) that are defined as above the Q3 + 1.5IQR are displayed. The y axis is truncated. Extreme outliers and the maximum are not shown. 
Figure A7. Age-specific cumulative pension income, by education.
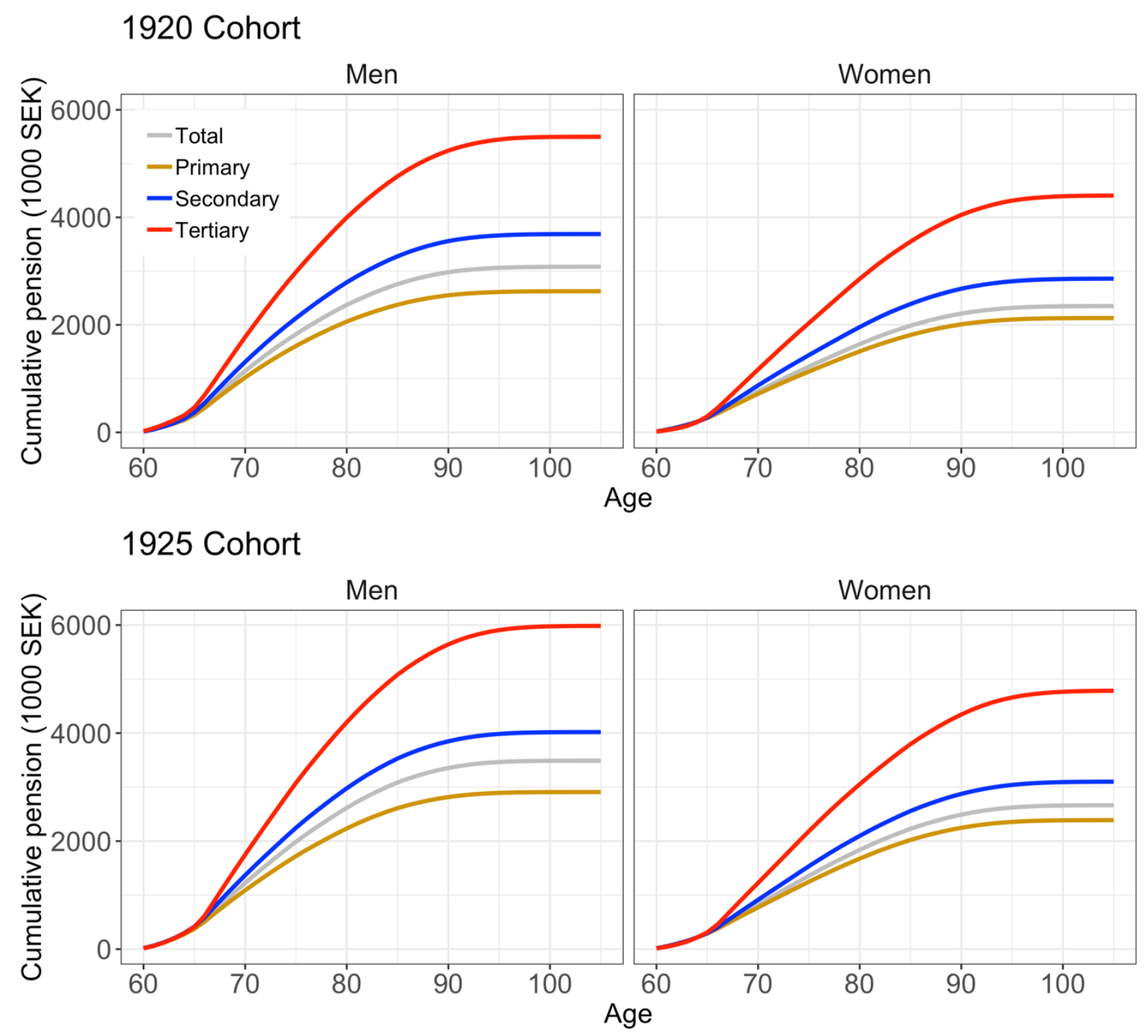

Source: As for Table A1.

Notes: Age-specific average accumulated pension income refers to the expected value of pension between age 60 and $x$ along the age axis. The values at the end points of the lines are equivalent to the values of group specific lifetime pension incomes. 
Figure A8. Age-specific cumulative pension income, by earnings.
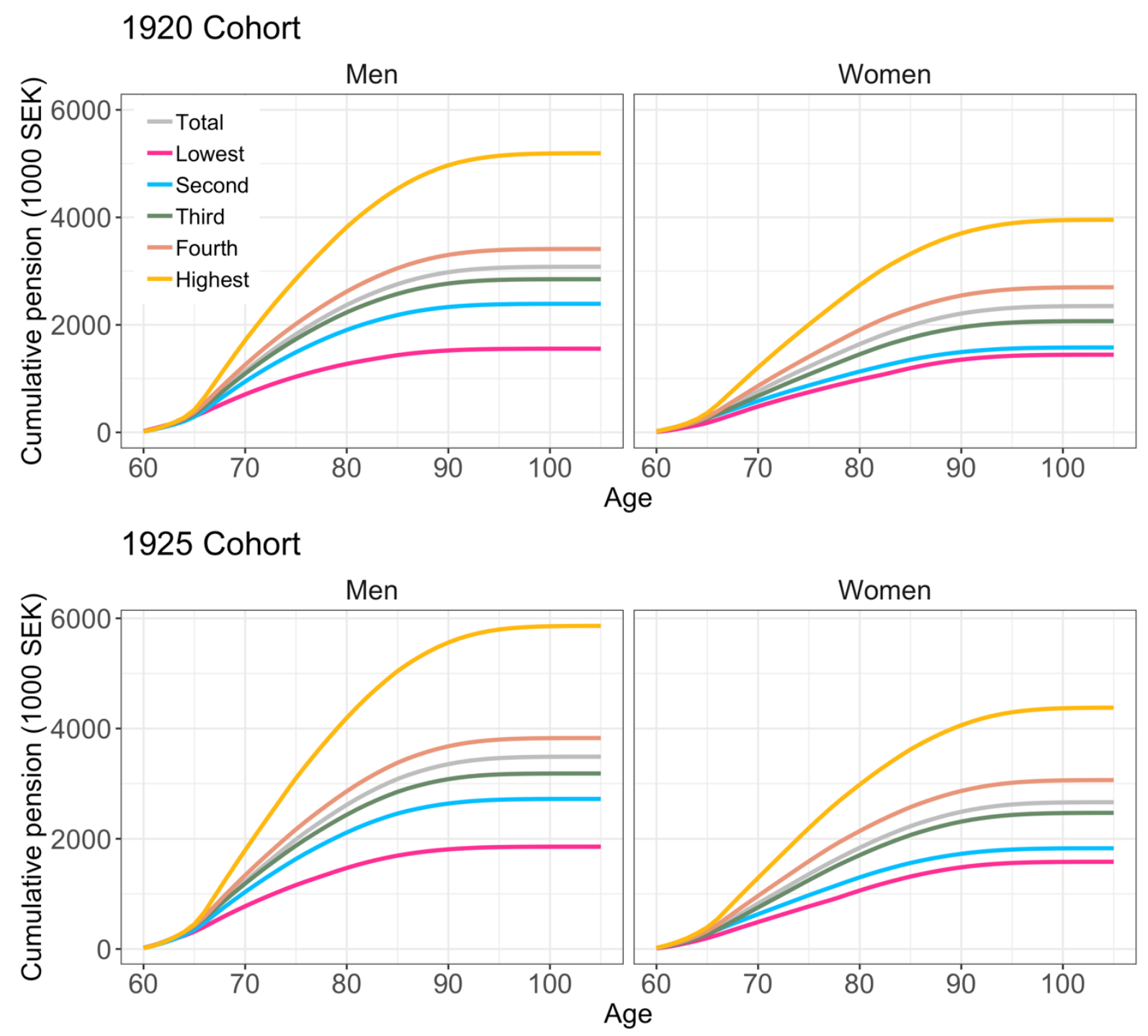

Source: As for Table A1.

Notes: Age-specific average accumulated pension income refers to the expected value of pension between age 60 and $x$ along the age axis. The values at the end points of the lines are equivalent to the values of group specific lifetime pension incomes. 
Figure A9. Decompositions of total lifetime pension differences between men and women into differences explained by age and mortality.

Differences between men and women

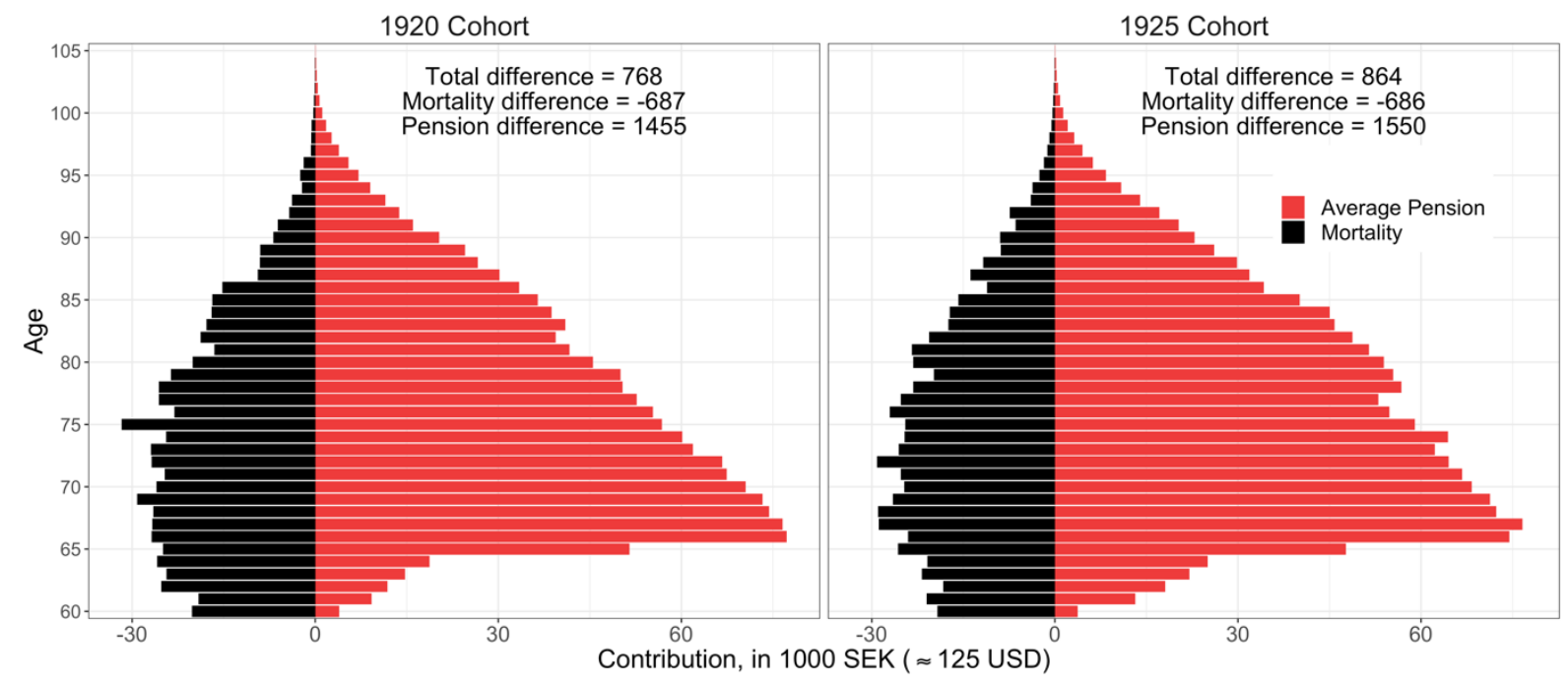

Source: As for Table A1. 
Figure A10. Mortality ratio between men with primary and tertiary education, 1920 cohort.

Mortality ratio between men with primary and tertiary education, 1920 cohort

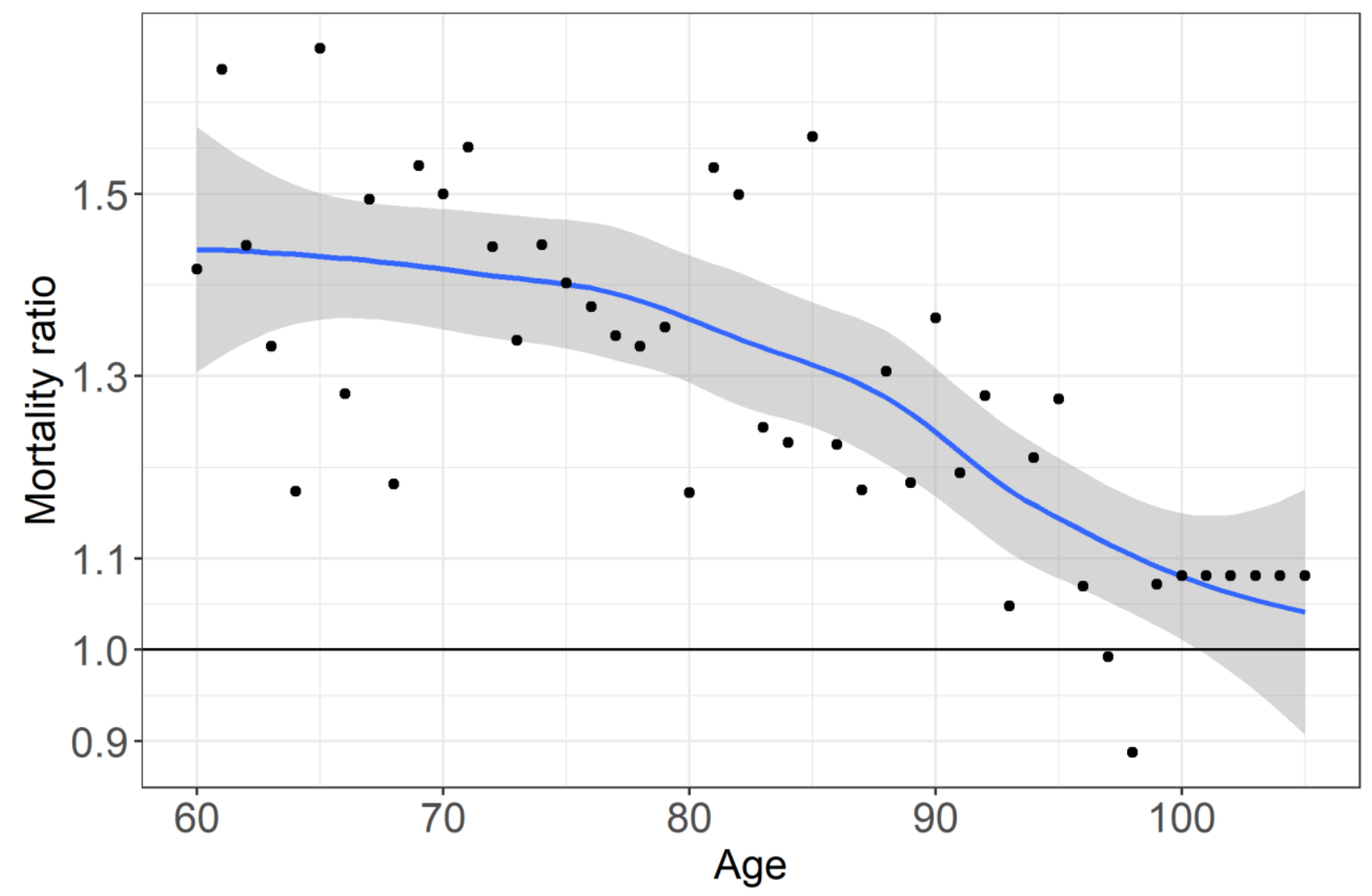

Source: As for Table A1.

Note: Mortality ratios above age 100 are assumed to be constant as the average over the last three years (i.e., ages 97-99). The smoothed line is estimated using loess regression. 
Figure A11. Decompositions of life expectancy $\left(e_{60}\right)$ differences between primary and tertiary education groups into differences explained by differences in age-specific mortality.

Differences between primary and tertiary education, men

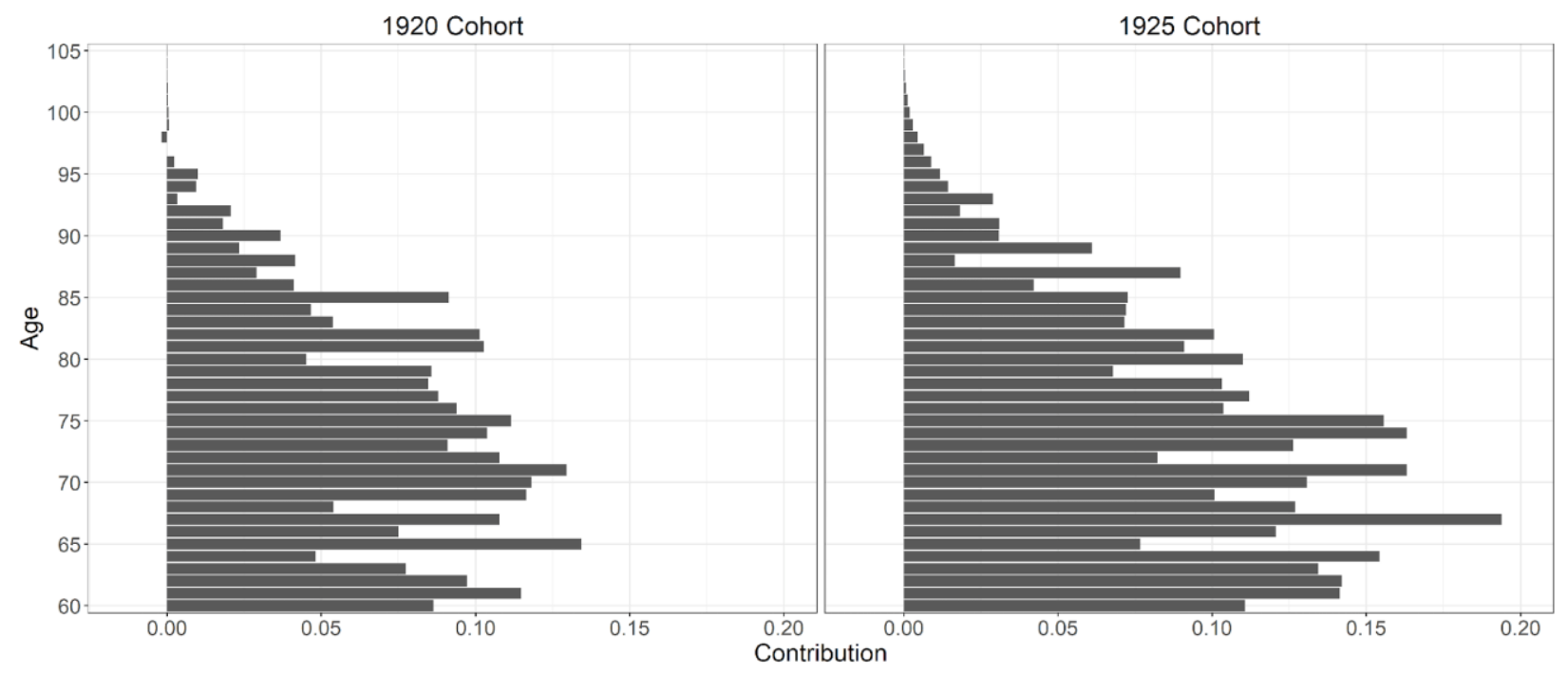

Differences between primary and tertiary education, women

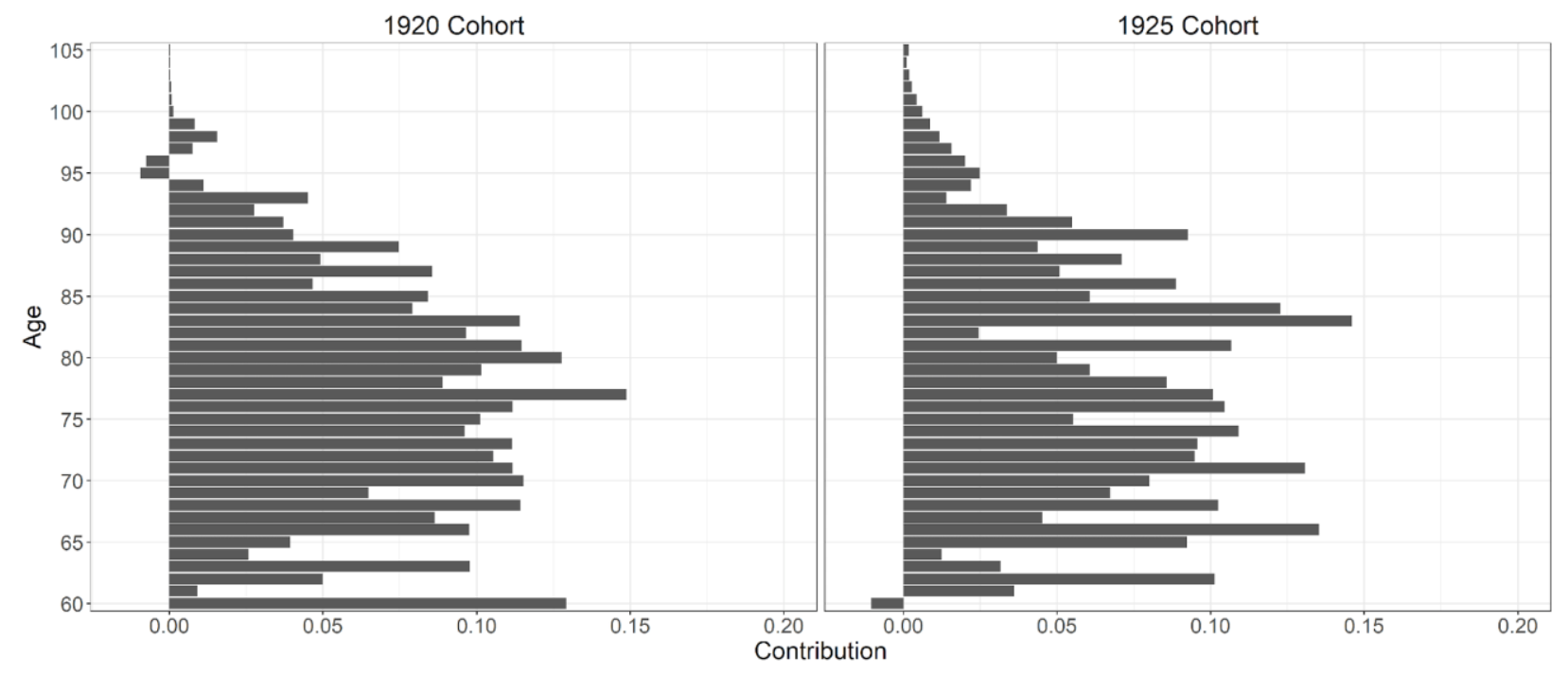

Source: As for Table A1. 
Figure A12. Decompositions of total lifetime pension differences between primary and secondary education groups into differences explained by age and mortality.

Differences between primary and secondary education, men

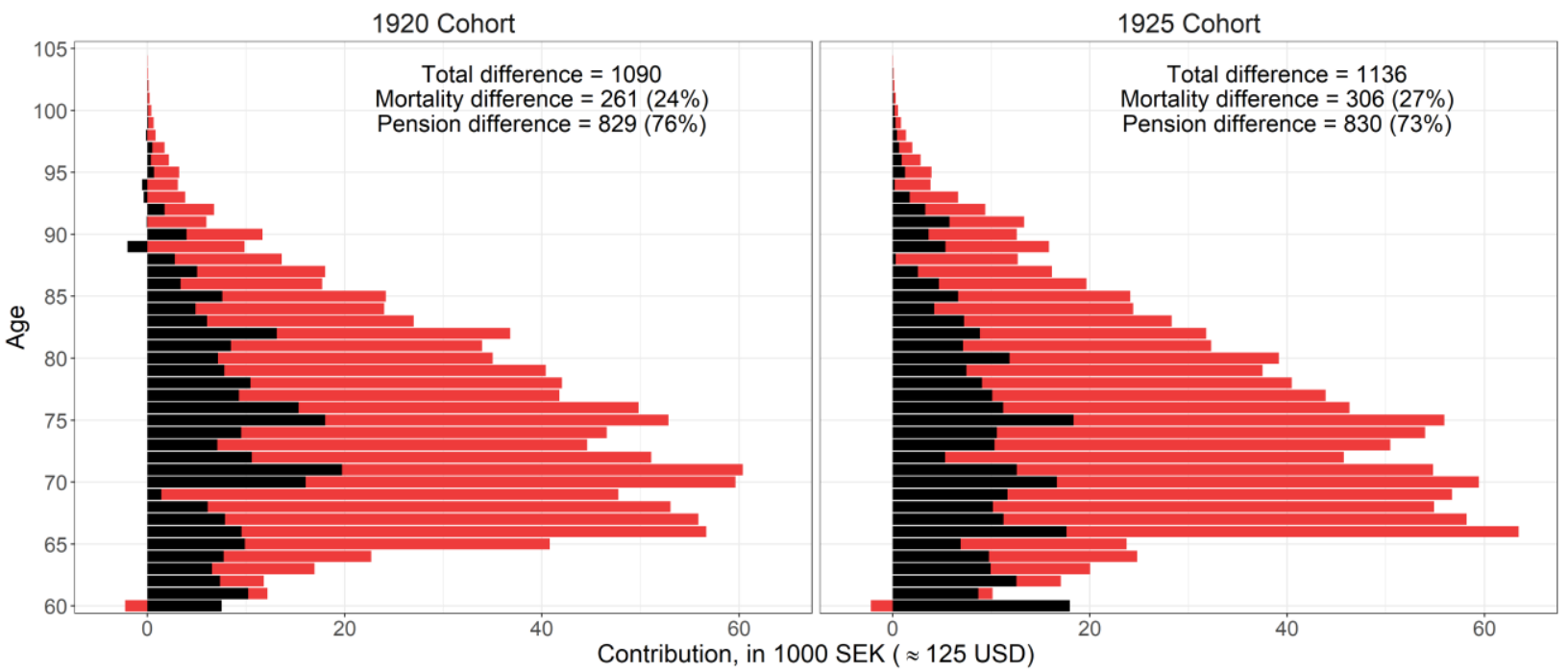

Differences between primary and secondary education, women

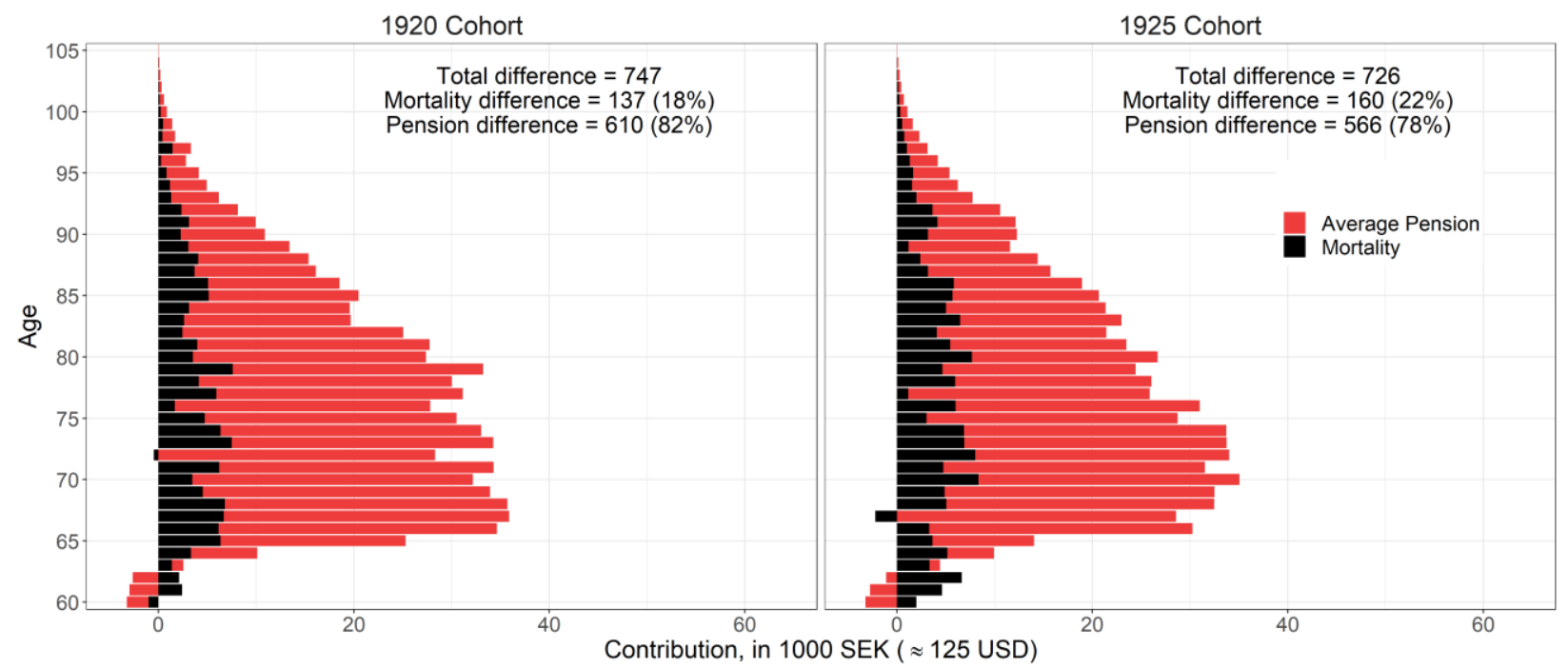

Source: As for Table A1. 
Figure A13. Decompositions of total lifetime pension differences between secondary and tertiary education groups into differences explained by age and mortality.

Differences between secondary and tertiary education, men

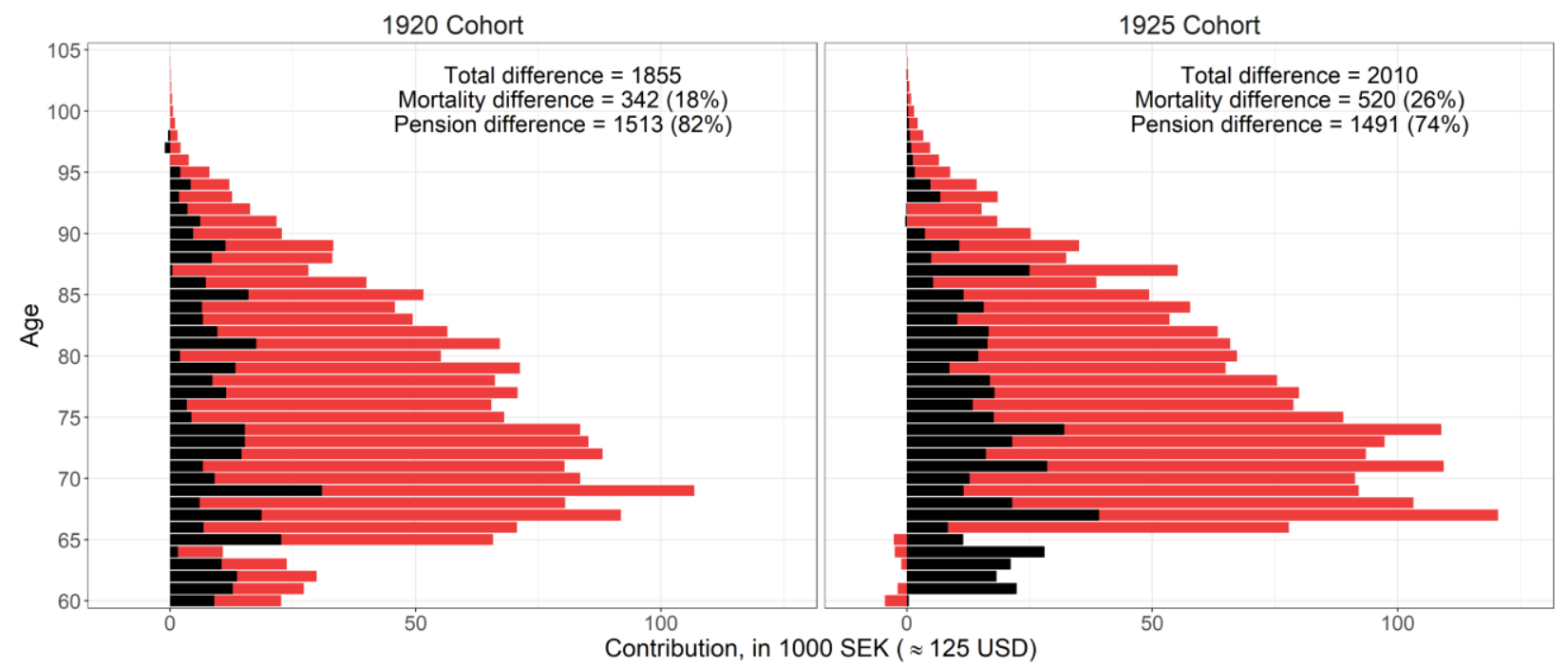

Differences between secondary and tertiary education, women

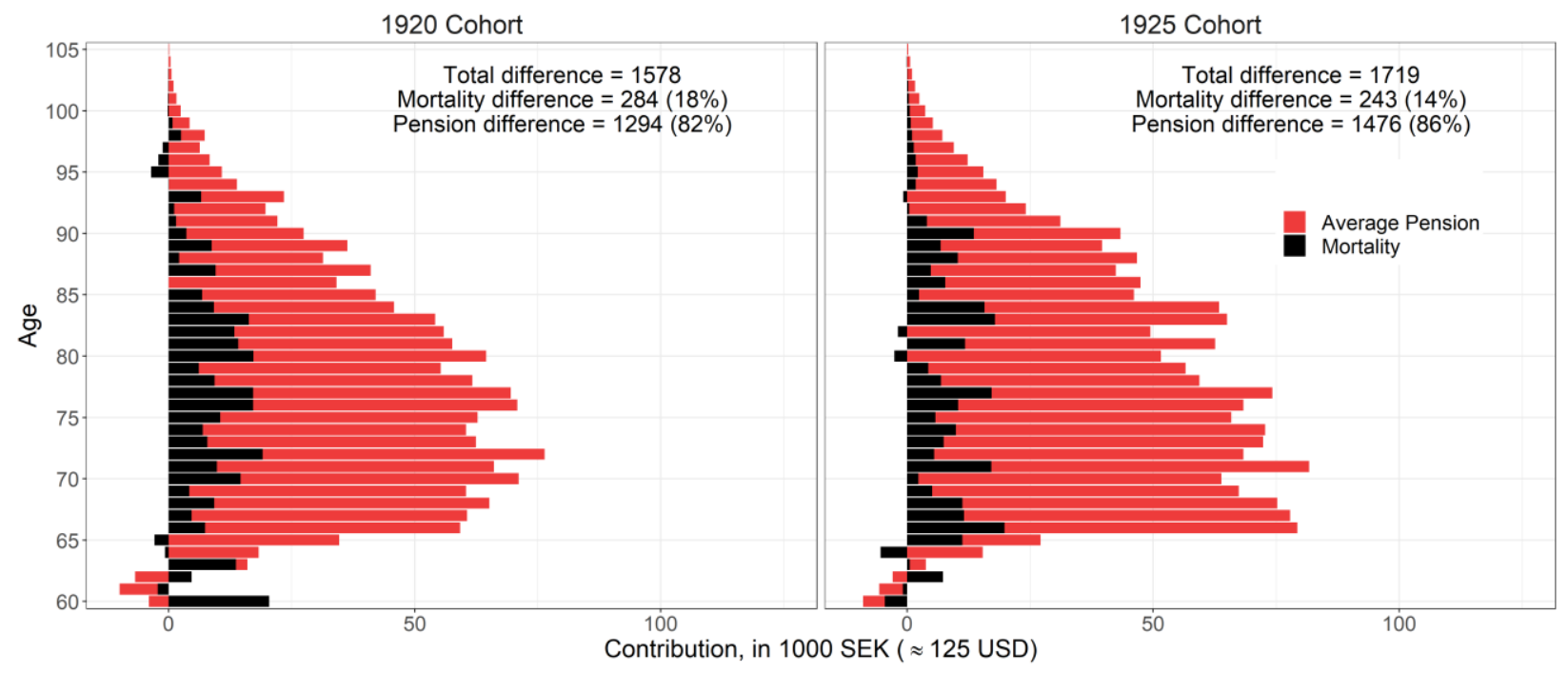

Source: As for Table A1. 
Figure A14. Decompositions of total lifetime pension differences between the lowest and the third earnings quintile groups into differences explained by age and mortality.

Differences between the lowest and the third quintiles, men

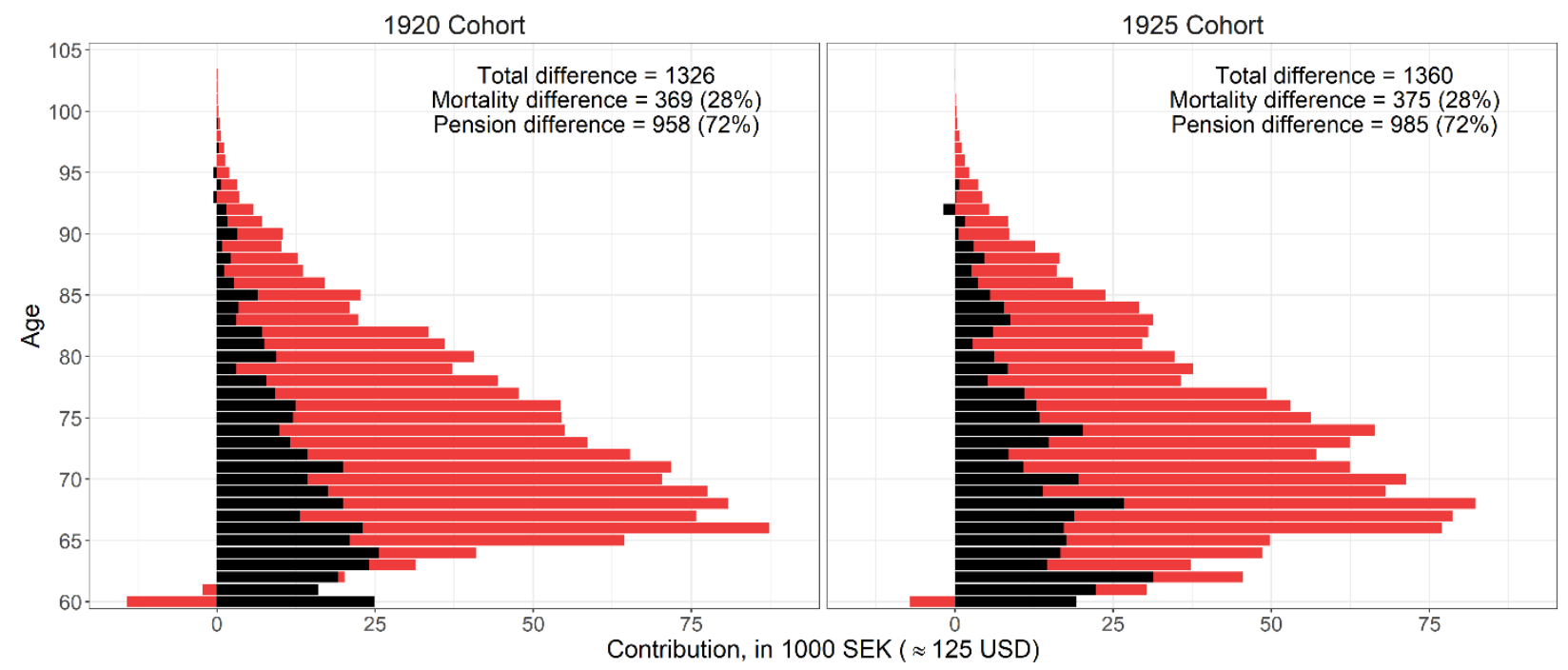

Differences between the lowest and the third quintiles, women

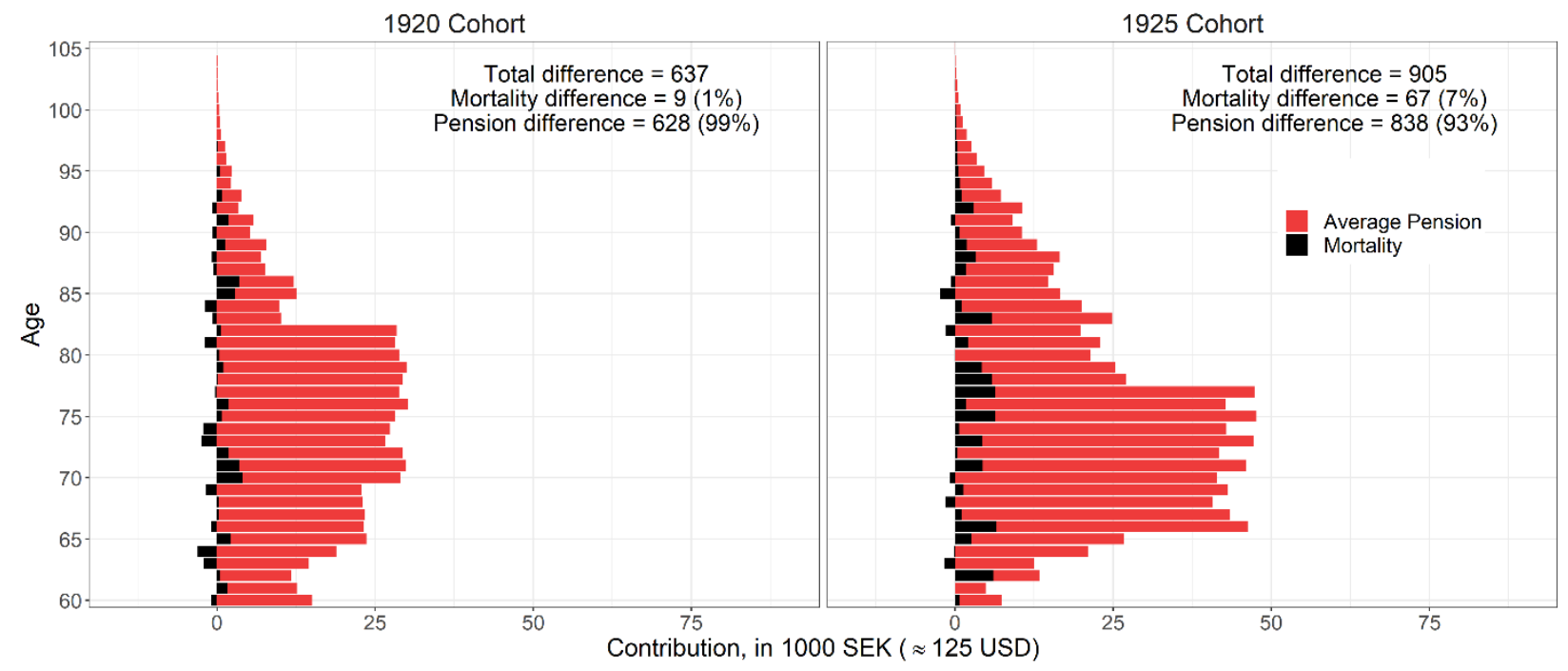

Source: As for Table A1. 
Figure A15. Decompositions of total lifetime pension differences between the second and the fourth earnings quintile groups into differences explained by age and mortality.

Differences between the second and the fourth quintiles, men

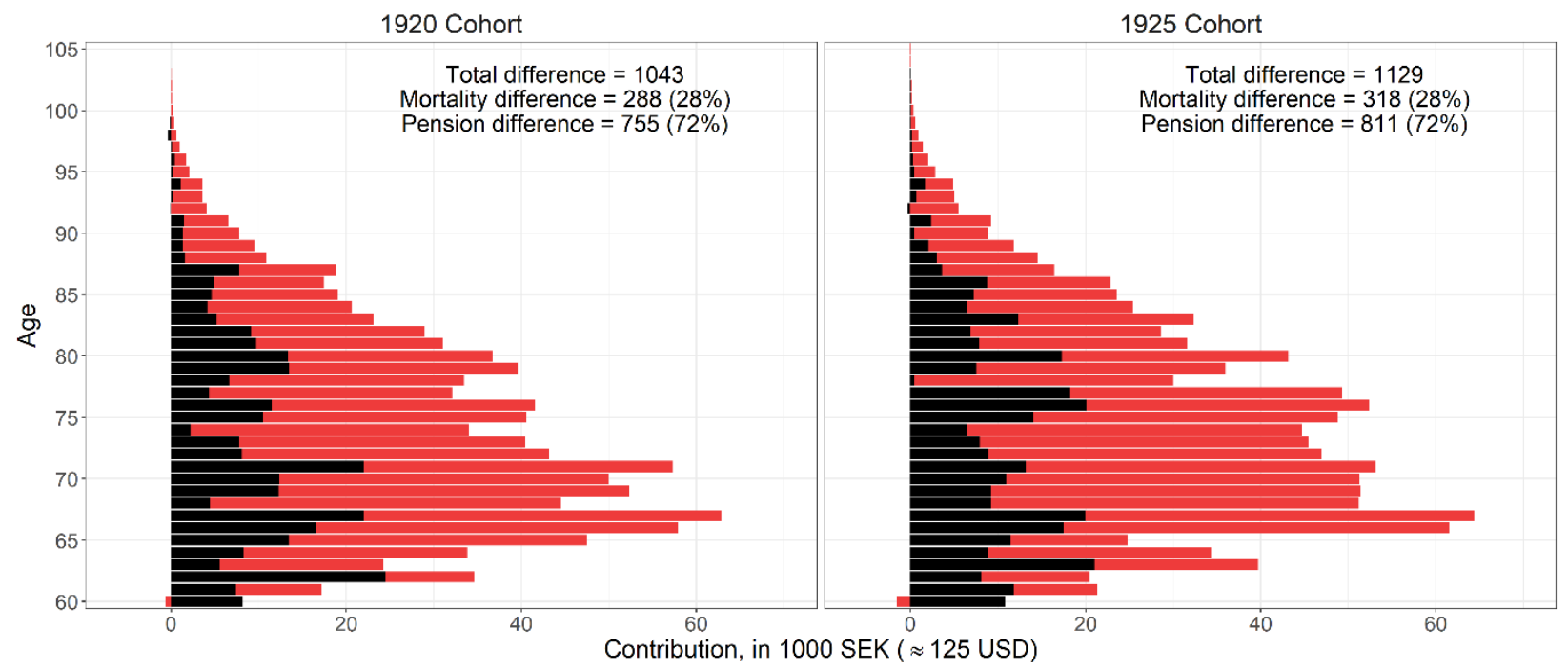

Differences between the second and the fourth quintiles, women

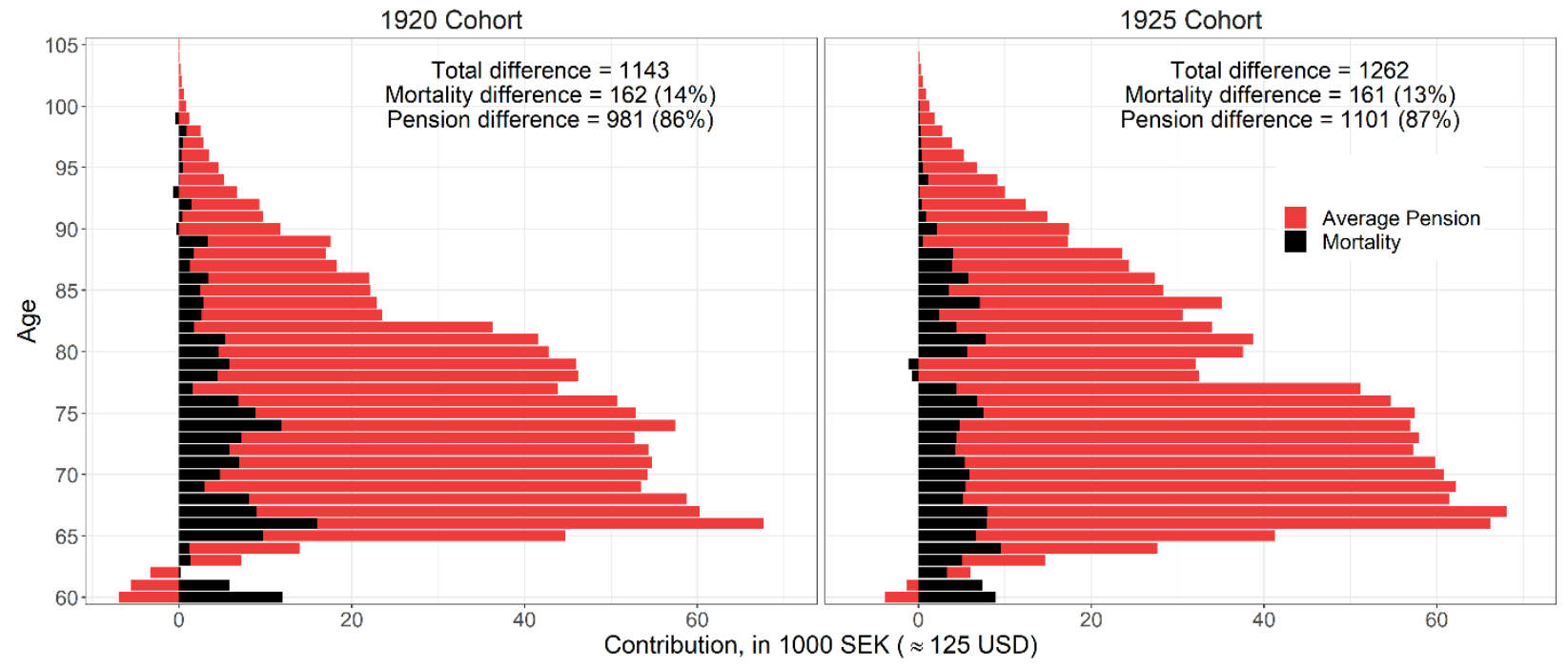

Source: As for Table A1. 
Figure A16. Decompositions of total lifetime pension differences between the third and the highest earnings quintile groups into differences explained by age and mortality.

Differences between the third and the highest quintiles, men

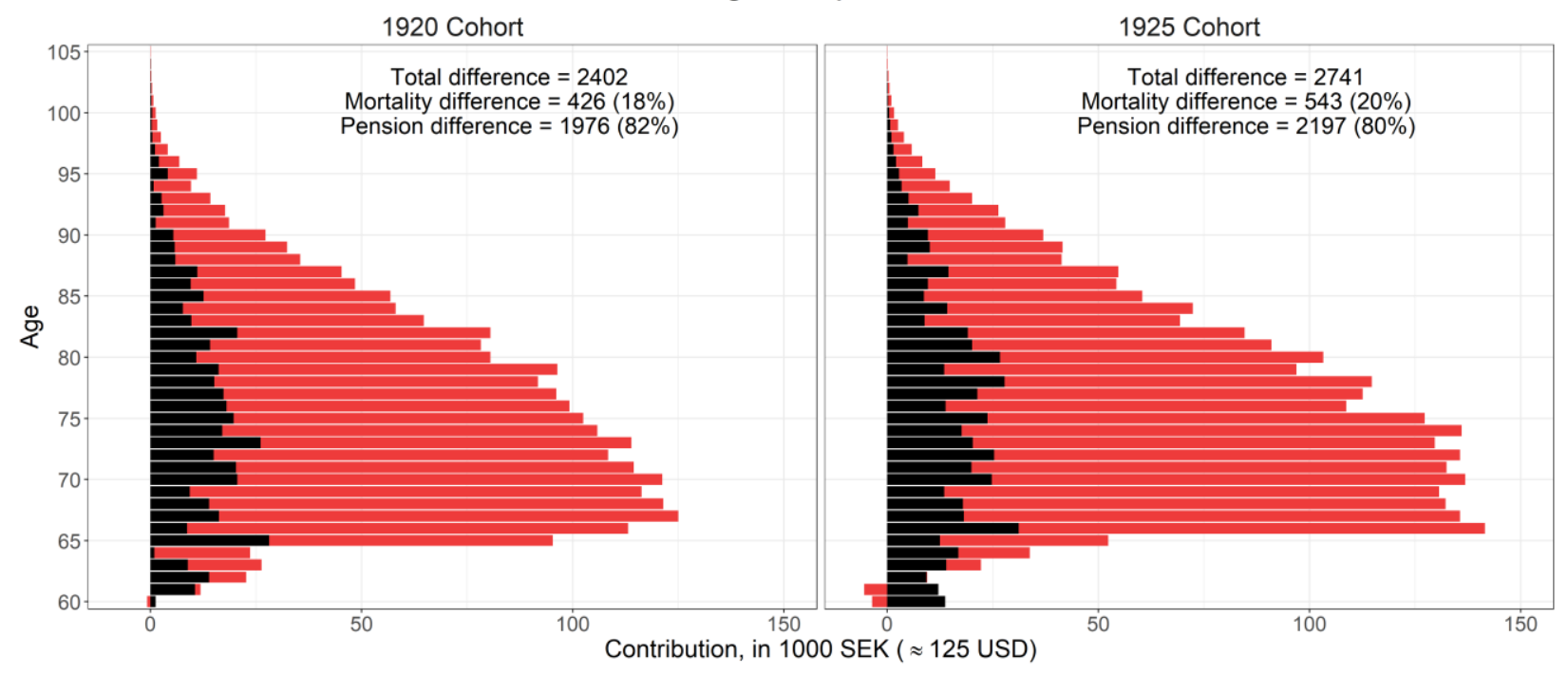

Differences between the third and the highest quintiles, women

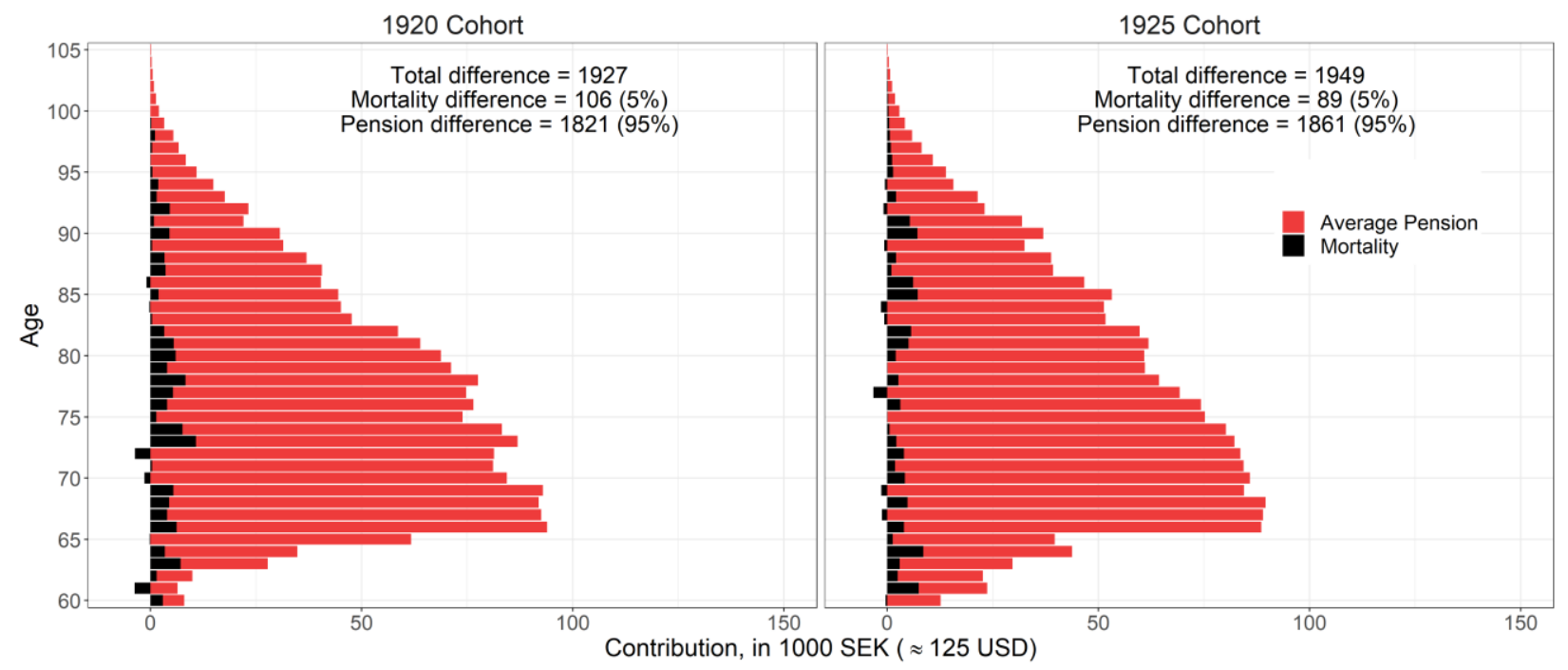

Source: As for Table A1. 
Figure A17. Decompositions of total lifetime pension differences between primary and tertiary education groups into differences explained by age and mortality, with $2 \%$ discount rate.

Differences between primary and the tertiary education, $2 \%$ discount rate, men

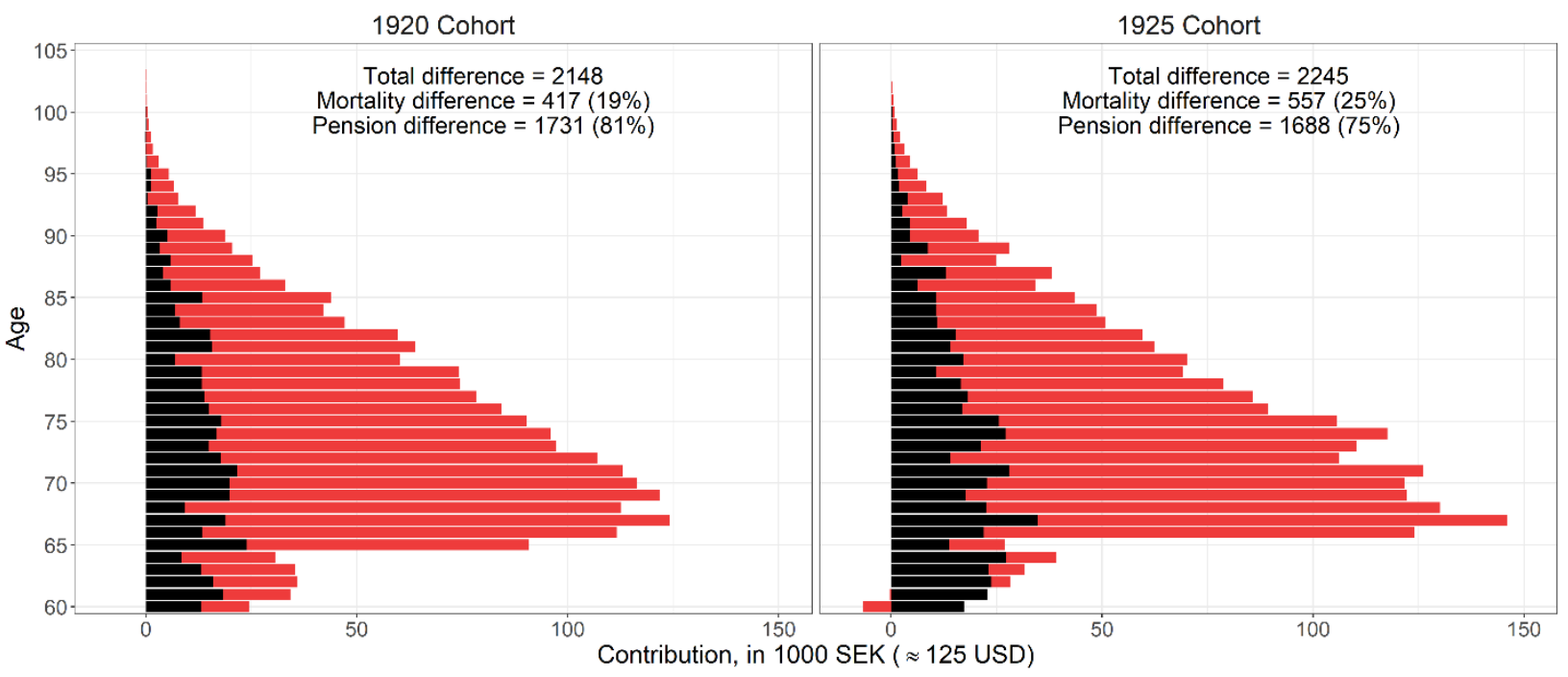

Differences between primary and tertiary education, $2 \%$ discount rate, women

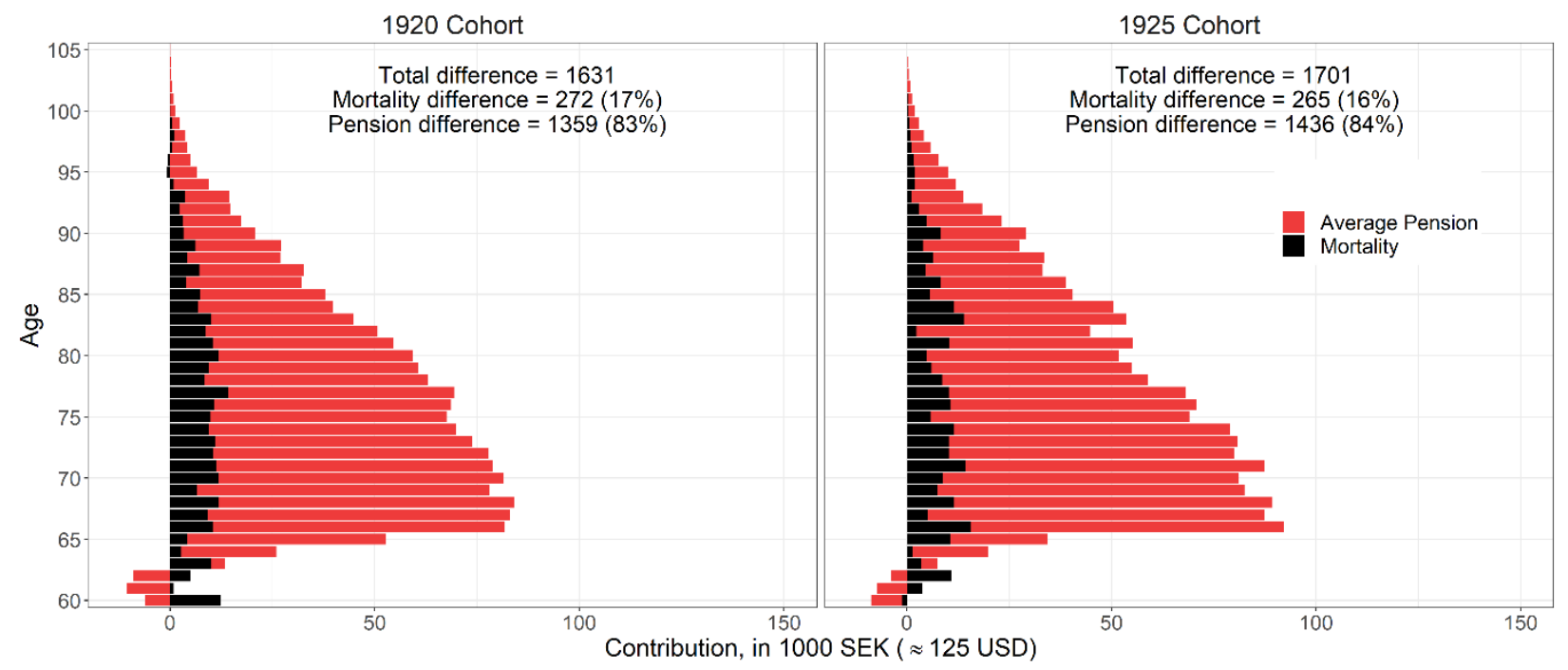

Source: As for Table A1. 
Figure A18. Decompositions of total lifetime pension differences between the bottom and the top earnings quintile groups into differences explained, with $2 \%$ discount rate.

Differences between the lowest and the highest quintiles, $2 \%$ discount rate, men

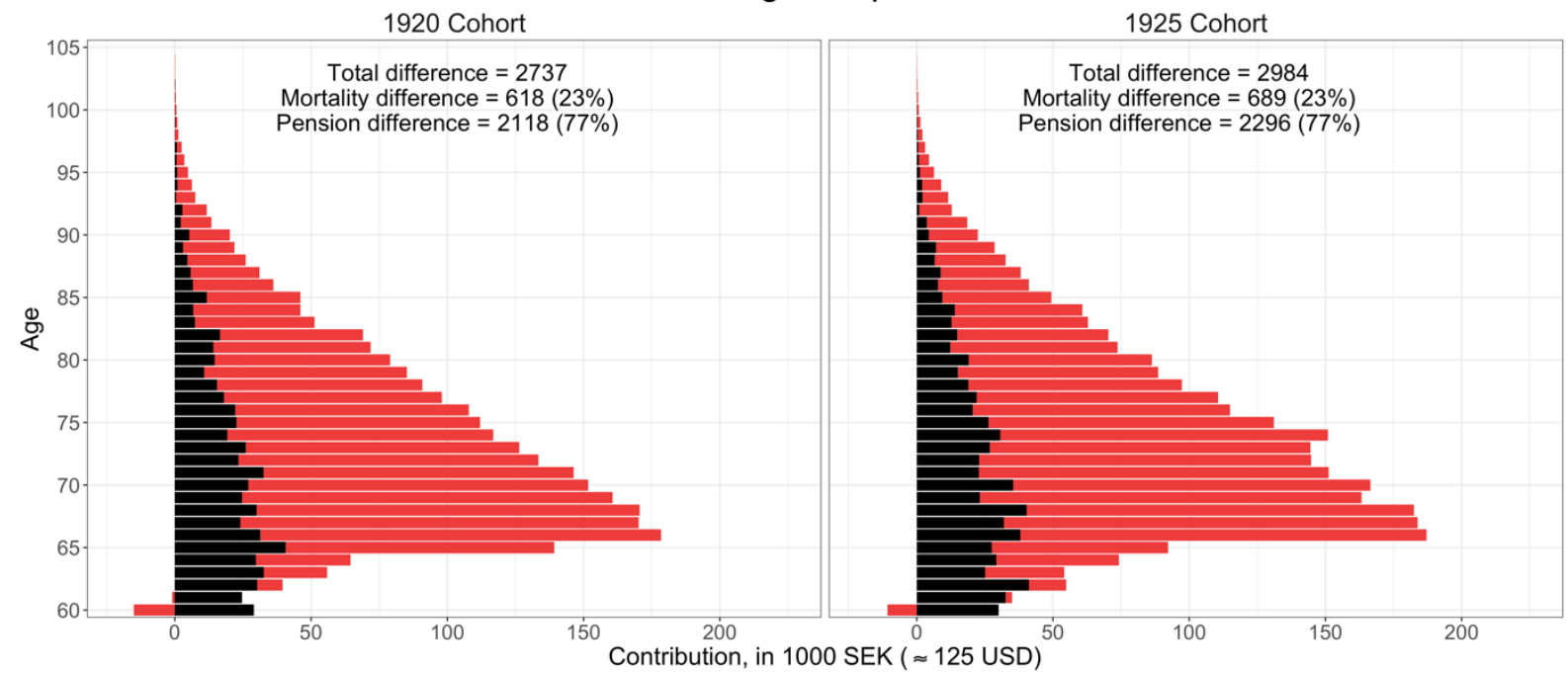

Differences between the lowest and the highest quintiles, $2 \%$ discount rate, women

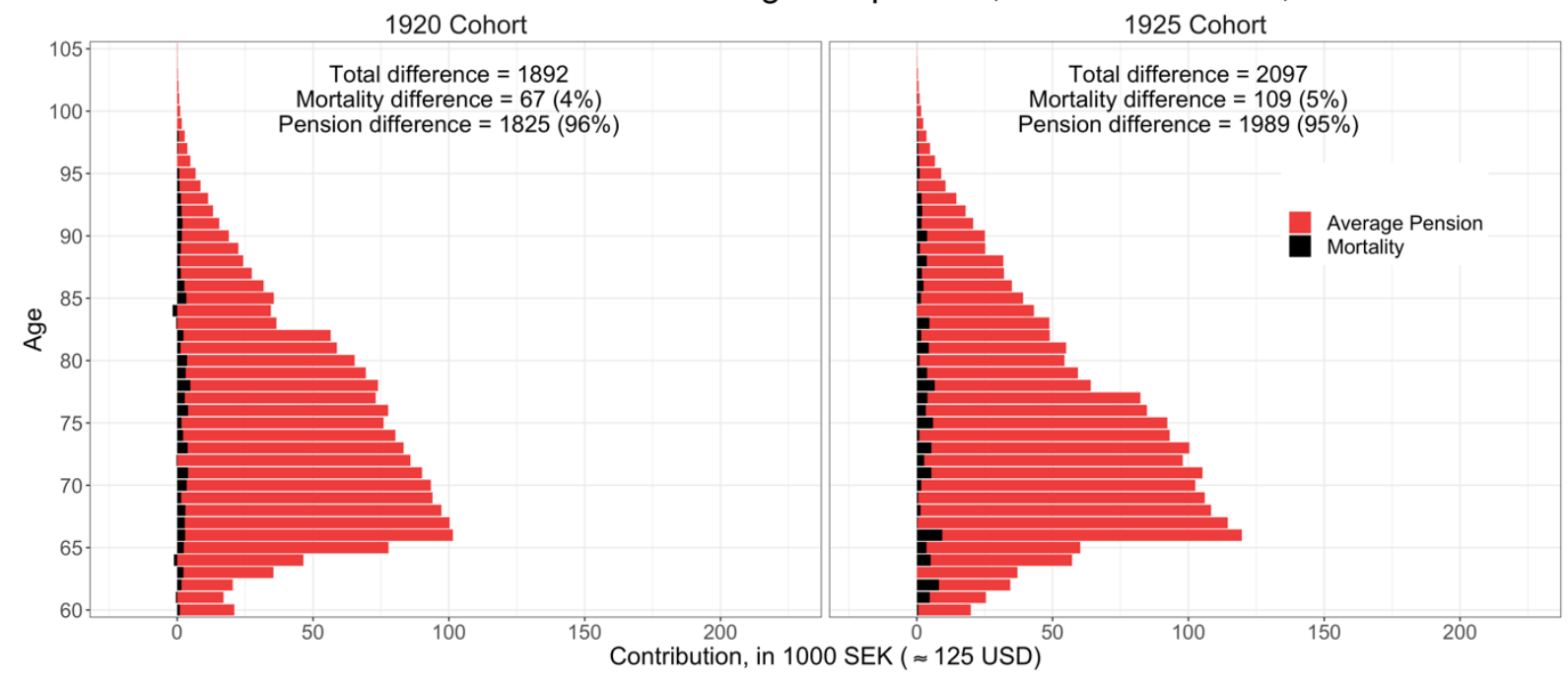

Source: As for Table A1. 